\title{
a short tale: THE CRAFT OF PLAY IN CHILDREN'S HOSPITALS
}

\author{
by \\ Nourhan Zaky \\ fulfillment of the required degree of \\ Master of Architecture \& Urbanism \\ at \\ Azireli School of Architecture \& Urbanism \\ Carleton University \\ Ottawa, Ontario
}

A thesis submitted to the Faculty of Graduate and Postdoctoral Affairs in partial

(C) 2018

Nourhan Zaky 


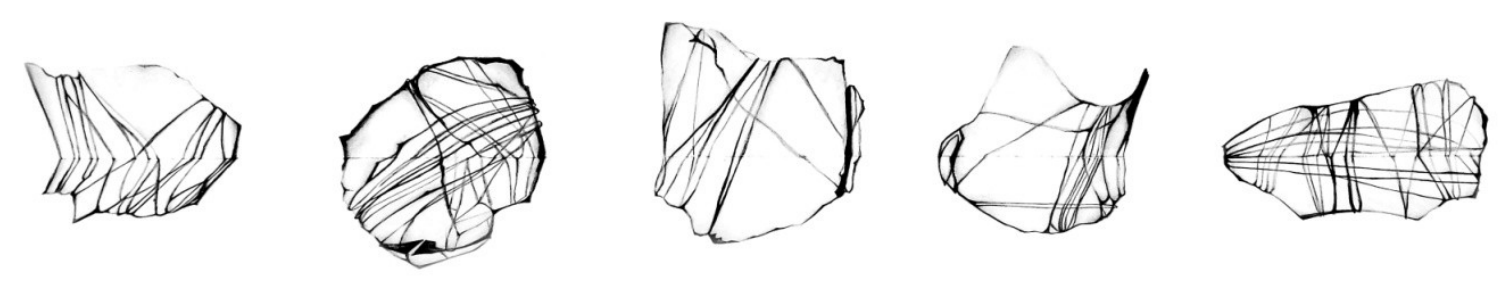

Let's PLAY 


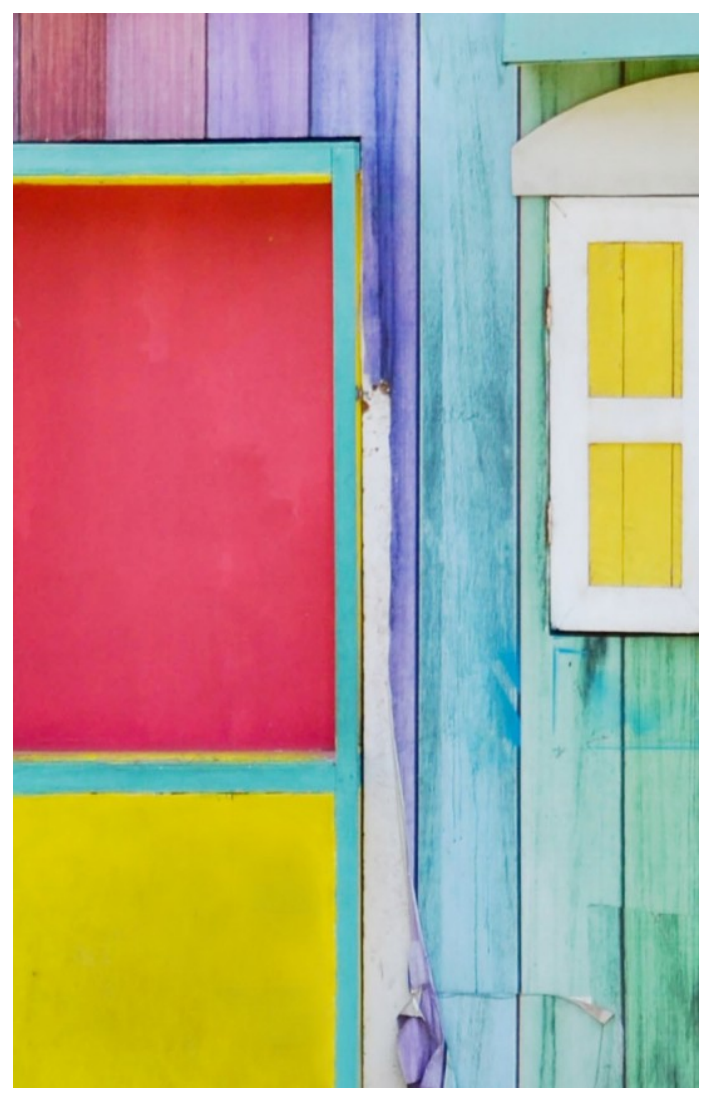

\section{a short tale:}

THE CRAFT OF PLAY IN CHILDREN'S HOSPITALS 


\section{abstract}

Surroundings can be easily taken for granted, and it is possible to underestimate how much an atmosphere influences one's being. As one lies down in a hospital bed, surrounded by anonymous neutral surfaces and clamped by the feeling of apprehension, solitude is exuded. It's easy for a patient to feel trapped, internalized and cut off from the world - as a hospital environment is traditionally executed. Considering architects' responsibility to take into account the individual occupant's wellbeing, in the design of Health Care Centers and hospitals, stimulates the necessity to tackle the challenge to design meaningful hospital design, beyond the mere necessity to house medical equipment and serve a purpose that is beyond function. The recognition of the importance of this purpose further motivates the need for architecture to make a contribution to thinking about the places that are beyond the medicalized spaces of being ill. This thesis asks whether it is possible to design a space that engages the imagination of the patient contributing to their sense of place in the world beyond their condition of illness. There is a fine line between perception and imagination. What distinguishes one from the other is the place where the imagined exists and makes itself manifest in - the space around us. This design proposal utilizes play as an instrument, challenging space to stimulate a sense of wonder. 


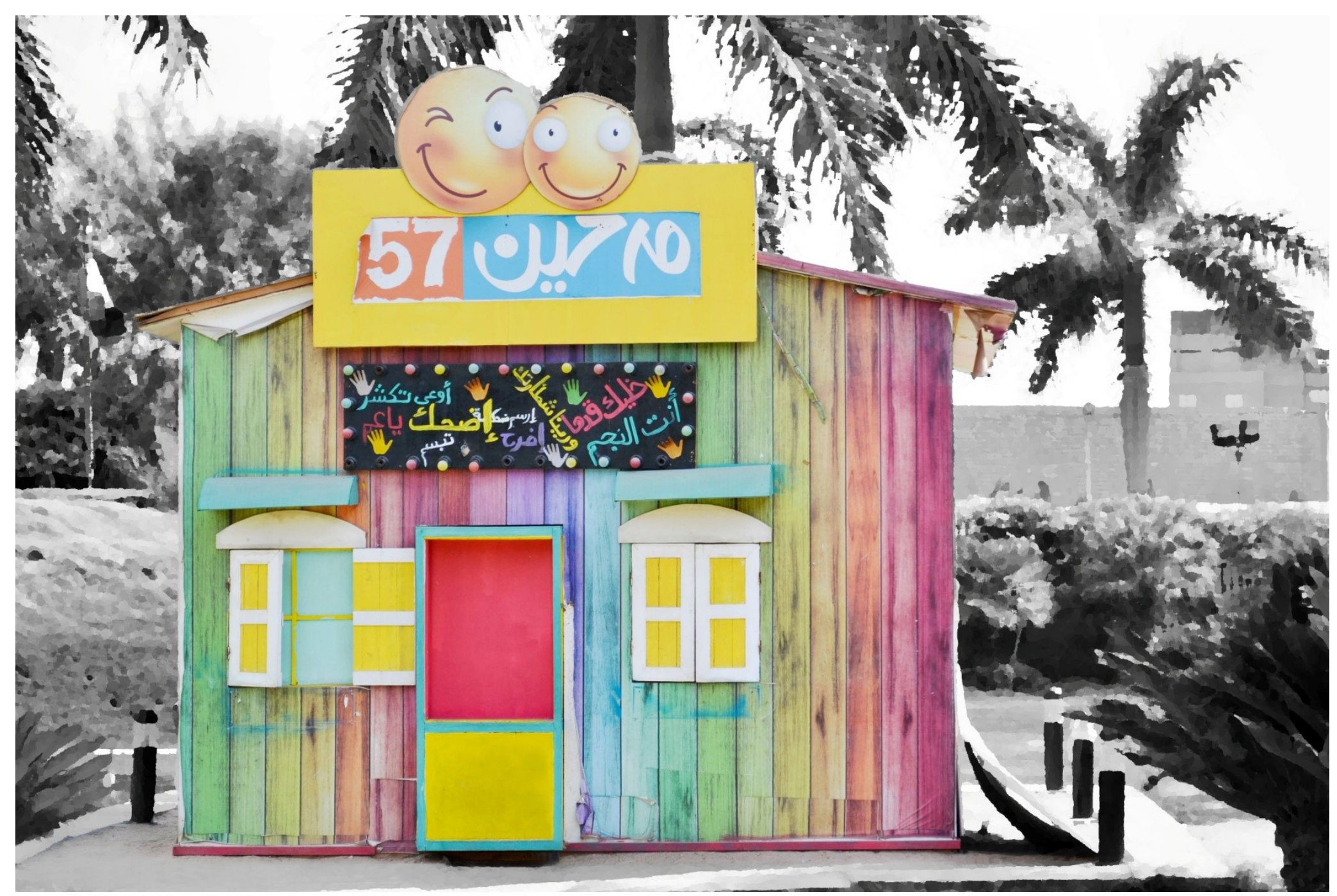

FIGURE 1

Recreating the P I a y h o u se 


\section{acknowledgements}

First and foremost, I would like to express my utmost gratitude towards God, my father, my mother and my sister. I want to acknowledge the sacrifices they have made for me. To my parents, I am constantly moved by you open hearts, your unrelenting faith, and your commitment to family. It has been the foundation of my accomplishments and my courage. To my sister, you are my greatest blessing.

To the pediatrics staff at 57357, thank you for opening your doors and sharing stories closest to your hearts with me. To the business development, communications and Marketing Director at Shriners hospital, thank you for showing me around the facility and taking the time to go the extra mile. Their passion towards what they do and who they aspire to become for the children is moving.

To my friends, and also medical students at the University of Ottawa, you were one of my biggest inspirations to pursue my thesis topic in healthcare design. You have seen me through so much, and I thank you for helping me grow. You have showed me a balance between personal growth, professional growth and personal relationships.

Thank you to all the visiting critics that guided us throughout this journey and to Professor Greg Andonian for believing in me.

To my academic advisor Professor Federica Goffi, I owe a debt of profound gratitude for your encouragement and continuous support in the production of this project. I am in constant awe of your one of a kind and valuable feedback. You inspire me and I have learned a lot from you. Thank you once again for your patience and your positive guidance. 


\section{contents}

i Abstract

iii

Acknowledgements

Contents

List of Illustrations

Introduction: Wonder

2

Exploring elements of Play: A design tool

Play as an Instrument..

3

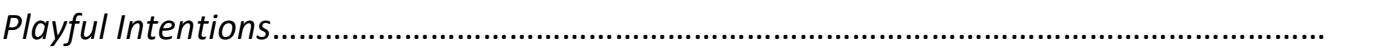

Playful as a Function ..................................................................................................

3

The play that is being played

Characters

Introducing characters as the types of play.

4

The role that this proposal is playing

Site Experiment: CHEO......

Architectural Proposal: Space Typologies.

Conclusion...

Bibliography. 


\section{list of illustrations}

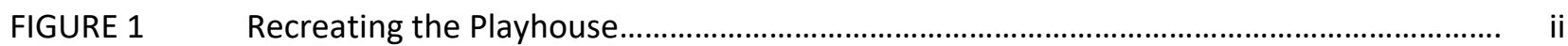

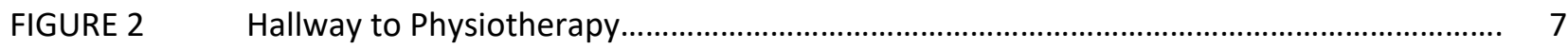

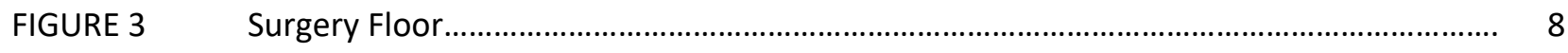

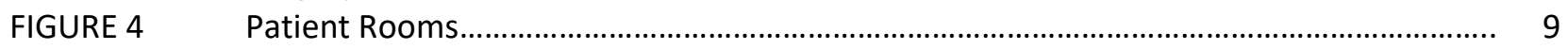

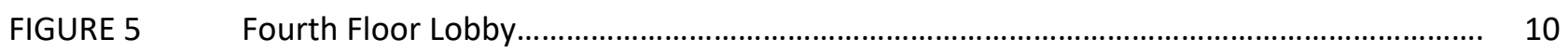

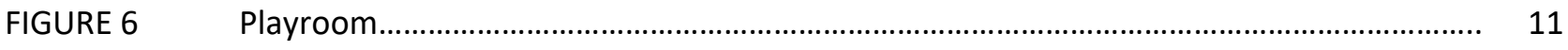

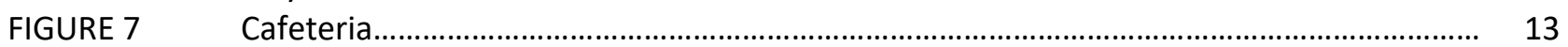

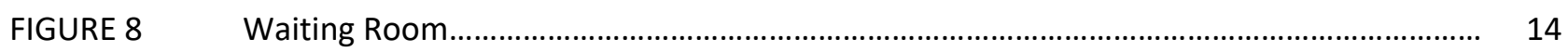

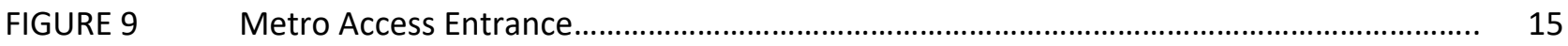

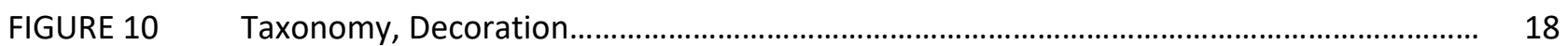

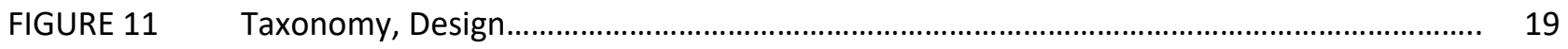

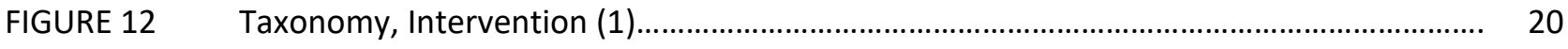

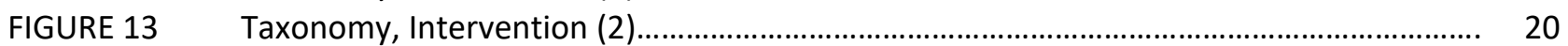

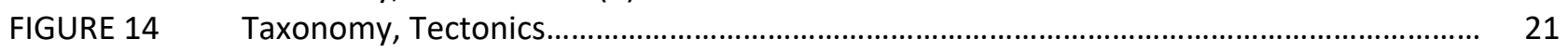

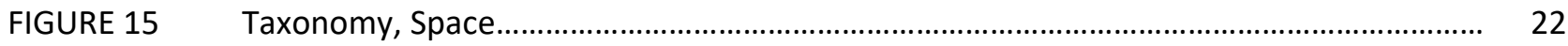

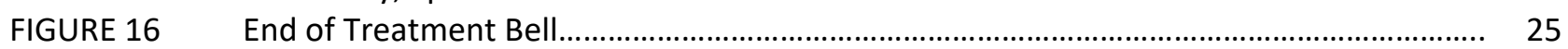

FIGURE 17 The Enthusiast: Social Play ……................................................................................. 30

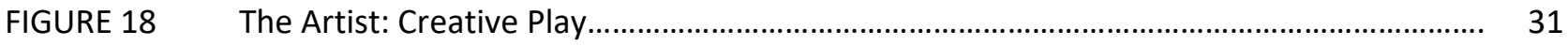

FIGURE 19 The Performer: Dramatic Play....................................................................................... 32

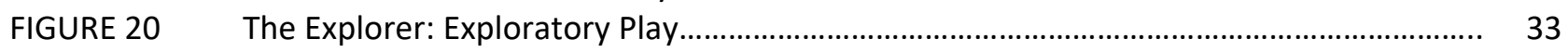

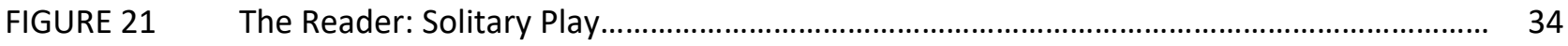

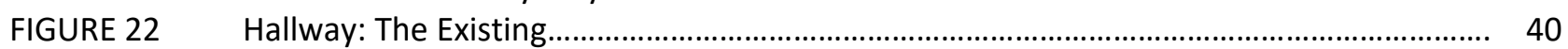

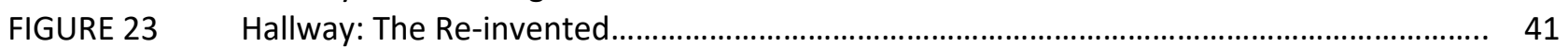

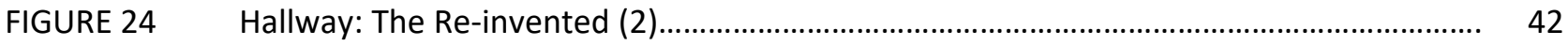

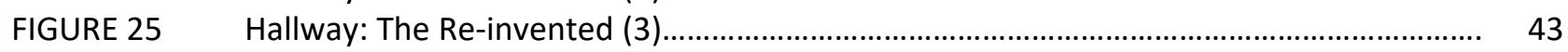

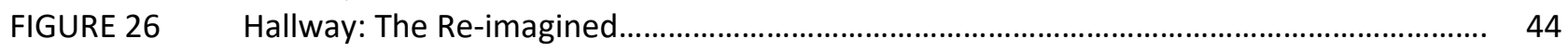

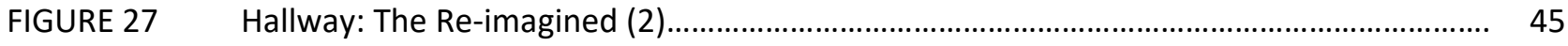

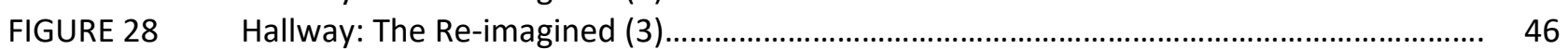

FIGURE 29 Hallway: The Re-imagined (4) .................................................................................. 47

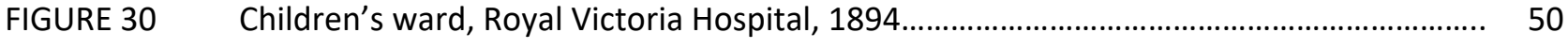

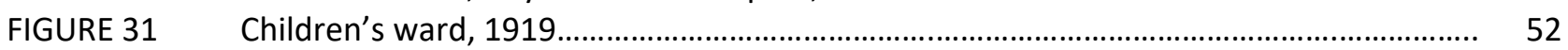


FIGURE 32

FIGURE 33

FIGURE 34

FIGURE 35

FIGURE 36

FIGURE 37

FIGURE 38

FIGURE 39

FIGURE 40

FIGURE 41

FIGURE 42

FIGURE 43

FIGURE 44

FIGURE 45

FIGURE 46

FIGURE 47

FIGURE 48

FIGURE 49

FIGURE 50

FIGURE 51

FIGURE 52

FIGURE 53

FIGURE 54

FIGURE 55
Patient's Room: The Existing ......................................................................................... 53

Patient's Room: The Re-invented............................................................................... 54

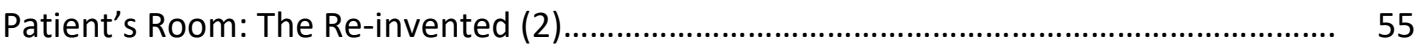

Patient's Room: The Re-invented (3)..................................................................... 56

Patient's Room: The Re-imagined................................................................................... 57

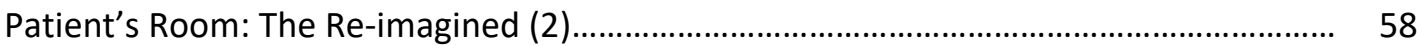

Patient's Room: The Re-imagined (3) ....................................................................... 59

Cafeteria: The Existing...................................................................................... 62

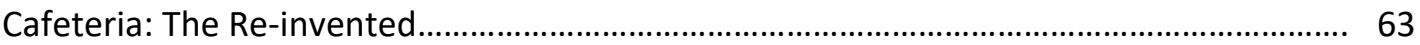

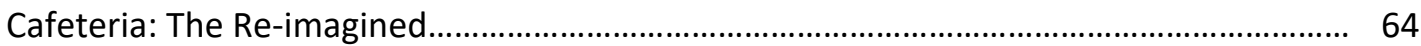

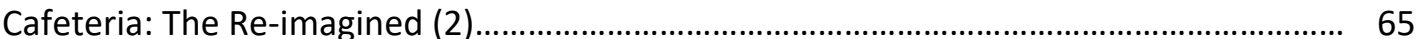

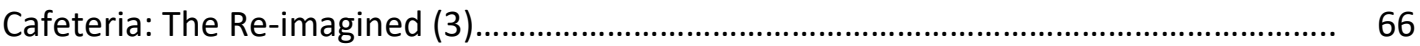

Cafeteria: The Re-imagined (4) .................................................................................. 67

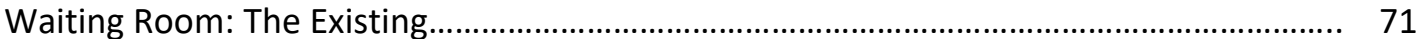

Waiting Room: The Re-invented............................................................................ 72

Waiting Room: The Re-invented (2)........................................................................... 73

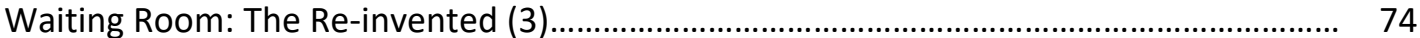

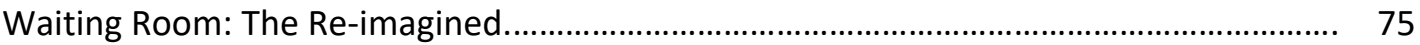

Waiting Room: The Re-imagined (2) ............................................................................ 76

Waiting Room: The Re-imagined (3) ................................................................... 77

Waiting Room: The Re-imagined (4),....................................................................... 78

Examination Room: The Existing................................................................................ 81

Examination Room: The Re-invented......... 82

Examination Room: The Re-imagined............................................................................... 83 


\section{1 introduction}

\section{Wonder...}

Clouds are captivating. They intricately float above ones presence, appearing with a varying and unique manifestation. Is it the way the light illuminates the form, percolating through it, or is it their elegance that makes one wonder? Is it both? One cannot say that the presence of Altostratus clouds, and their fibrous layers, has the same effect on ones mental being as the silky gleam of Cirrus clouds...

Studying architecture, I've always been fascinated with our ability to story tell and to empathize with the people we create for. We have a delicate responsibility to contribute, or conversely neglect, someone's sense of wellbeing in place. This sparks my interest in exploring healthcare design. I cannot express the importance of social support, and that the architecture environment can serve to facilitate that. I am a believer in that we need one another to heal. Being able to express our feelings alleviates pain. Positive attitudes impact positive emotions and hence, this can affect the body and support a healing process. Healing is not the simplest of terms to define and differs depending on the individual and the medical condition. When asked, "what does a healing environment look like to you?" that idea of place may look a lot different than the one of your neighbour's. However, the one thing we can't deny is that support is extremely significant - more than what we may think. I challenge spaces with the goal of achieving more of this objective.

My background experience with children manifests an appreciation for their innocence. They are incredibly intelligent and I find that their purity has the magic to heal. They are exceptionally observant and I admire that it's in the little things that they find enthusiasm. Watching anyone struggle with an illness is difficult as it is, but having to watch them tackle it at such an early stage of their life is tragic. 
My chosen area of study is pediatrics because I challenge spaces of medical practice to incorporate a component that children already employ - play. The irony is that despite play being seen as a relief from seriousness, it is in fact serious for development, learning, and possibly also coping with illness.

Growing up in an Egyptian community, the health care industry is a popular career choice. I have always had a high level of respect and interest towards the profession. Upon my visit back to Egypt, I stopped by 57357 - the Children's Cancer Foundation hospital in Cairo. Built strictly on charities and donations, 57357 is one of the largest children's Cancer hospitals in the world. Touring the hospital gave me an insight on the factors that impact the facility the most, as well as ideas that inspire room for development. Buildings should reflect the lifestyle we want to lead. Thus, I wanted to give recognition to this Foundation for stirring the drive to pursue my thesis. 


\section{2 exploring elements of play}

\section{A design tool}

\section{Play as an instrument}

Play is a significant component to how children learn. They are an audience of excellence when it comes to dissociating themselves from their surroundings. Play can help them achieve that. When children are in the process of playing, they are able to mentally separate themselves from the present ambience and get lost in the game. It is in their amusement that they are able to freely express themselves and hence, an important part of their development. The play object may as well allow for interaction and in this contact, it stimulates feedback and support. As Dutch historian and cultural theorist Huizinga wrote in his memorable work on the subject in 1938, if "play casts a spell over us" and "it is invested with the noblest qualities we are capable of perceiving in things: rhythm \& harmony"1 then play becomes an instrument that must be utilized in our daily practice. The writings of Johan Huizinga emphasize the magic that develops out of play. He specifically elaborates on order, as one of the features, which derive from play. He argues that perhaps, it is one of the many reasons why we do play. The words that can be used to symbolize the fundaments of play are related to aesthetics. These are also terms that can be used to depict the effects of beauty ${ }^{2}$. These effects allure:

Huizinga, Johan. Homo Ludens: A Study of the Play-Element in Culture. London: Routledge \& Kegan Paul Ltd, 1949, 10. Ibid., 10. 
“...tension, poise balance, contrast, variation, solution, resolution, etc." ${ }^{3}$

For example, the element of tension relates to chanciness, which means the player will be taking risks and as a result, make his own decisions to ultimately "succeed". To learn to rely and trust oneself becomes a mechanism that the player must acquire through playful actions and risk taking. The daily hospital routine of a child is always extenuating and stressful, unless the child is getting better. Even so, however, when they are not required to go through a number of procedures, a day in the life of a patient's hospital schedule is difficult and draining. The reason to be admitted to the hospital in the first place for the need of being monitored is a cause for distress. Hence, it is intimidating for the infant, the child, or a teenager to be constantly surrounded by staff, "touching" or "poking" them. Whether it's with needles, equipment, or masks, their setting can be daunting and it's easy to feel extremely 'out of place'. Considering the lack of choices that they will undergo, by being at the hospital and taking part of the necessary protocols, there is a sense of autonomy that will be lost. Play allows the reclaiming of their freedom of choice and creates an approach to a way of providing comfort. Play becomes the apparatus that gifts the child back their independence.

Huizinga, Johan. Homo Ludens: A Study of the Play-Element in Culture. London: Routledge \& Kegan Paul Ltd, 1949, 10. 


\section{Playful intentions}

\section{Montreal's Shriners Hospital for Children}

Recently built precedents appear to encompass a common denominator - a method of storytelling. Greeting their first patients in 2015 , Montreal's Shriners hospital for children is the world centre for brittle bone disease. It only treats Orthopedics and especially those affected by very complex cases. There was a time when people were giving up on children with complicated bone issues. Shriners wanted to push those boundaries, taking these cases, and attempting to work with them. Hosting up to 25,000 visits yearly, the hospital is currently at 1100 surgeries, but it was designed for much more than that. If the hospital were to go up to $2500-3000$ surgeries, it would still not be at full capacity. To build for redundant room was a main design strategy, and considering the constant change in the staff and needs, the ability to multi-function was of priority. Every floor is themed through association with a different landscape of Canada. For instance, the second floor of Shriners is 'the Bad Lands of Canada' - a location known for its many fossils and dinosaurs (figure 2). Significant programs on this floor include the rehab room for physiotherapy and the room for occupational therapy. The rehab room is a space that involves various equipments to help get the muscles moving. The occupational therapy room, through which children learn to do the little things of everyday life - hold a fork, build a train track, etc. is similar. Metaphorically, strength and movement are the symbolic notions of this floor. Hence, choosing 'Bad Lands of Canada' as a theme delicately embeds a narrative to enhance the human experience. Whether it's in the paintings on the walls, the chosen colors of the space, etc. visitors subconsciously discharge from the stern atmosphere that the hospital typically conducts. The third floor, an alternative exemplar, tells the story of Canada's winter. Coordinating the program of that floor with the selected theme, the human scale is targeted. This is done by taking into 
consideration the details that come in direct human observation. Since the floor belongs to the operating rooms, winter suits the space best since it is always colder on surgery floors (figure 3). Once again, this thoughtfulness appears on the fourth floor where all the patients' rooms are located. The East Coast theme implies escape and serves as reminder of the place one cannot deny - vacation (figure 4, 5 and 6). One appears to recognize a pattern - the attempt of occupying the mind of the young patients. There is a vivid aspect in which the element of play, is being utilized as a form of distraction. There is a playful relation that begins to develop, not only with the patient and their parents but, with the patient and the staff. 


\section{2 exploring elements of play}

"Just follow the dinosaur ...he'll lead the way."

HALLWAY TO PHYSIOTHERAPY, SHRINERS

FIGURE 2

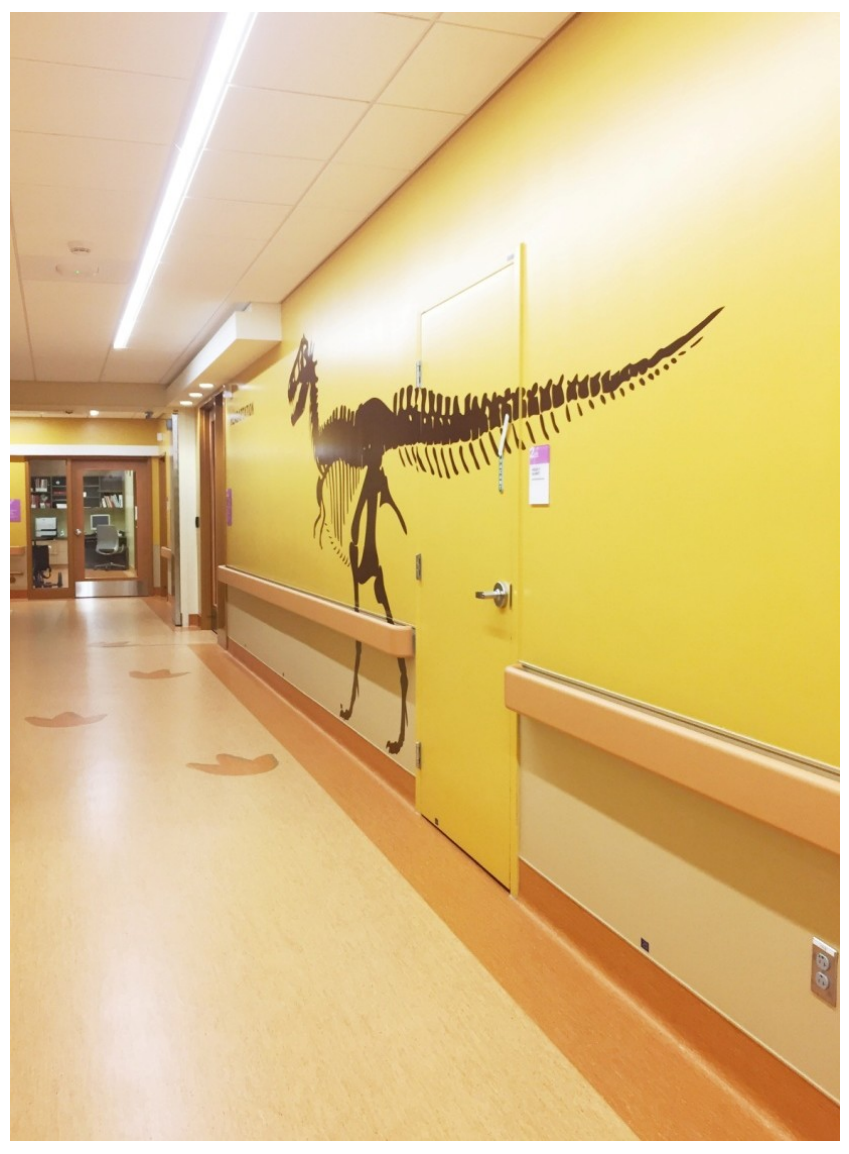


2 exploring elements of play

"Brrrr! stay warm!"

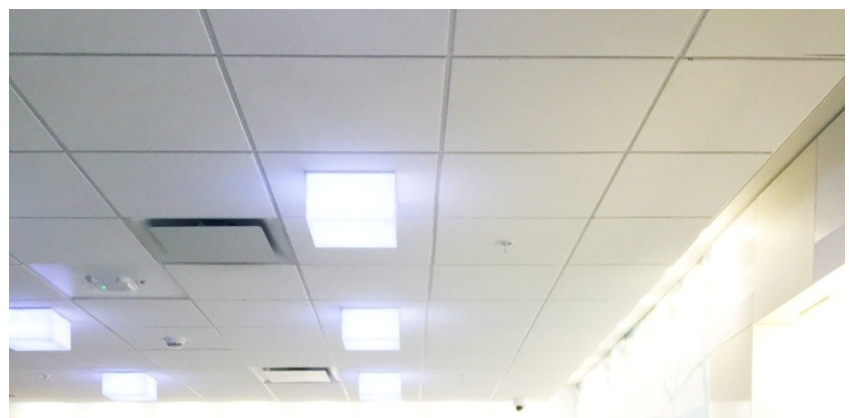

SURGERY FLOOR, SHRINERS

FIGURE 3

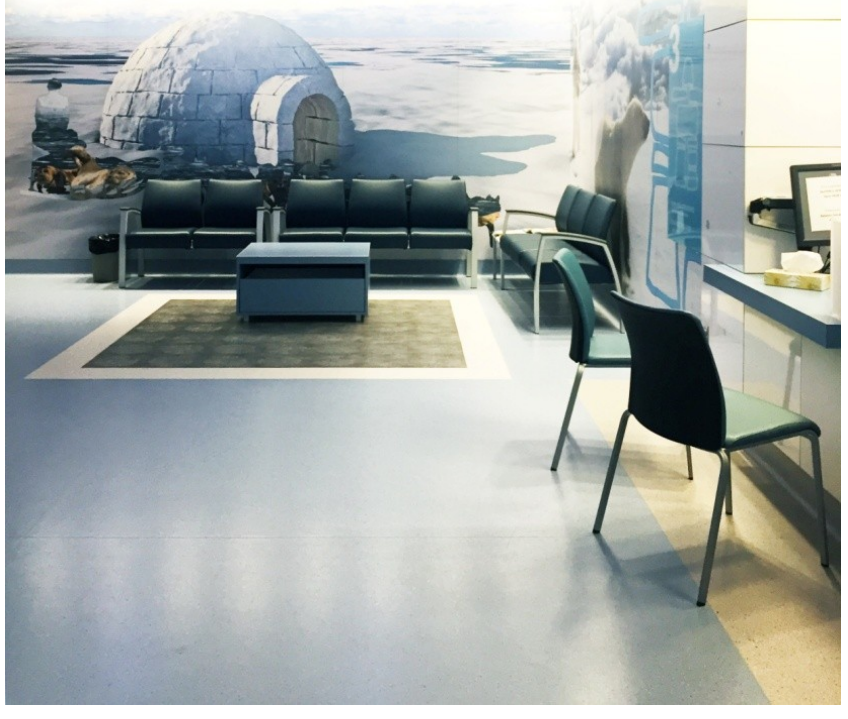


"Take a deep breath! we're about to dive to the Ocean!"

FIGURE 4

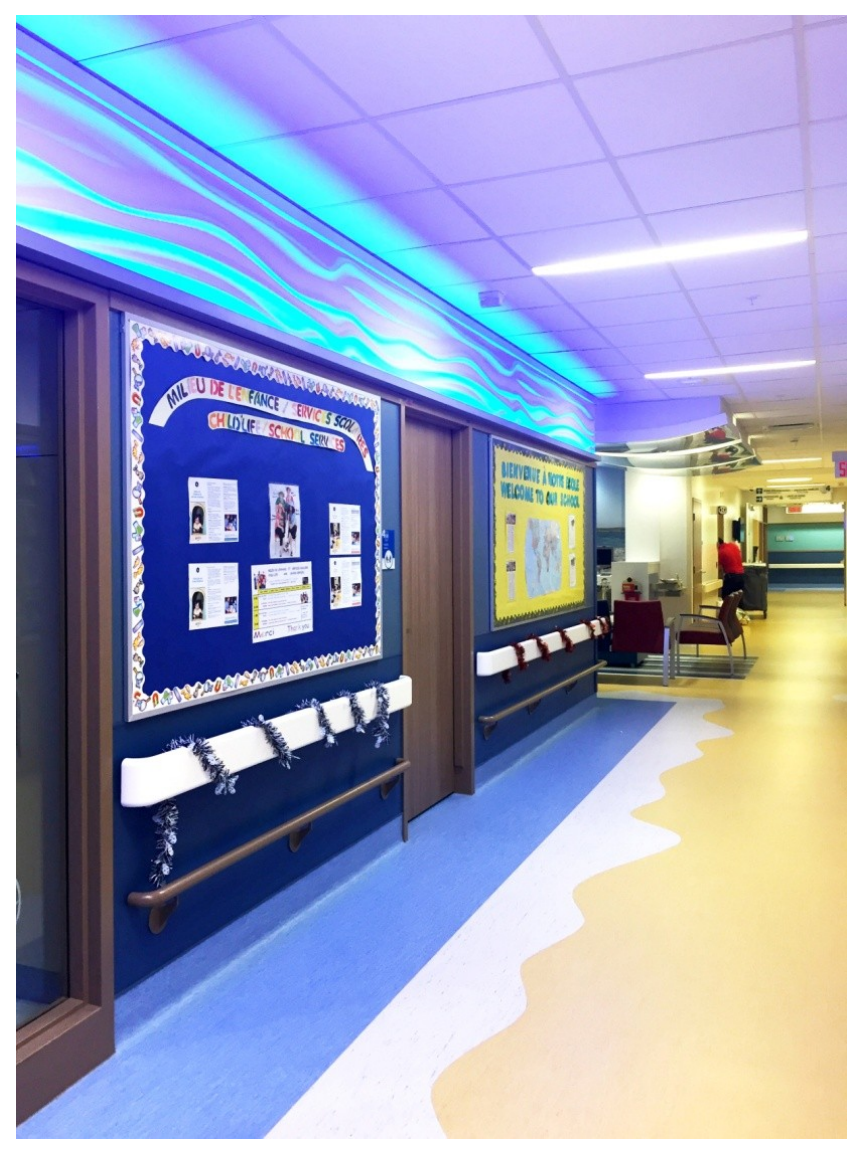


"All Aboard!"

FOUTH FLOOR LOBBY, SHRINERS

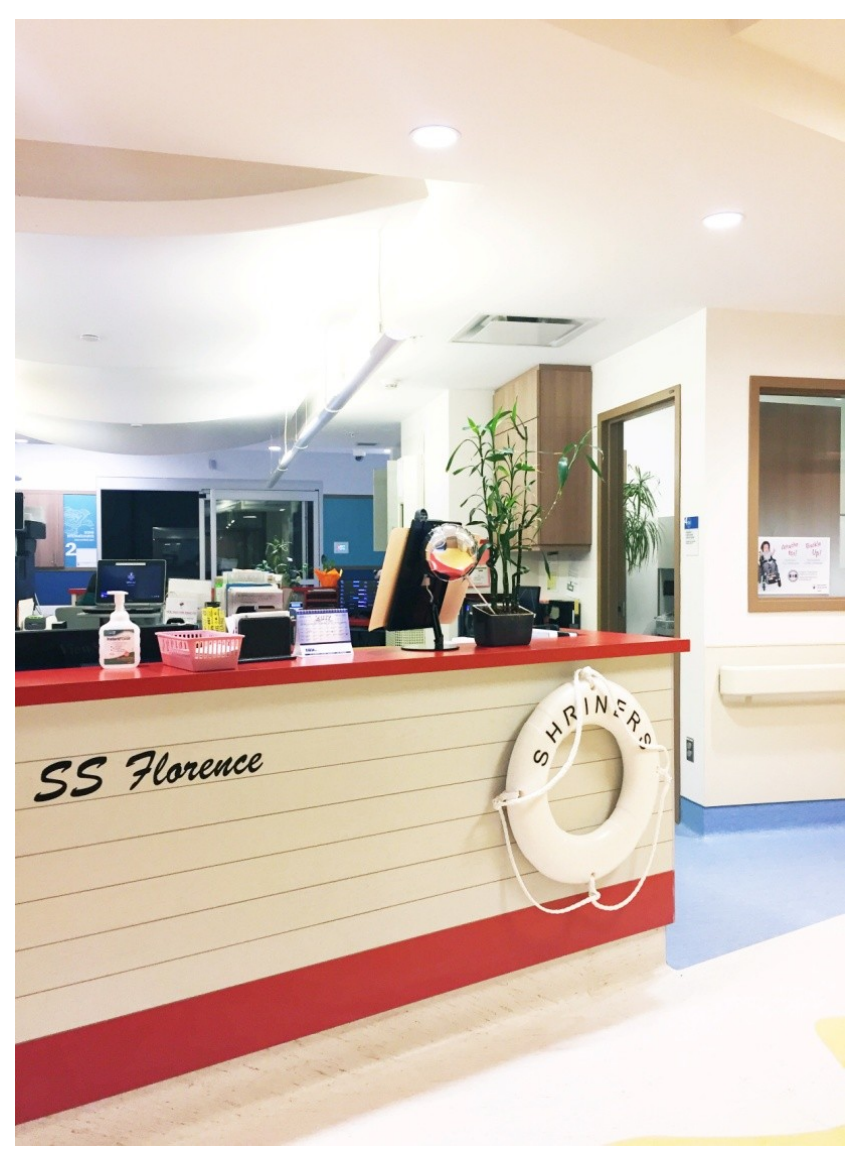

FIGURE 5 
2 exploring elements of play

"Under the Seal"

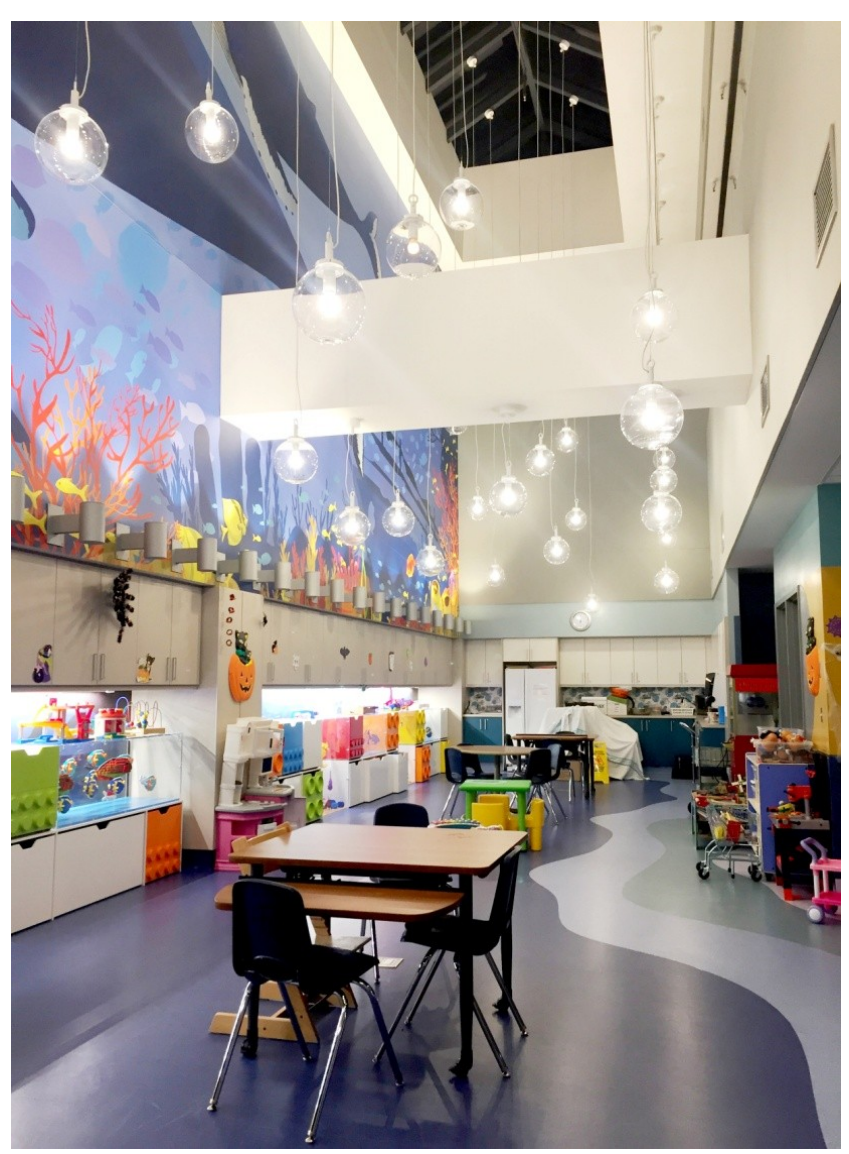

PLAYROOM, SHRINERS

FIGURE 6 


\section{The Centre Hospitalier de l'universite de Montreal (CHUM)}

The Centre Hospitalier de l'universite de Montreal (CHUM) it is a model that steps outside of hospitals dedicated solely to pediatrics. Opened in October 2017, it is one of the largest healthcare projects in North America. The medical facility, located in Montreal, is a series of high-rises that are meant to revive the downtown district from an urban stance. Serving as an excellent, and up to date, precedent the project showcases a current approach to healthcare design. Tackling all design scales was one of its distinct features - the urban element, the neighborhood context, and the human component. Two historic structures occupy the site, a facade of an old stone building and a $19^{\text {th }}$ century church steeple, which the team partially preserved. The facility is light filled (figure 7), with a futuristic approach (figure 8), and is home to the highest concentration of public art in the city of Montreal (figure 9). By examining the approach of this present day healthcare facility, it solidifies certain questions and answers. Spaces are reinvented to 'look-like' another space. Whether it was intentional, or not, there is a playful intent in the way one reinterpreted the design of how one perceives a typical hospital environment. Creating light filled spaces, thematically enhanced by high ceilings, emphasizes the priority that has been given to light and breathing space. Their futuristic approach suggests contemporary and vibrant atmospheres, and spaces appear to be in mint condition. The presence of public art around the hospital provides the individual with opportunities for wondering away from the immediate concerns. The installations become moments of distraction from the most personal matters, and it is through them that the element of wonder is enticed. Hence, the question - what is this aspect of 'looking-like' something else? How does it add, or subtract to the improvement of our physical environment? How are these connotations positive, playful, ones? From Shriner's thematic narratives, to CHUM's use of modernity, figments of imagination appear to be a common strategy to utilize when creating enriching environments. 
2 exploring elements of play

"Airport or IKEA?"

FIGURE 7

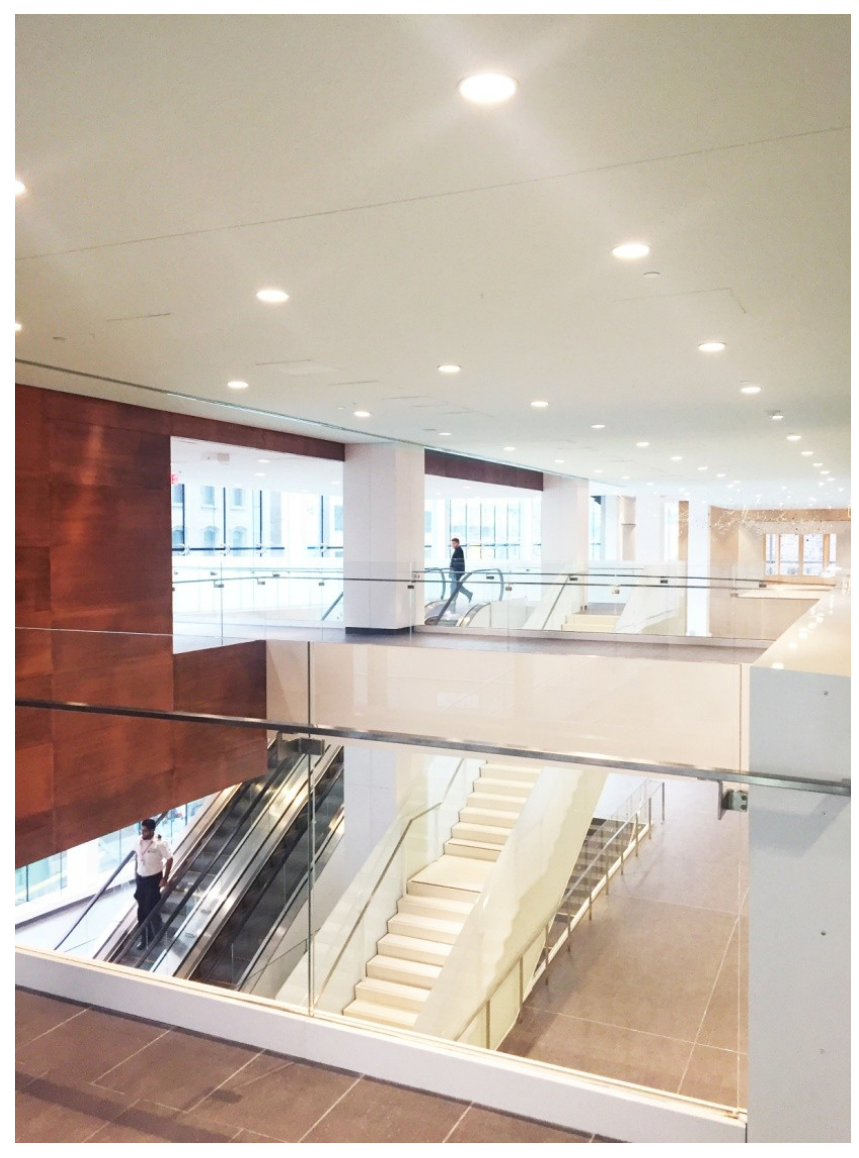


"Gate number 10 is now boarding..."

FIGURE 8

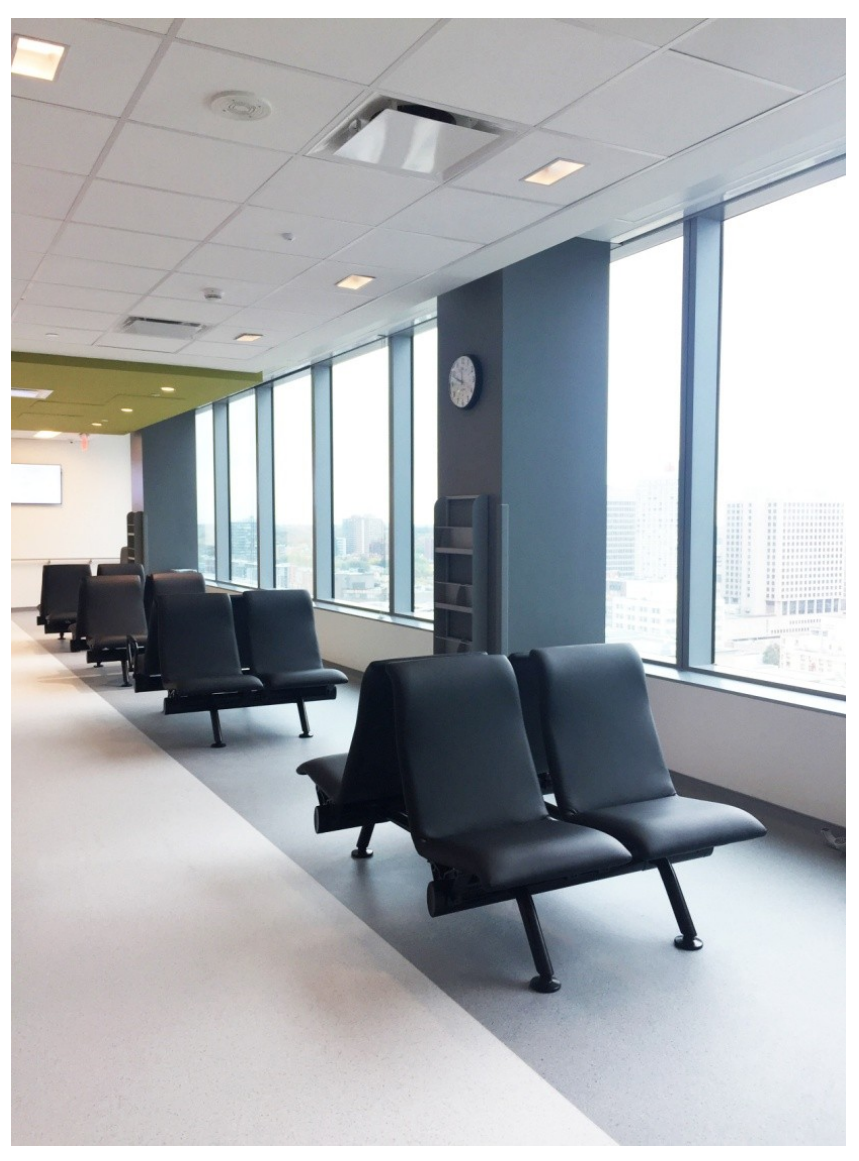




\section{2 exploring elements of play}

“Museum?"

METRO ACCESS ENTRANCE, CHUM

FIGURE 9

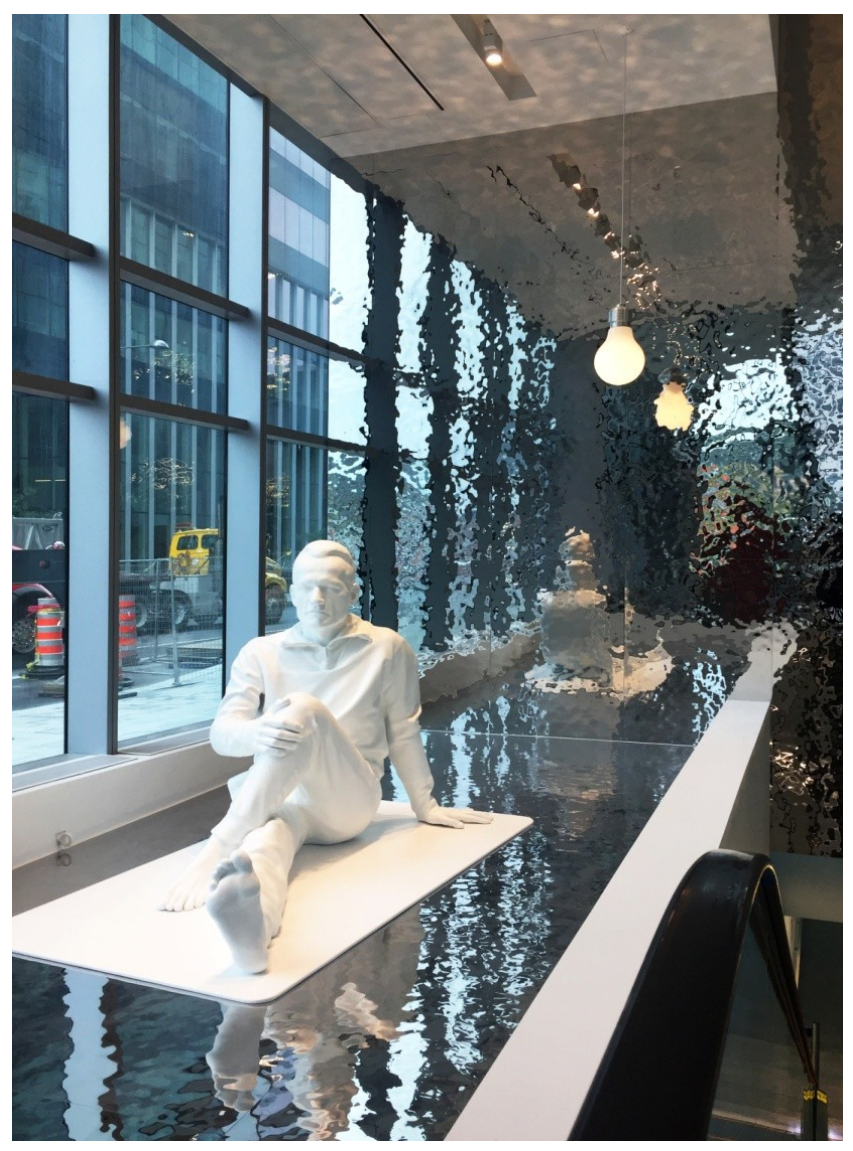




\section{Play as Metaphor}

Using play as metaphor in design adds to our perceiving and understanding of it across space, thus attempting to define - architecture. Many precedents today showcase an intention, where a narrative is used in either one, or more of the following - the decoration, the design, the intervention, the tectonics, or the space. Developing taxonomy to study potentiality in what is currently being used, what is working, and what is lacking, is essential to assess where the element of play is applicable. Beginning with decoration (figure 10), which merely relates to the interior, the prop, the painting, or the colors of a room can add to the development of an intended theme. The design of the interior (figure 11) - the lighting, the installation, the materiality - contributes to generate an atmosphere, ultimately adding to the story of the theme. Intervention rethinks the existing. It aims to design for multi-functionality and flexibility. This requires looking outside what is considered the norm (figure 12). For example, while one space may serve for just the patients, one may unravel the possibility to include elements of comfort for the staff and the visiting families. This improvement is apparent at Shriners. When a patient is going into surgery, the child is usually separated from the parent(s). The induction room is where the child gets prepared for surgery and now the space is accessible for the parent(s), so they can sing their child's favourite songs, or read them their favourite books during the process of anesthesia. This was achieved by creating a separate door for parents to leave the induction room, as well as a separate door for where the kids are rolled into surgery. The parents may now be present when the child falls asleep and they are present when they awake in the recovery room (figure 13). 
Moving to tectonics, the construction of a building may do more than merely perform the function to support weight and allow spatial organization (figure 14). Contributing towards the overall space, it must aim to be spiritually uplifting and not just physically housing a program. In hopes of making the space more inviting and a source of respite, present works of successful projects attempt to integrate art and architecture (figure 15). The lines are blurred between them and thus, the human experiences of the inhabitants become heightened.

Metaphors are traditionally associated with their verbal and literary content. However, suggesting play as metaphor induces a notion that metaphors arise from our physical integrations. In Juhani Pallasmaa's The Embodied Image, he proposes topics of imagination and empathy as topics for architectural education. The Metaphor is a crucial tool for thinking and communication and Pallasmaa articulates how architecture has the power to evoke deep layers of history and culture through metaphoric essence ${ }^{4}$. The correlation between architecture and metaphors places an emphasis on the power of poetics. Examples of this, according to Pallasmaa, include how:

"the windows articulate the encounter of indoors and outdoors and transfers natural light into an architecturally moulded light. The fireplace creates a center of welcome, security and warmth". ${ }^{5}$

The utmost mental effect in architecture occurs in distinct aspects, or confrontations that one has within a space. ${ }^{6}$

Pallasmaa, Juhani. The Embodied Image: Imagination and Imagery in Architecture. Chichester: John Wiley \& Sons Ltd, $2011,068$.

Ibid., 128.

Ibid. 
exploring elements of play

Taxonomy

decoration

INTERVENT!ON

TECTONI!ICS

SPACE

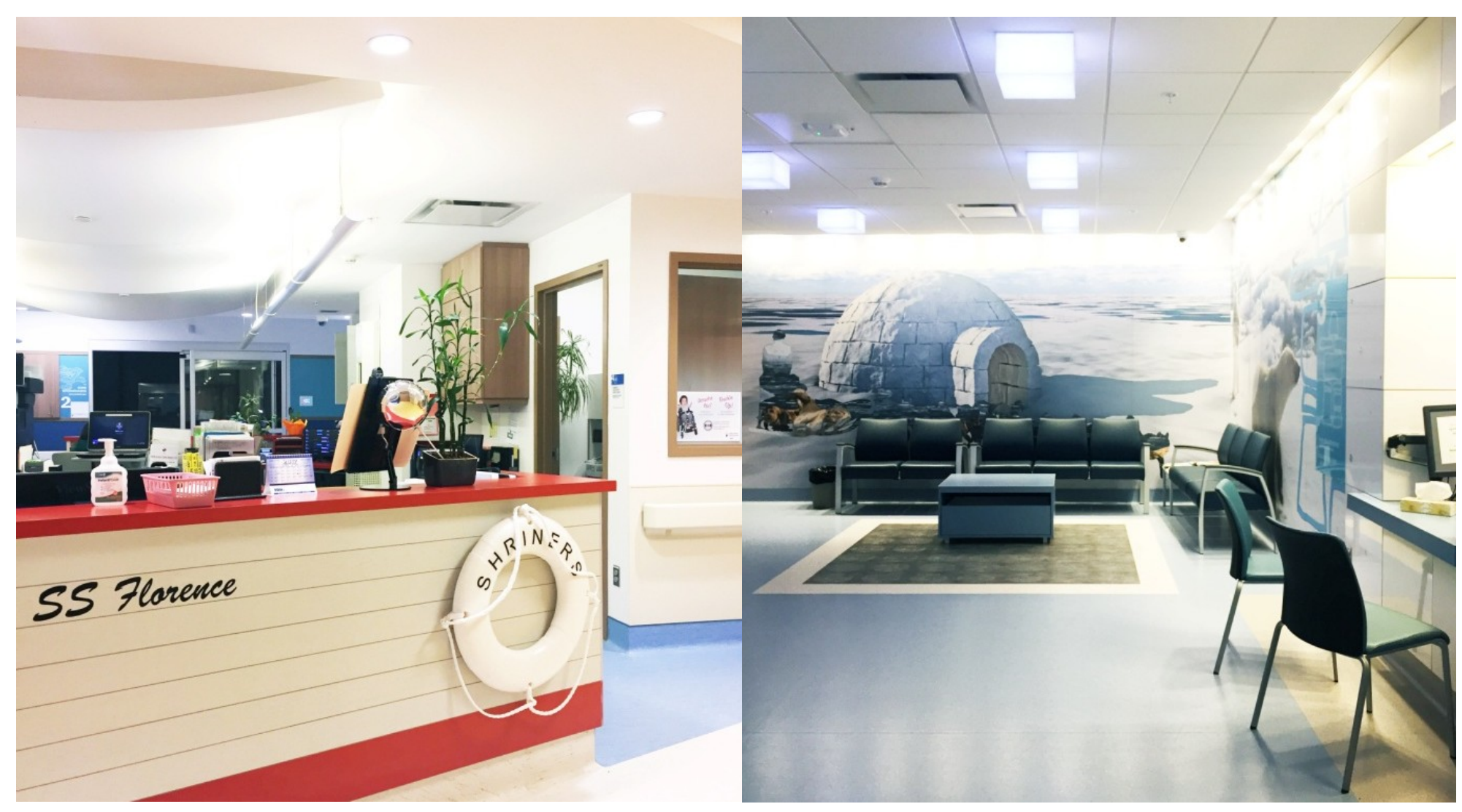

FIGURE 10 

exp | oring
ele $\mathrm{m}$ e $\mathrm{n}$ t s
of
$p \mid a y$

Taxonomy

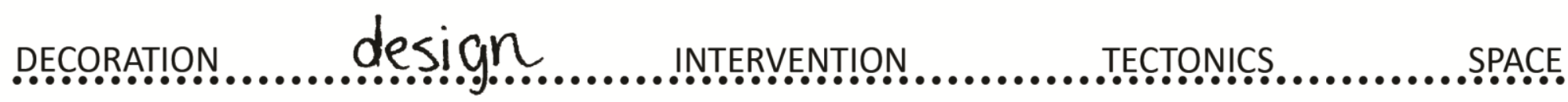

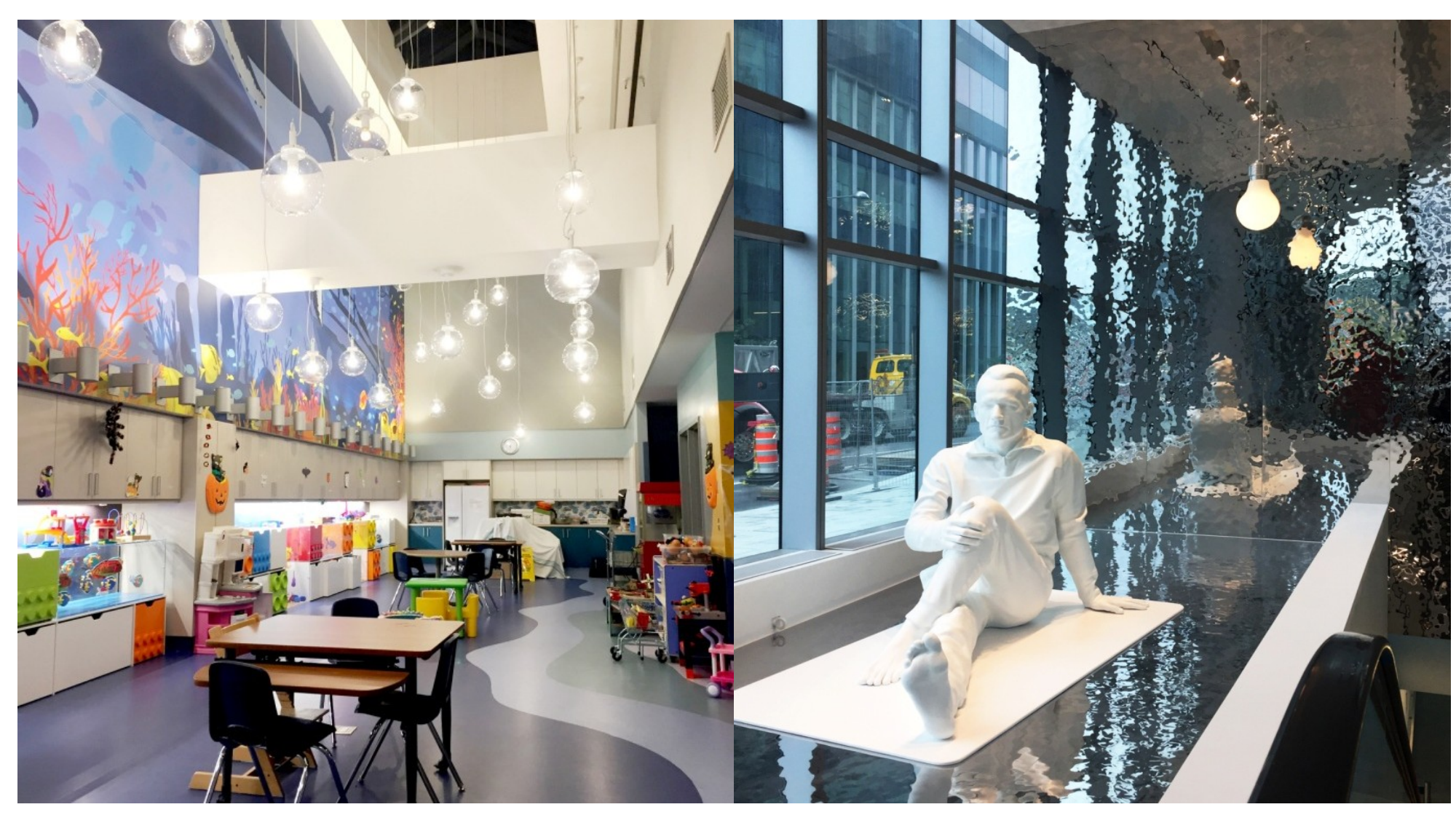

FIGURE 11 
2 exploring elements of play

Taxonomy

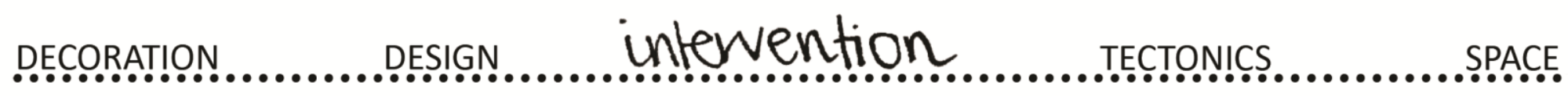
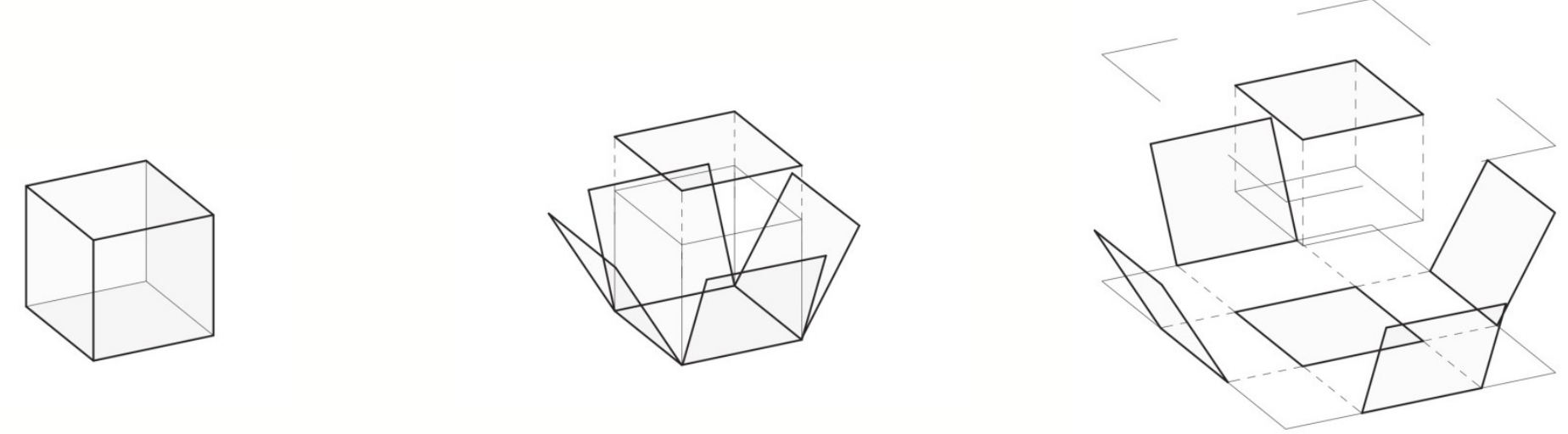

FIGURE 12
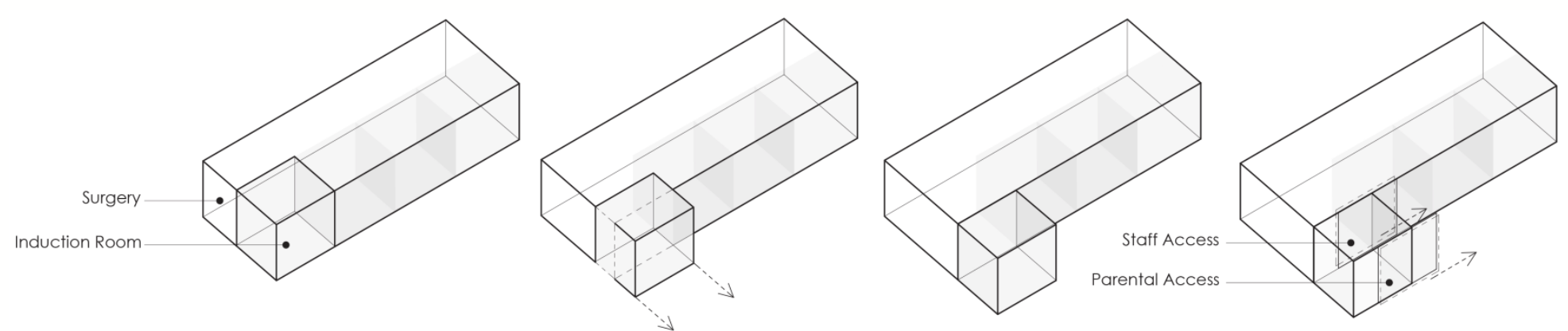

FIGURE 13 

exp | o ring
ele $\mathrm{m}$ e $\mathrm{n}$ t s
of
$p \mid$ a $y$

Taxonomy

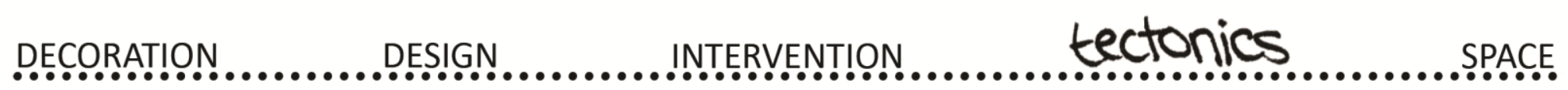

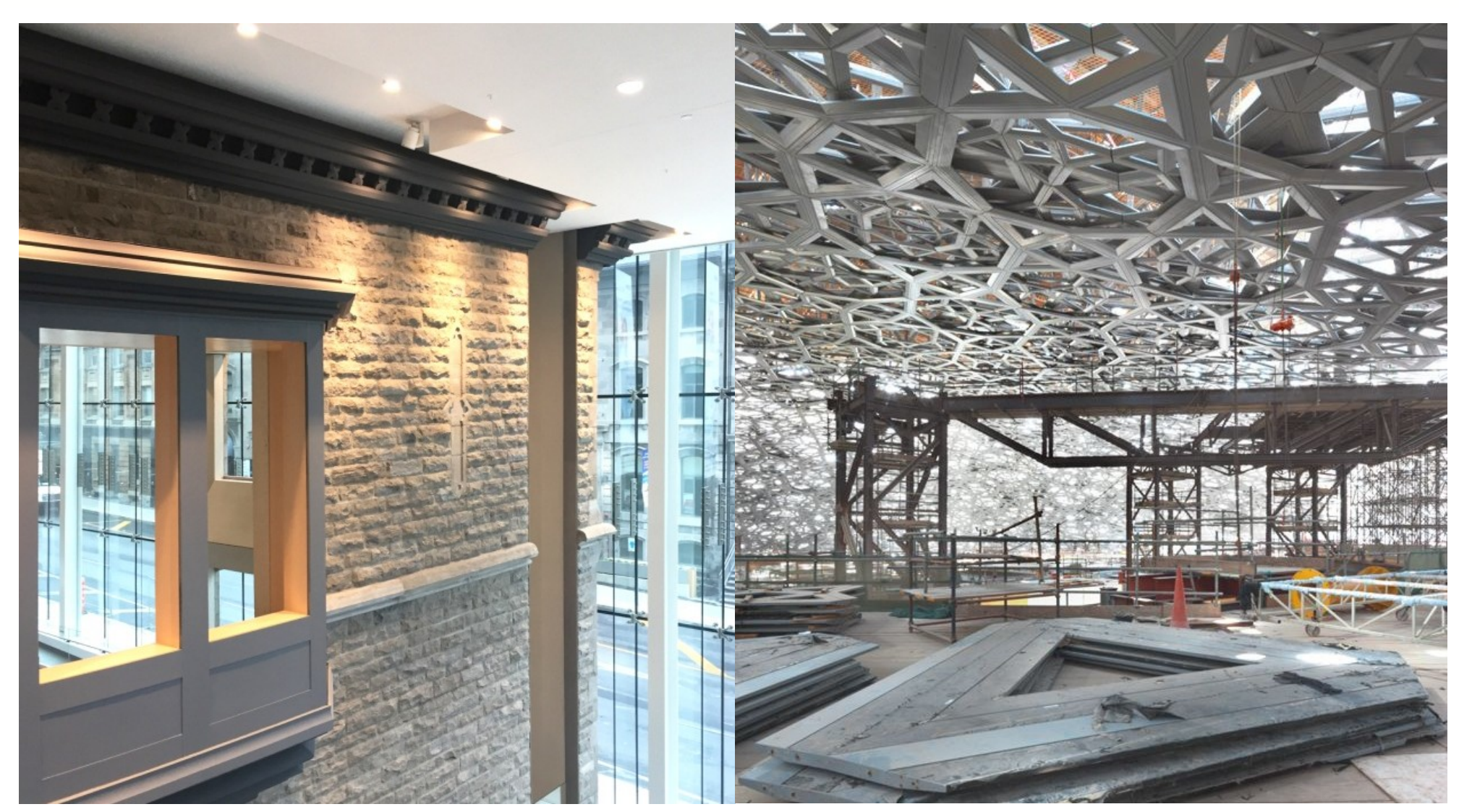

FIGURE 14 
exp\|oring elements of p lay

Taxonomy

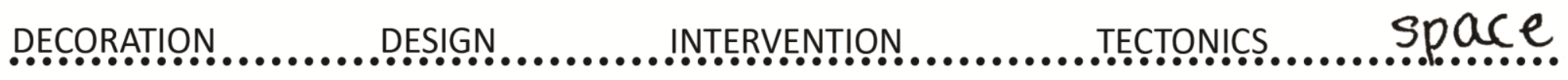

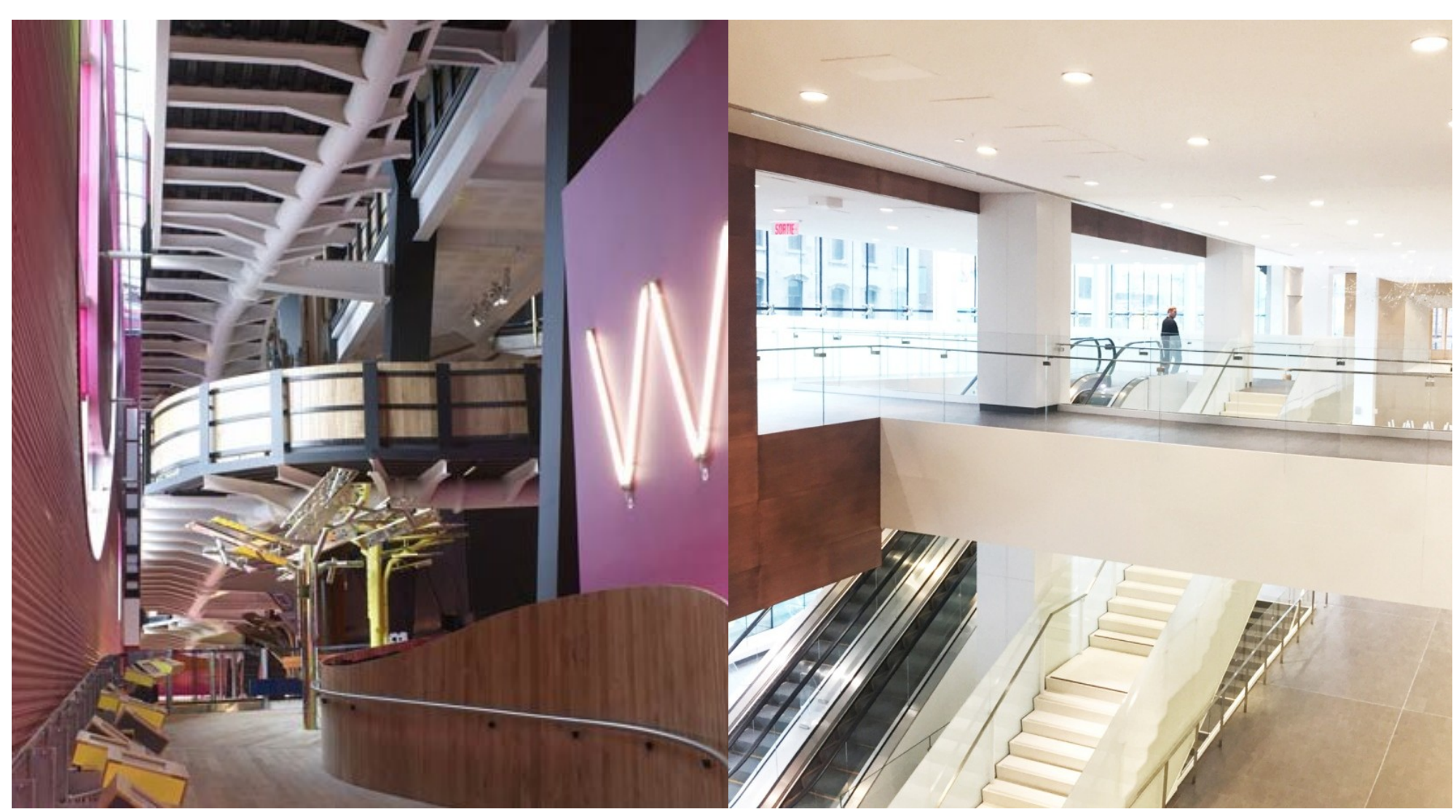

FIGURE 15 


\section{Play as a function}

The term play signifies a function. In play there is something 'at play' which transcends everyday needs of life and informs meaning and conversely our actions ${ }^{7}$. It is an activity - a verb which fulfils a purpose. Huizinga states that:

"play must serve something which is not play", whilst another explains that the "fun of playing, resists all analysis, all logical interpretation". ${ }^{8}$

The analysis of the concept of play brings into question the possibilities of where this function may be applicable. Experimenting with its use invites imagination and eventually, perception. For instance, the play object may invite another play object, forming an open-ended range of games. The player has thus moved past the set function and made up their personal system. 


\section{The End of Treatment Bell}

At the Children's Hospital of Eastern Ontario (CHEO), figure 16 is a drawing of the 'End of Treatment Bell' which hangs on the walls of this pediatric facility. The bell is for the patients to ring when they have completed chemotherapy. It is a playful activity to celebrate their milestone, while the sound serves as a reminder to their fellow patients to look forward to their own achievements to look forward to. The simple gesture functions beyond the physical action of 'ringing the bell'. It is a communication that does not arise from words but the cognitive and sensory process. ${ }^{9}$ We generally tend to believe that we think and communicate directly through words and linguistic structures, but instead, we think and communicate through mental images and models ${ }^{10}$. Research confirms that the use of mental images is inherent in the processes of thinking and speaking, solidifying the correlation between language and our senses. 


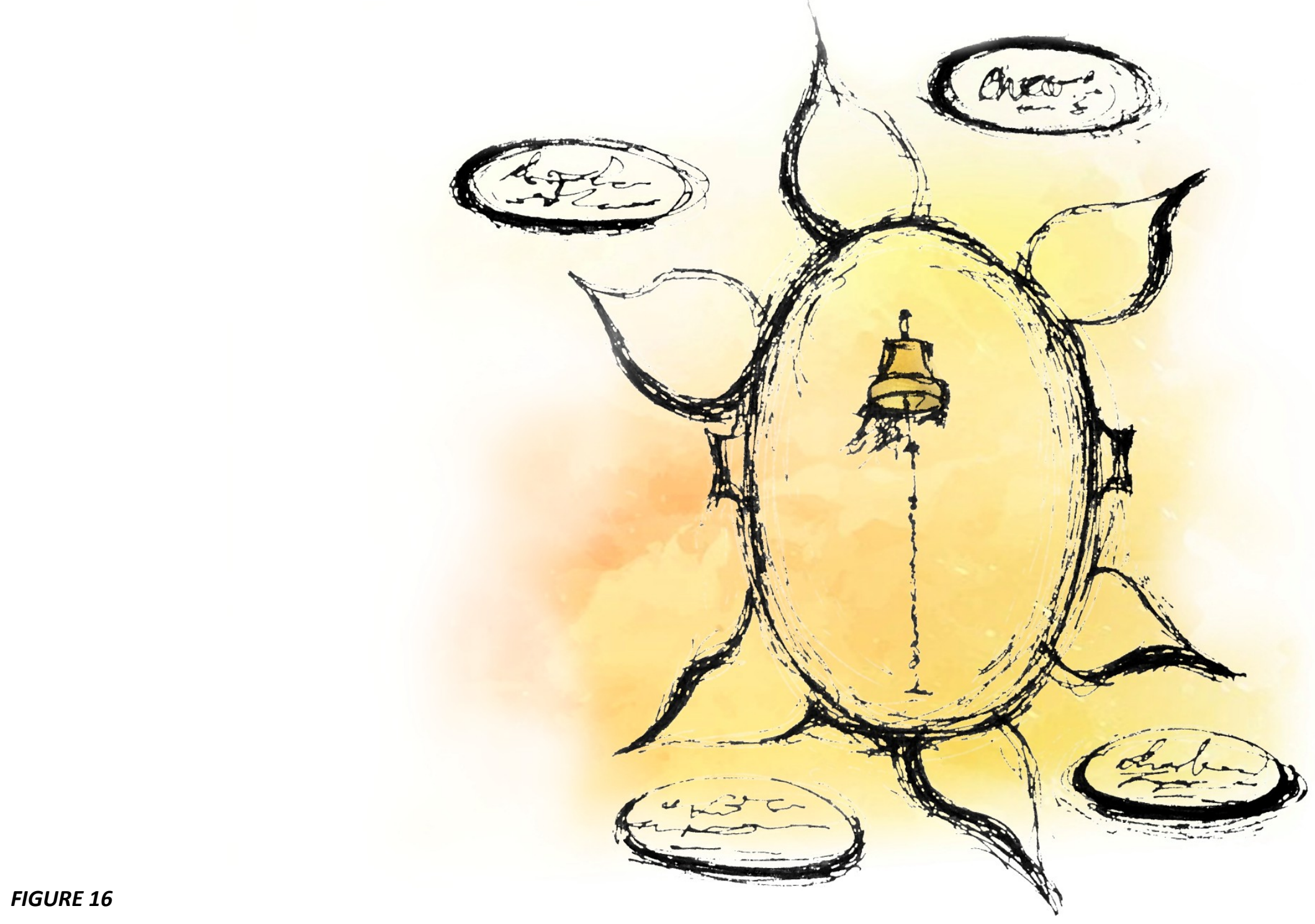




\section{3 the play that is being played}

\section{Characters}

It's limiting to define individuals depending on their illness. That is precisely how one risks losing sight of the sense of humanity and personality. The design proposal places emphasis in the recognition of individual characters based on the types of play required for a child's development. While it can be a strategy to design for the varying and unique personalities of children, the types of play introduces programmatic narratives. Architecture is about relationships and the setting up of these relationships inside the facility will be determined according to its inhabitants - first and foremost, the children. If social support is a significant component of healing, participation is what it becomes all about. Even the onlooker becomes a participant. Play in itself becomes a form of communication in such a way that the person playing is difficult to separate from the person watching the play. Whether it is another patient, a staff member, or a parent, to "go along with" is participating and hence, there is a sharing of this action that is of play. ${ }^{11}$ Asserting that space matters to health and encouraging social relationships go hand in hand. Referring back to Montreal's Shriners hospital for children, ideas circulated around the redesigning of the offices for staff, which were scattered. The reason is because staff members feel separated from the action since most of the offices occupy the sixth floor (purposely done for close proximity to each other and the value of privacy). Despite the design idea carrying good intention, social integration seems to be an issue, which they feel is lacking. One can agree that this design strategy does not express their full potential in medical facilities because there is a predetermined hierarchy upon 
entering a space such as a hospital. The hierarchy based on professionalism has the ability to dominate patients and suppress their attempts at expressing themselves ${ }^{12}$, ultimately forming that immediate stern aura that one meets upon entering a hospital. The need to be "in control of the situation" is a popular and obvious demand in a hospital setting. If patients experience a lack of control over their daily activities, they ultimately become demoralized and feel powerless. ${ }^{13}$ Playfully introducing into the design tale 'characters' as types of play, required for a child's development, can help the patient to reclaim their independence back, while simultaneously producing programmatic narratives.

\section{Introducing characters as the types of play}

\section{The Enthusiast: Social Play}

Introducing the Enthusiast, the free spirit, the soul full of life - they will represent the Social Play. This is when the child is immersed in a play whereby the interaction and the engagement, between other Enthusiasts, are explored - games, conversations, the merging of two imaginative worlds, etc. The objective of this play allows the child to develop relations with other patients and work on their communication skills. This is not only beneficial for the child's development, it allows for participation and social support - the main components of healing. Spaces of such nature are meant to be open and to invite free play of all kinds (figure 17). 


\section{The Artist: Creative Play}

Introducing the Artist, the painter, the composer - artisans will represent the Creative Play. This is the child's way of letting their imagination out, through their hand and into drawings. It is a transformation of information - finger painting, sketching, coloring, etc. Drawing is essential for a child to express what they are thinking and feeling. It is a method one can use to be in touch with the child's imagination. Through this kind of play, the patient is able to dissociate themselves from their pain through their imagination - inviting color and visual representations that will derive out of it. Spaces are meant to encourage a desire to engage with art and the activity of painting - celebrating the gift of color (figure 18).

\section{The Performer: Dramatic Play}

Introducing the Performer, the superhero, the princess - this will take the form of the Dramatic Play. This is when the child transforms the play object, or ordinary items, into people and locations of their imaginative worlds - playing "dress up". The play of make believe helps with the self-esteem of the character - the discovery that one can be anything they set their mind to. The benefits of "pretending to be something", allows for the child to experiment with different roles in life. The child may also be the spectator of this, not necessarily the one pretending. Hence, spaces as such may include a theatrical place of performances, or a stage that the "princess" can convert into her "castle" (figure 19). 


\section{The Explorer: Exploratory Play}

Introducing the explorer, the curious, the producer - this character takes the form of the Exploratory Play. This child engages with the many possibilities of the (hand-eye) manipulation or the movement of an object - the stacking of building blocks, jumping rope, etc. This is a play which rearranges the world in the vision of a child, led by mainly a play instinct. It is accomplished by an intellect and it is where the conventional rules of how something is played may not be applied. Spaces of such character involve the engagement of our sensory system. The space may be made up of objects which can be reoriented, moved around, and experimented with (figure 20).

\section{The Reader: Solitary Play}

Introducing the Reader, the dreamer, the storyteller - this child takes part into the form of Solitary Play. This is when a child enjoys a space of solitude whereby their play is self-guided and independent - to write, or read their favourite novel series, or work on a puzzle, etc. The objective of this play is meant to reinforce self-reliance and to cultivate reflection. The play also allows for the individual to tackle tasks at their own pace. Spaces of such type may include areas of a calmer atmosphere where one may find pockets of space for the Reader to lay back and enjoy their escape (figure 21). 


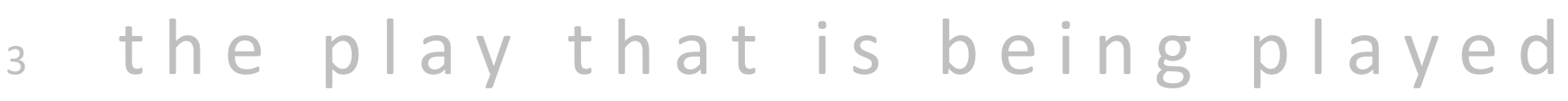

Introducing characters as the types of play

The Enthusiast: Social Play

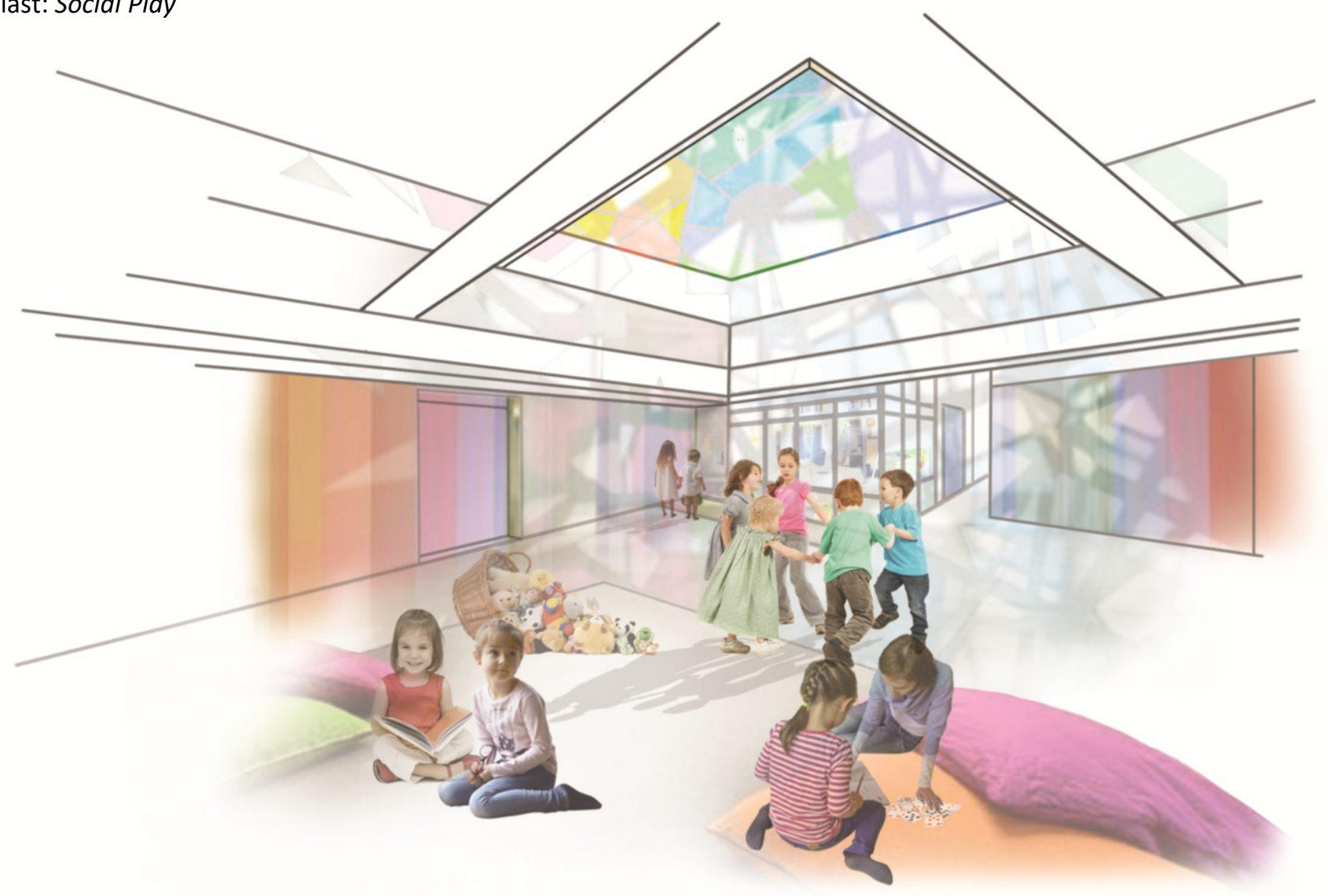

FIGURE 17 
3 the play that is being played

Introducing characters as the types of play

The Artist: Creative Play

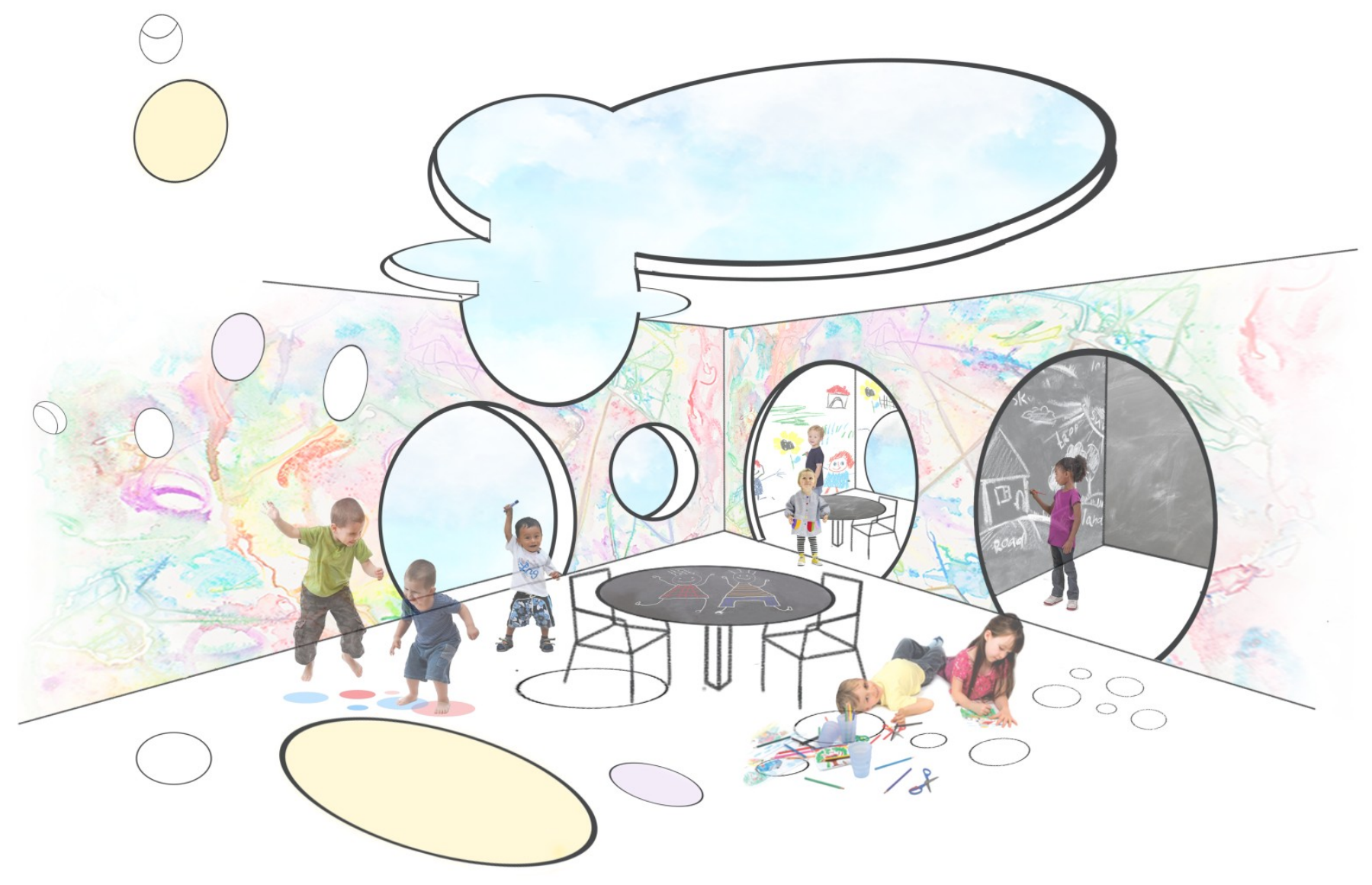

FIGURE 18 
3 the play that is being played

Introducing characters as the types of play

The Performer: Dramatic Play

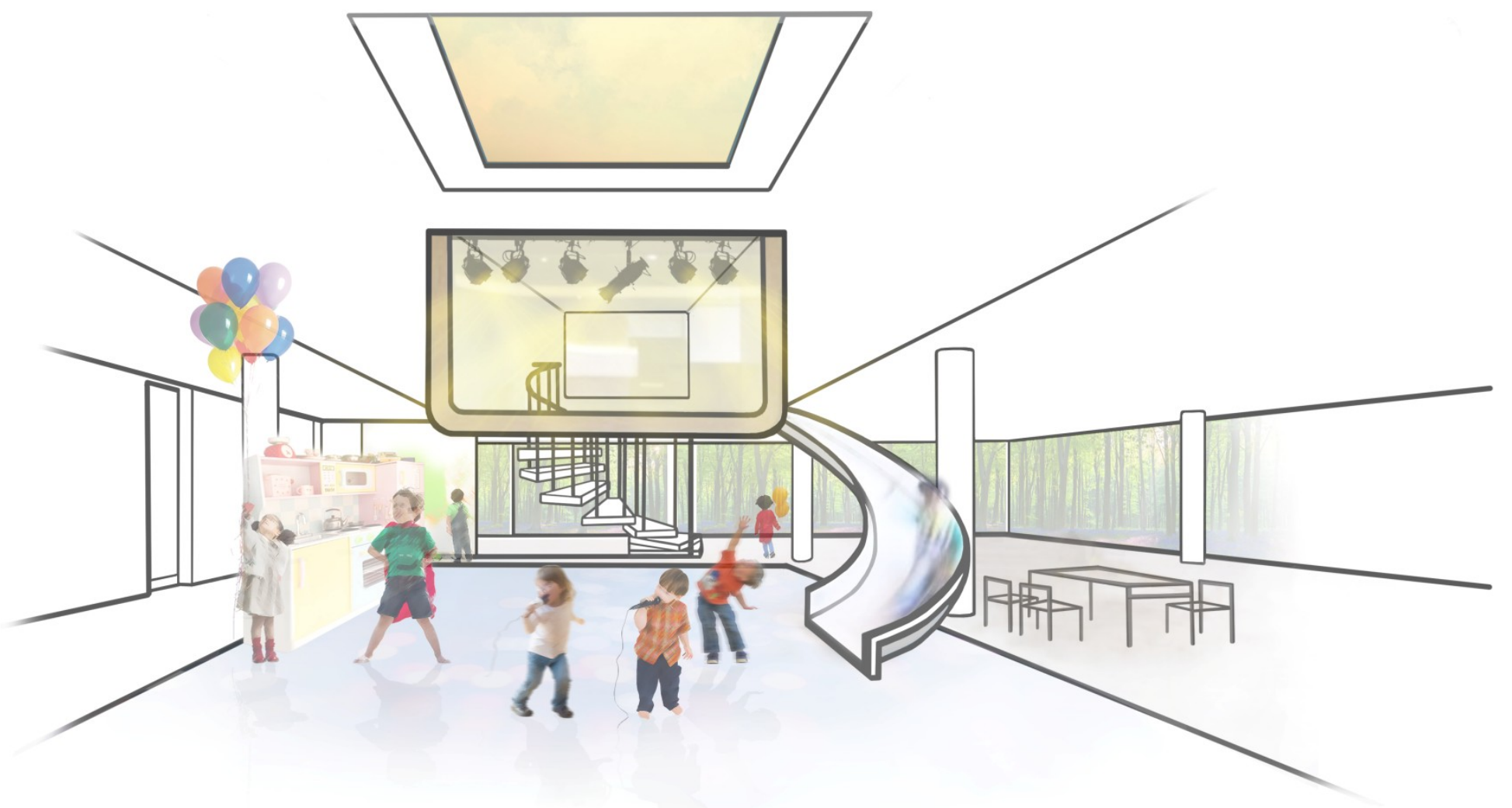

FIGURE 19 
3 the play that is being played

Introducing characters as the types of play

The Explorer: Exploratory Play

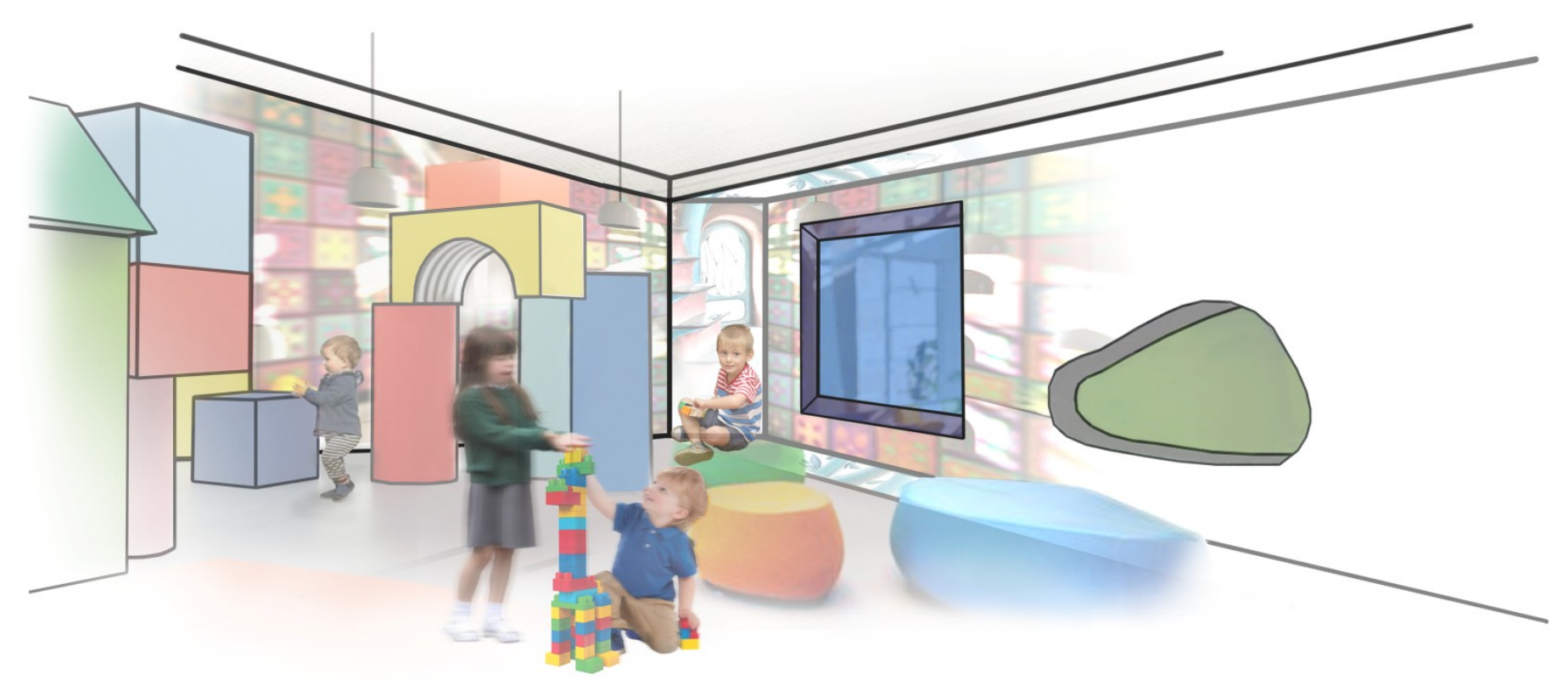

FIGURE 20 
3 the play that is being played

Introducing characters as the types of play

The Reader: Solitary Play

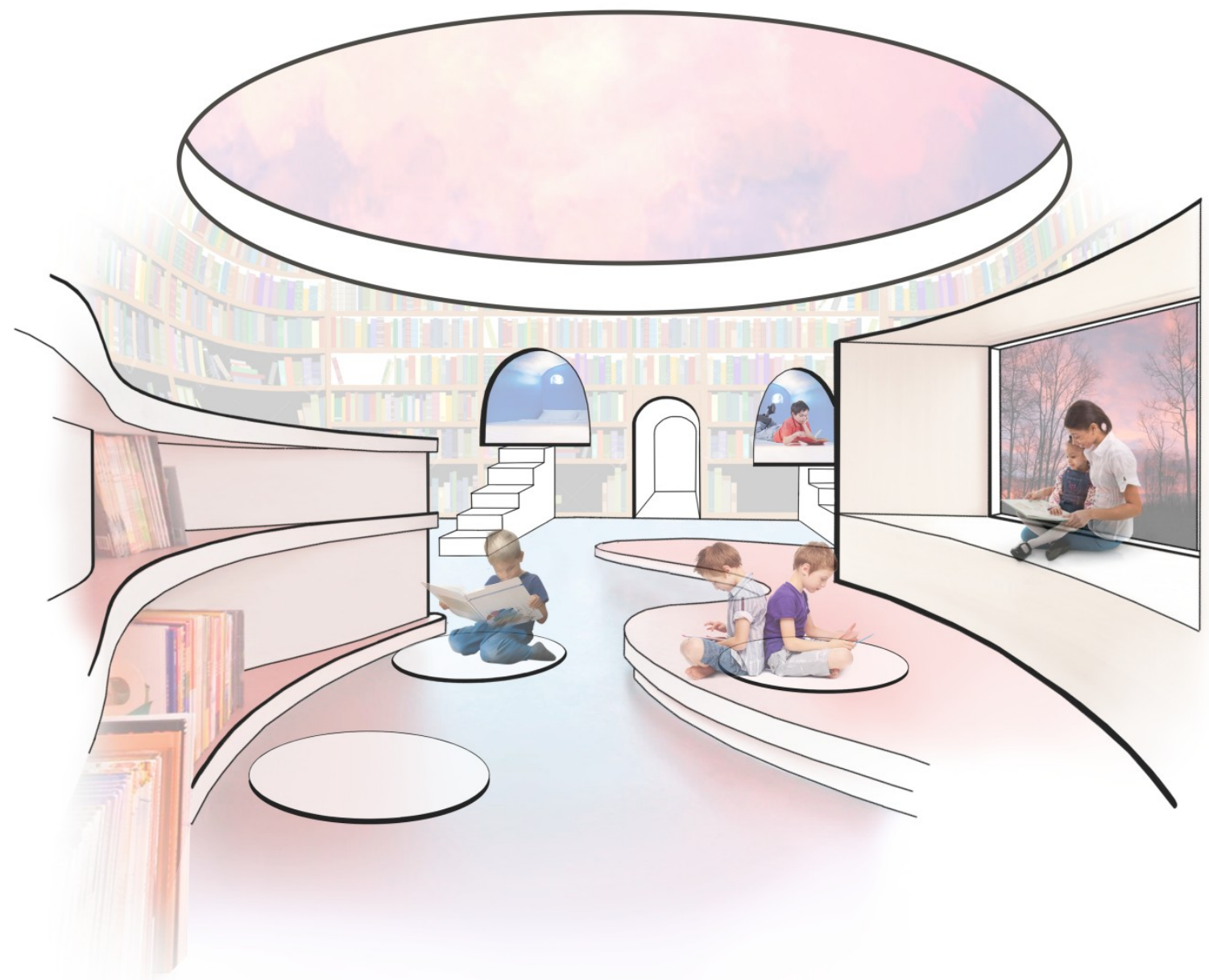

FIGURE 21 


\section{the role that this proposal is playing}

\section{Site Experiment: $\mathrm{CHEO}$}

Regarding the Children's Hospital of Eastern Ontario, this pediatric health and research center facility is an opportunity which can be utilized for speculative design. It sets an example to work off of considering it is a hospital that inspires improvement. CHEO has been around for over 40 years, since opening its doors in 1974, and continues to have one of the busiest pediatric emergency rooms in Canada.

\section{Architectural Proposal: Space Typologies}

As a strategy to design, utilizing space typologies at CHEO defines a scheme of spacial exploration. Many hospitals that were designed with a functionalist approach, during the 60 s and 70 s, are here to stay. They could be significantly improved through changes addressing the idea of narrative through play. In addition these spaces will also be re-imagined to explore their full potential through play. This dual design strategy is useful because it is important to consider both scenarios in order to showcase how minor changes could create a lot of differences even when compared with a new design. Since this design proposal utilizes play as an instrument to challenge space to stimulate a sense of wonder, what if spaces 'looked-like' drawings - as canvases of our fictive imagination? In the case of the reinvented, space constraints remain the same and one attempts at finding solutions to improve the existing issues occurring in that typology, the overall wellbeing of the habitual dwellers of the facility, and the application of the types of play. In the case of the reimagined, space restrictions are removed and one has the liberty of being as flexible as possible. The challenge becomes providing 
functionality within the aesthetics to successfully show the narrative of play. Once again, this design strategy would attempt to improve issues which are standard in the typology, provide security for the patients, visitors, and the staff, and accommodate to the tale of characters for a growth oriented approach. Since this proposal hopes to motivate design to engage the imagination of the patient, in order to stimulate feedback and support to cope with illness, the collection of drawings will generate a children's book. The use of the book is a way of stimulating the occupants (children, parents, staff members) to express their feelings about spaces within the hospital as if they were part of designing the space typologies themselves. By using the author's perceived experience as a demonstration, this exercise challenges experts of their own experience to be able to make a contribution in the solution of the problem. Given that social support is the most momentous component of healing, making room for participation is crucial. By listening to the voice of the habitual dweller, one is able design meaningful solutions to enhance the staff and occupant's gratification. The current character moving around the spaces in the book is a visitor. Its vagueness is to imply the varying age group in pediatric hospitals - zero to eighteen years of age. However, different characters could be added in (or different versions of the book can be produced, depending on targeted audience) that would suit the age of the child reading the book. 


\section{Hallway}

\section{The Existing}

The first space typology - the hallway - relates to the way-finding within a medical facility. The current hospital condition at CHEO greatly depends on the visual senses for ease of navigation, utilizing tools such as signage. Given the present, and common, dimensions of the hallway (2.5m in width), it appears that the current standard can create traffic amongst the many activities that are occurring within this compact space. The space is functional and efficient for utilities such as wheelchairs, stretchers, etc. However, considering the importance of a hallway in terms of circulation, the flow of movement must be flexible when a staff member, a patient, a visitor, etc. is travelling from one place to another. The issue being encountered is the storage of the utilities in the hallway. When this occurs, it interferes with the circulation and hence, creating the traffic. Not only does this create a cluster of items that may slow down the passersby, but the utilities add to the occurring stern atmosphere of a hospital. The blank walls, white lighting in the grid ceilings and colorless floors create an empty canvas waiting to be immersed in life. There is an isolation that occurs where the walls, the floors, and the ceilings become their own entity, enforcing an atmosphere of a casket. The space lacks a unity.

\section{The Re-invented}

Taking into account the first design strategy - creating minor alterations to the existing - one can accommodate to the characters of the types of play at the existing hallways of CHEO. Keeping in mind the existing constraints, $2.5 \mathrm{~m}$ width, the modifications would not interfere with the existing space restrictions but attempt to eliminate some of the stern ambience that comes with way-finding at the 
medical facility. In fact, the use of color on this 'empty canvas' is the first phase to engage in this strategy. In Esther Sternberg's, Healing Spaces, she elaborates on color having an effect on mood, and how this notion is not a new one. The way we see things evokes powerful emotional responses and this idea has been taken advantage of by many marketers across the world. ${ }^{14}$ However, this is not possible with only color.

"Walk into a department store and you are surrounded by objects vying for your attention. The ones you'll notice are the ones placed directly in your field of vision. They are often large, bright, glittery, or high-contrast."15

Other features of visual perception must be utilized, such as size and position. Along with color, elements such as the shape and associations of an image are what stimulate the audience. ${ }^{16}$ Similarly, one can treat re-inventing the hallway with the same approach. If one were to place large shapes of bright puzzle pieces on the walls, ceilings, and floors of the hallway, what would this do to the space? These forms would merge different surfaces together. For instance, at the corner condition of the wall to ceiling, the wall would become book shelves and eventually develop into lighting. The transformation of the perception of the space hopes to reduce the congested feeling that might occur from the $2.7 \mathrm{~m}$ ceiling height. In reference to the characters, the performer may feel as though they have entered into a world of jigsaw puzzles, while the artist may feel like they have entered into their canvas. The enthusiast may momentarily interact with the reader, picking up a book to read, while the explorer can latch onto the railing - which physically stands

Sternberg, Esther M. Healing Spaces: The Science of Place and Well-Being. Cambridge, Massachusetts: Belknap Press of Harvard University Press, 2010, 44. Ibid. 
out within these sensorial volumes. The hallway, hence, converts into one theatrical experience. By tempering with visual perception of how one typically views a hospital hallway, the introduction to re-imagining the hallway entirely is stirred.

\section{The Re-imagined}

Employing the idea of the above alterations to the next strategy, one begins to re-imagine the shapes on the surfaces as spacial identities. What if the 'moments of pause' become places of programmatic narratives? Given that there are no existing restrictions in this scenario, there is an added $1 \mathrm{~m}$ in ceiling height and an additional $1.5 \mathrm{~m}$ in width (applied to either side of the hallway) - unlocking potential in solving the current issues that one is faced with in this hospital typology. The spaces developed desires to accommodate for all ages, designed in various sizes for different age groups and diverse uses. Keeping in mind functionality, certain sizes are to be utilized by staff for wheelchair storage. Playing on this idea of visual perception, applying spacial narratives intensifies the benefits for the prospective characters. For the performer, the entire typology should allow them to feel that they are a part of a stage-like experience. The artist can escape to a nearby chalk board and freely express themselves, while the reader may steal a calmer corner to enjoy their book. The enthusiast may stop to intermingle at these activated spacial gaps, or help the explorer on his search for their most suitable nook. 
4 the role that this proposal is playing

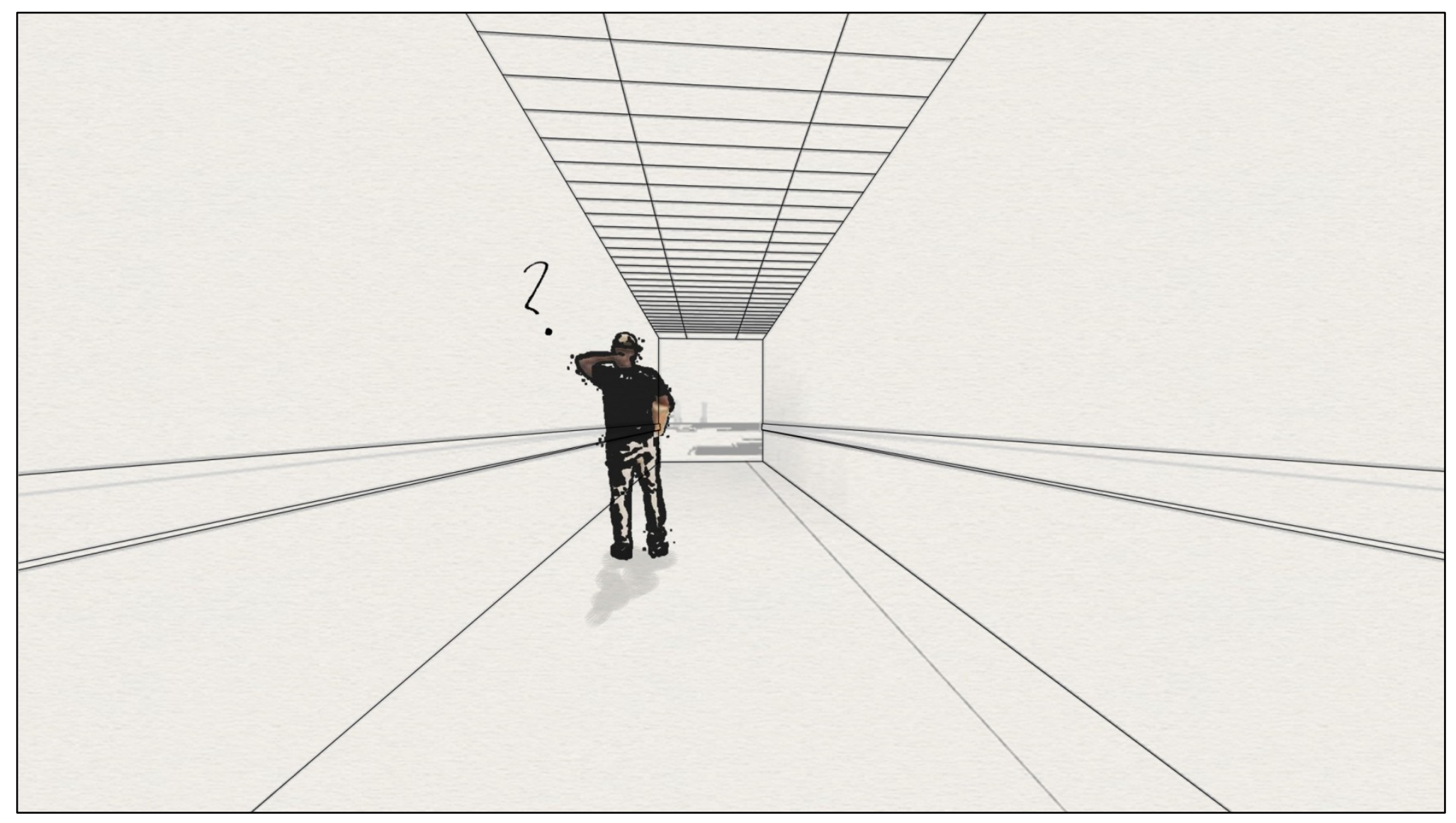

FIGURE 22

Hallway: The Existing 
4 the role that this proposal is playing

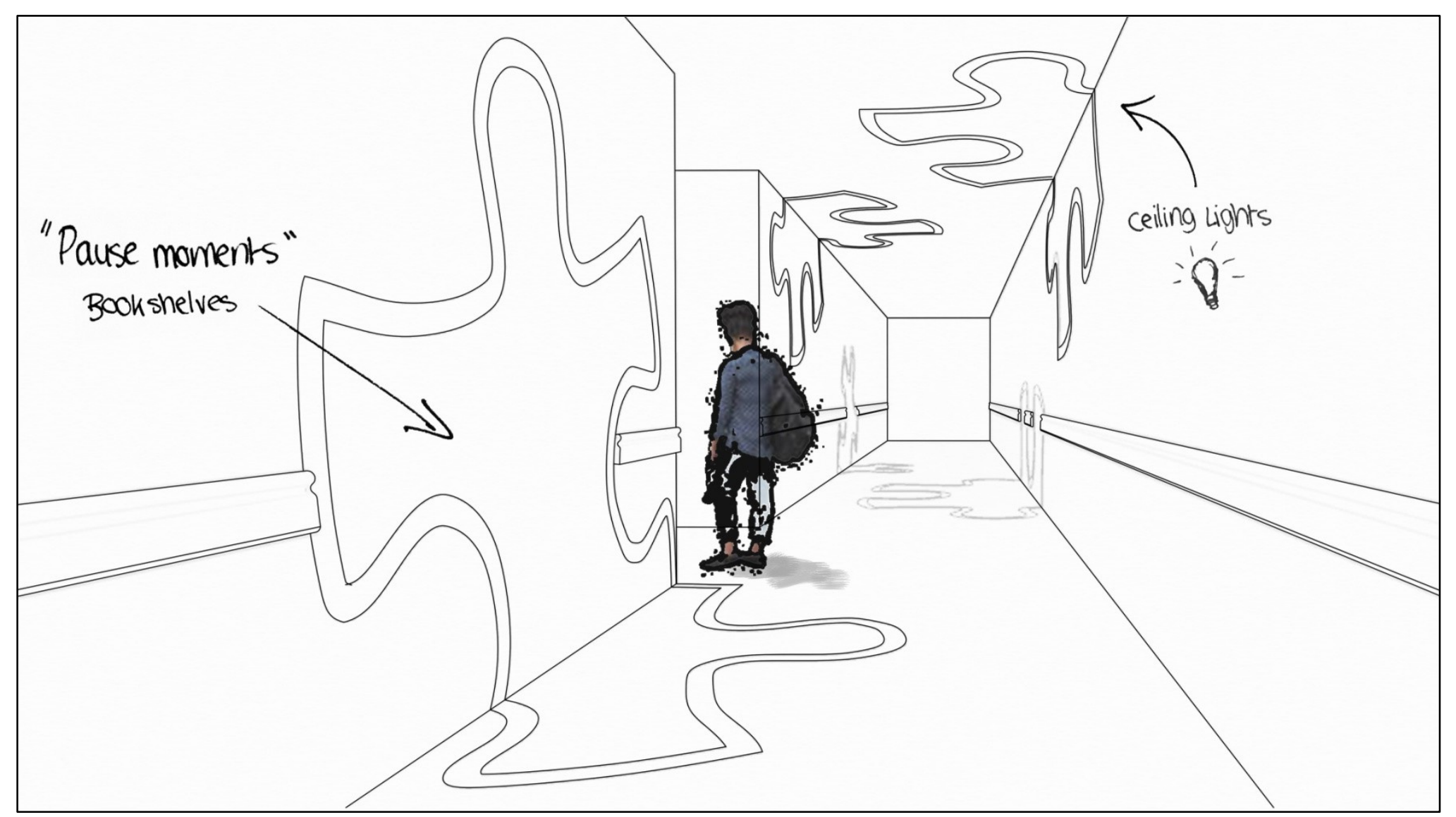

FIGURE 23

Hallway: The Re-invented

41 
4 the role that this proposal is playing

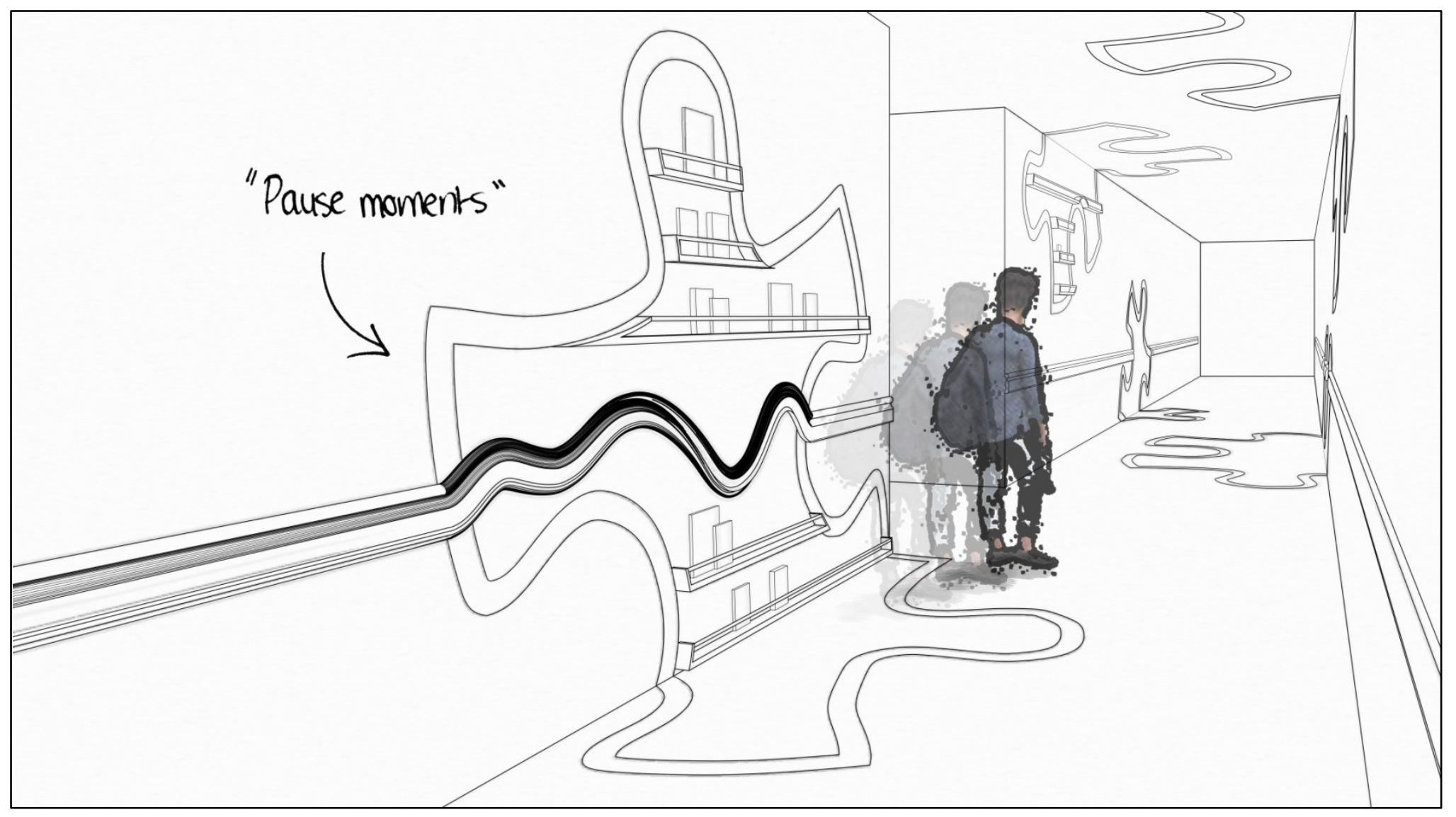

FIGURE 24

Hallway: The Re-invented (2) 
4 the role that this proposal is playing

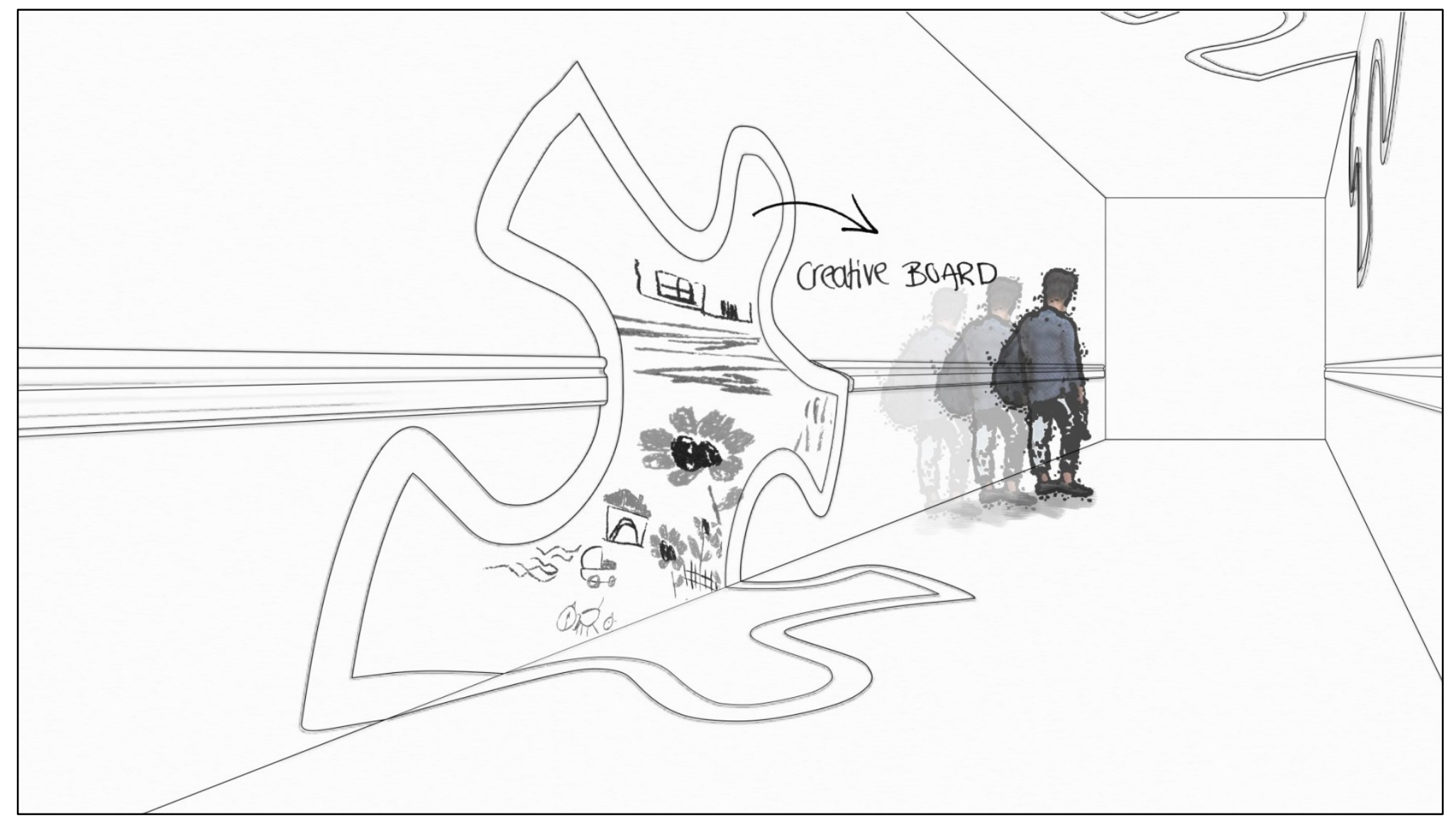

FIGURE 25

Hallway: The Re-invented (3) 
4 the role that this proposal is playing

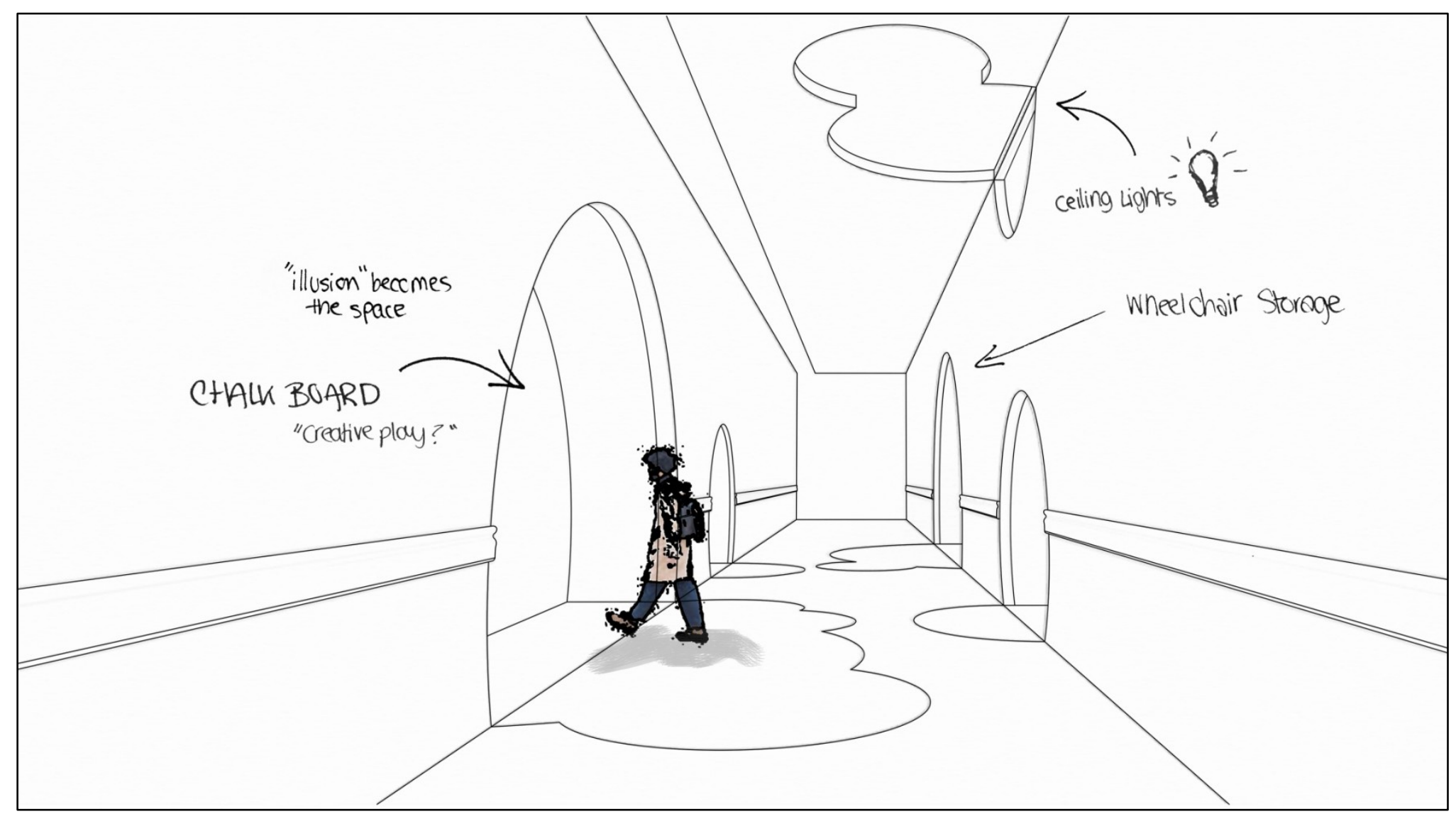

FIGURE 26

Hallway: The Re-imagined 
4 the role that this proposal is playing

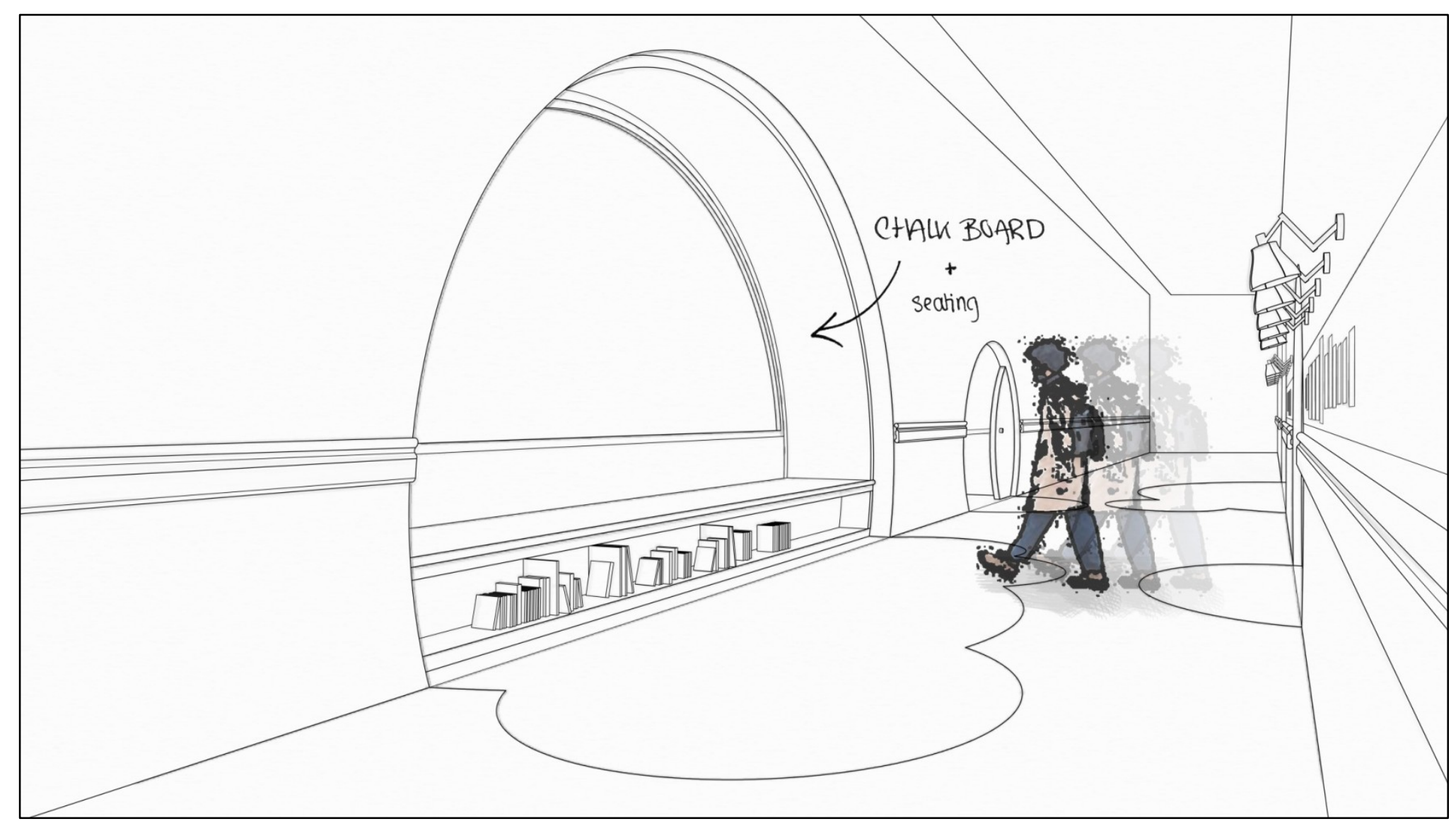

FIGURE 27

Hallway: The Re-imagined (2) 
4 the role that this proposal is playing

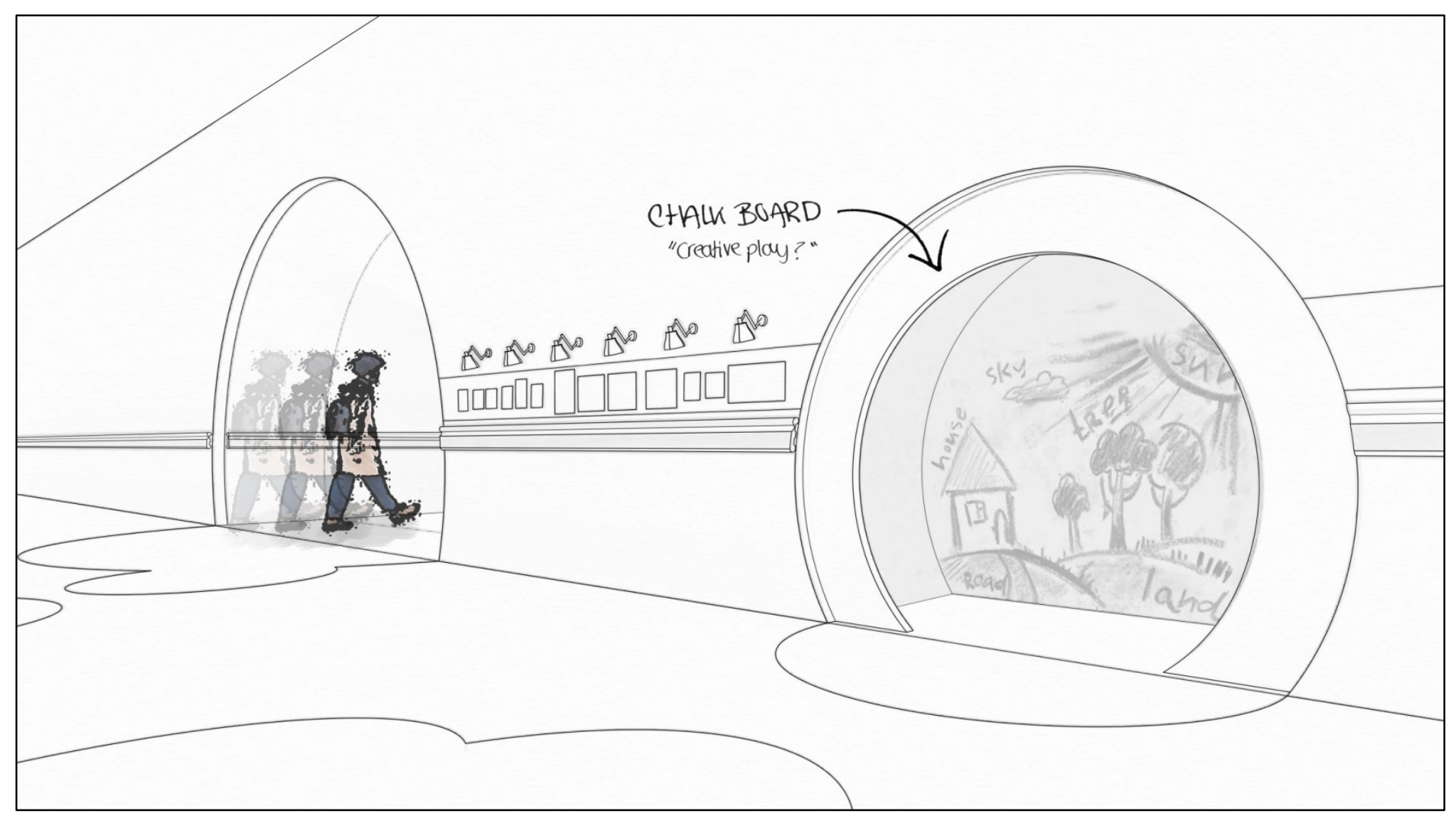

FIGURE 28

Hallway: The Re-imagined (3) 
4 the role that this proposal is playing

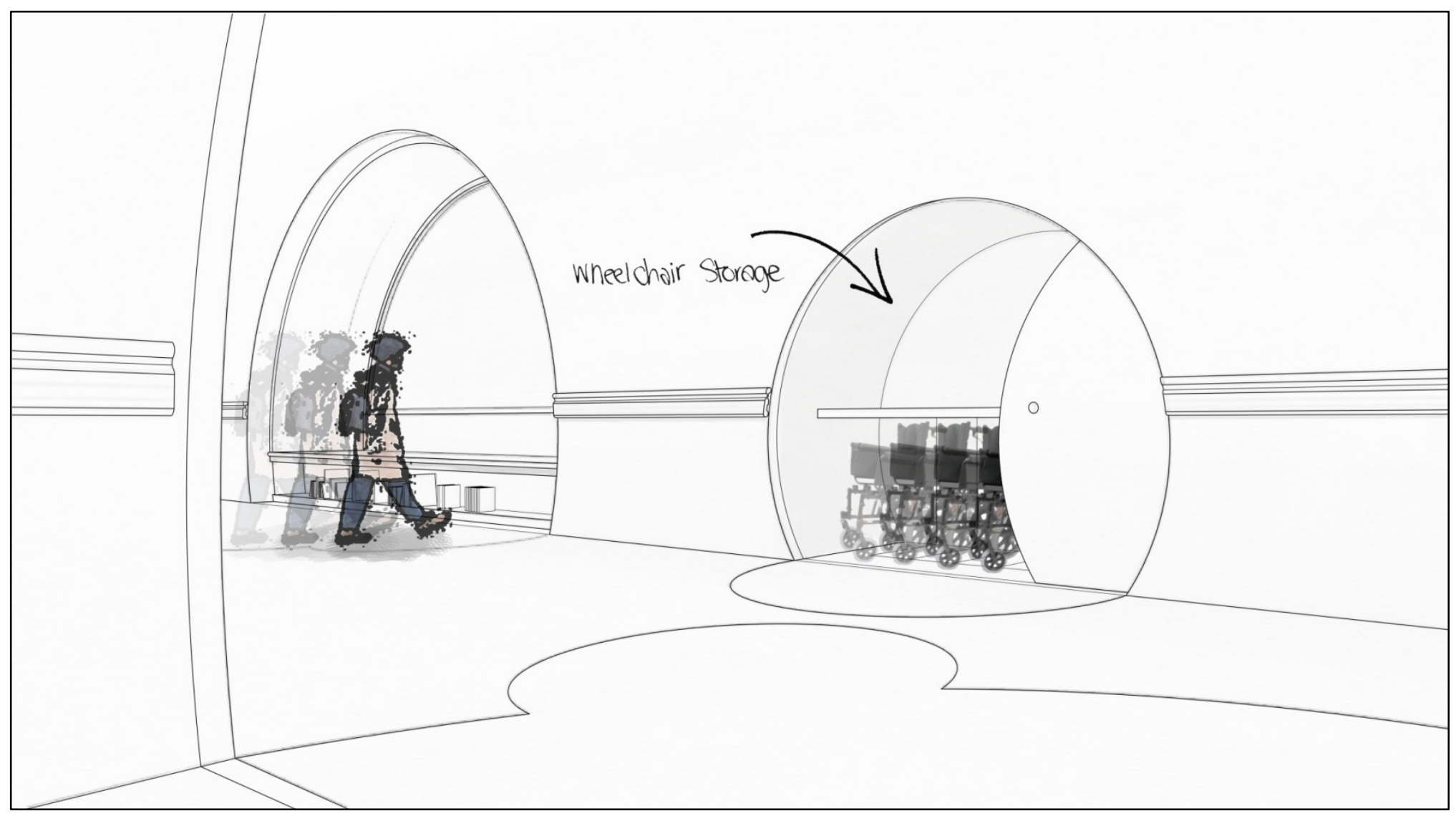

FIGURE 29

Hallway: The Re-imagined (4) 


\section{Patient's Room}

\section{The Existing}

The second space typology - the patient's room - relates to the dwellings within a medical facility. The current hospital condition at CHEO is functional but it's struggling from a lack of space. This results in the combination of two beds per room, accommodating for two patients, instead of one. A typical room of a patient consists of a hospital bed, a sink, the bathroom, a chair for visitors, and curtains that may separate one patient from the other. The window is almost not available to one of the patients, considering it is on one side of the room (beside one of the hospital beds). There's no room for the patient to get comfortable around the space without feeling as though they are interfering with their neighbor. Even though, the current state appears to possibly encourage the patients to engage with one another, the room lacks the 'little piece of home' sentiment for the long-term dwellers, or the short-term ones. Once again, the blank walls, white lighting in the grid ceilings and the monotonous floors create a lifeless ambience waiting to be personalized by its dwellers. How can one re-invent or re-imagine the existing introducing a narrative through play?

\section{The Re-invented}

Approaching this strategy - minor alterations to the existing - it is important to ask what is missing and how will adding it bring meaning to the present condition. Given the space constraints, the challenge becomes applying value to the existing without taking up too much room. A series of fold-down mechanisms are used to re-invent the space (and especially since children tend to seek out movable objects). Fold-down chairs and a table are applicable, deploying a space for work or leisure. This may allow the artist to pursue their 
endeavors or encourage the enthusiast to play their favourite board game. The mechanisms additionally offer fold-down shelves for personal items, such as a place for the reader to store their books. The transformable space is itself a way of engaging the explorer to reinvent their room themselves - a method of helping the child regain their sense of autonomy - and in the case of the performer, the flexibility in the configuration of the space may convey attributes of a black-box theatre. In Annemarie Adam's Medicine by Design: The Architect and the Modern Hospital, she references William Notman's astonishing photograph of the Children's ward at the Royal Hospital in Montreal (figure 22).

"Notman's photo shows six children, seated in small rockers, enjoying "tea" with a tiny tea service at a table specially scaled for them." $^{17}$

What differentiates this ward from the others (adult wards) of the hospital is the recreational use of the space. Despite being captured in 1894 , the image showcases the priority given to spaces of leisure for the children. The photograph reveals twelve beds and seventeen children, and although the patients' room appears to occupy a large population, the small gestures of the rockers hints at the importance towards these positive playful interactions. 


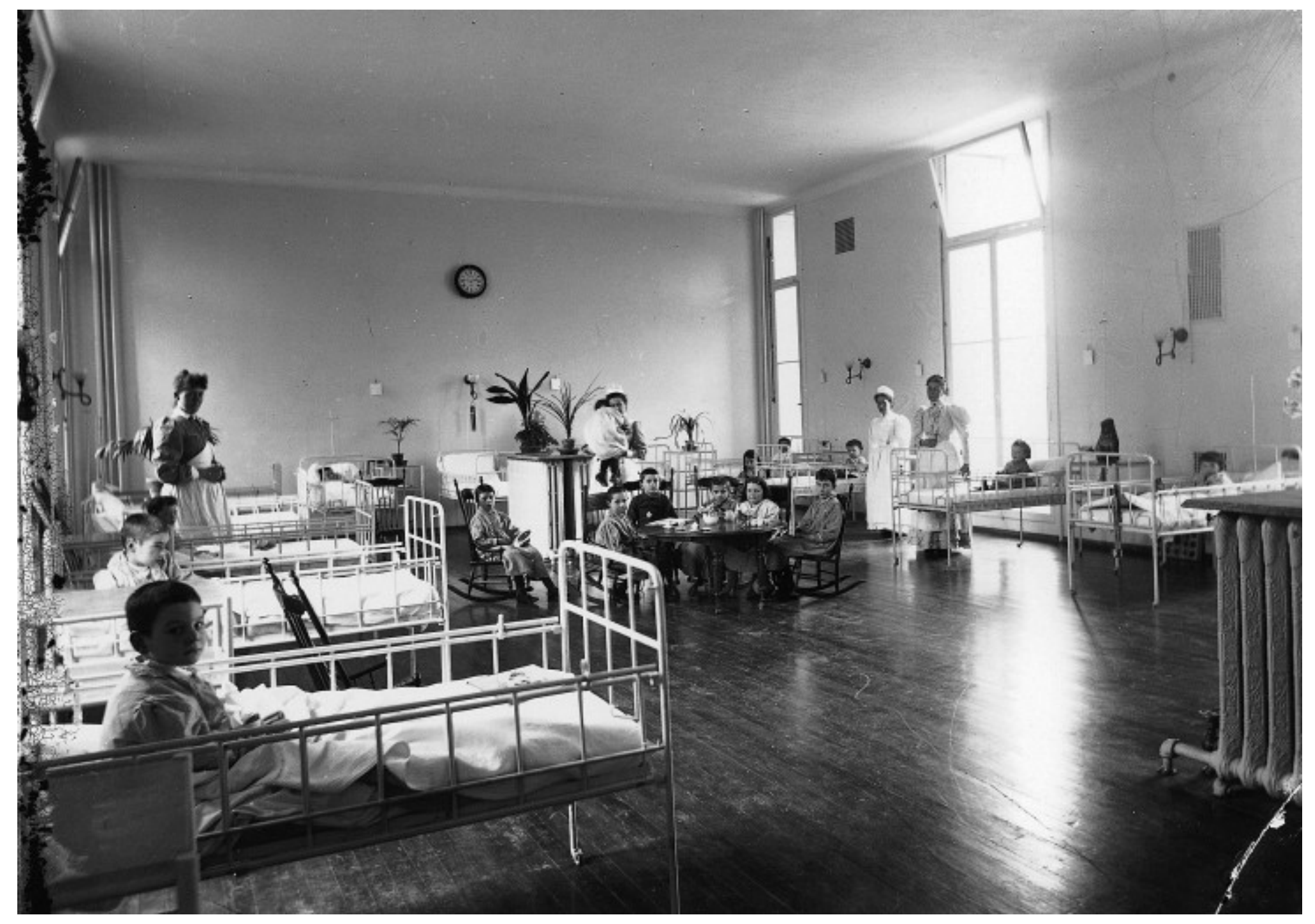

FIGURE 30

Children's ward, Royal Victoria Hospital, 1894. 


\section{The Re-imagined}

By starting with minor alterations, the design strategy makes way for the next one. What if space was no longer a constraint? Ideally, patients would receive their individual private rooms with their own single bathroom. The ceiling would be higher for better breathing room and visiting guests would have a place to rest, or a place to work. However, how does the space become of value for a child? How can one employ the types of play? Once again, the wall to ceiling and wall to floor connections are significant to apply visual continuity and to bring a theatrical experience to the performer. The continuation of tempering with visual perception invites the child's imagination into their room. The space for guests becomes the place for the enthusiast to play their board game, or the artist to create artwork. This is possible by transformable gestures of the space (pull-down chair and desk). Once again, it places emphasis on the importance of place configuration. It allows for the child to feel as though they have a say in how their room appears, while at the same time creating elements of surprise for the explorer to discover. Since it wasn't until 1907 that pediatrics was given its own ward, in 1919, a photograph of a children's ward shows beds on only one side of the room. Nevertheless, apart from this arrangement, the space stands out from the adult wards (figure 23).

"In short, the visual evidence, from the time the hospital opened in 1893, shows that children were treated (spatially) like the other patients who stayed at the new hospital, except, crucially, they were given opportunity and spaces for play." ${ }^{18}$

By creating subliminal spaces suitable for all the types of play, it is important to note the impact it will have on their development. 


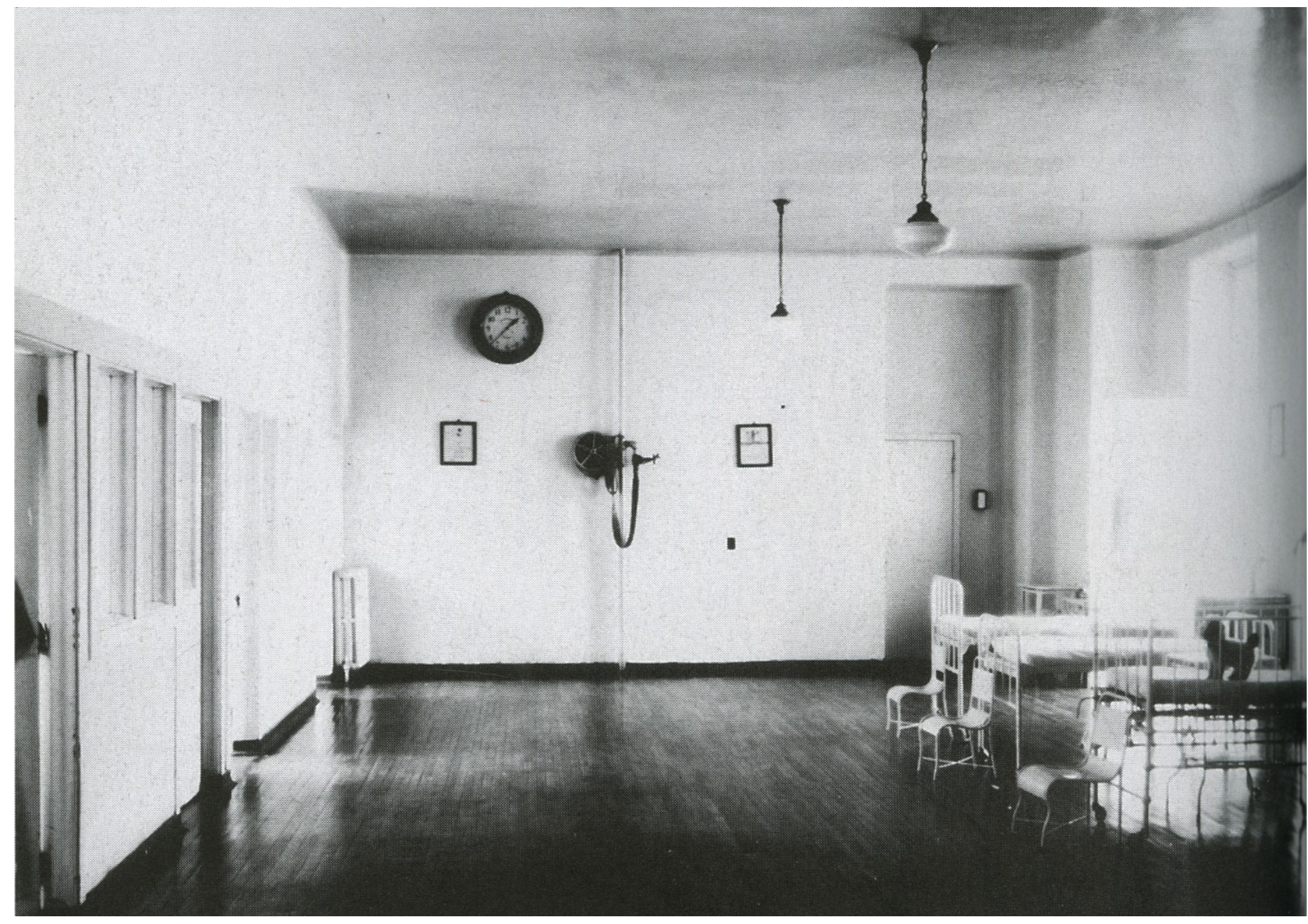

FIGURE 31

Children's ward, 1919. 
4 the role that this proposal is playing

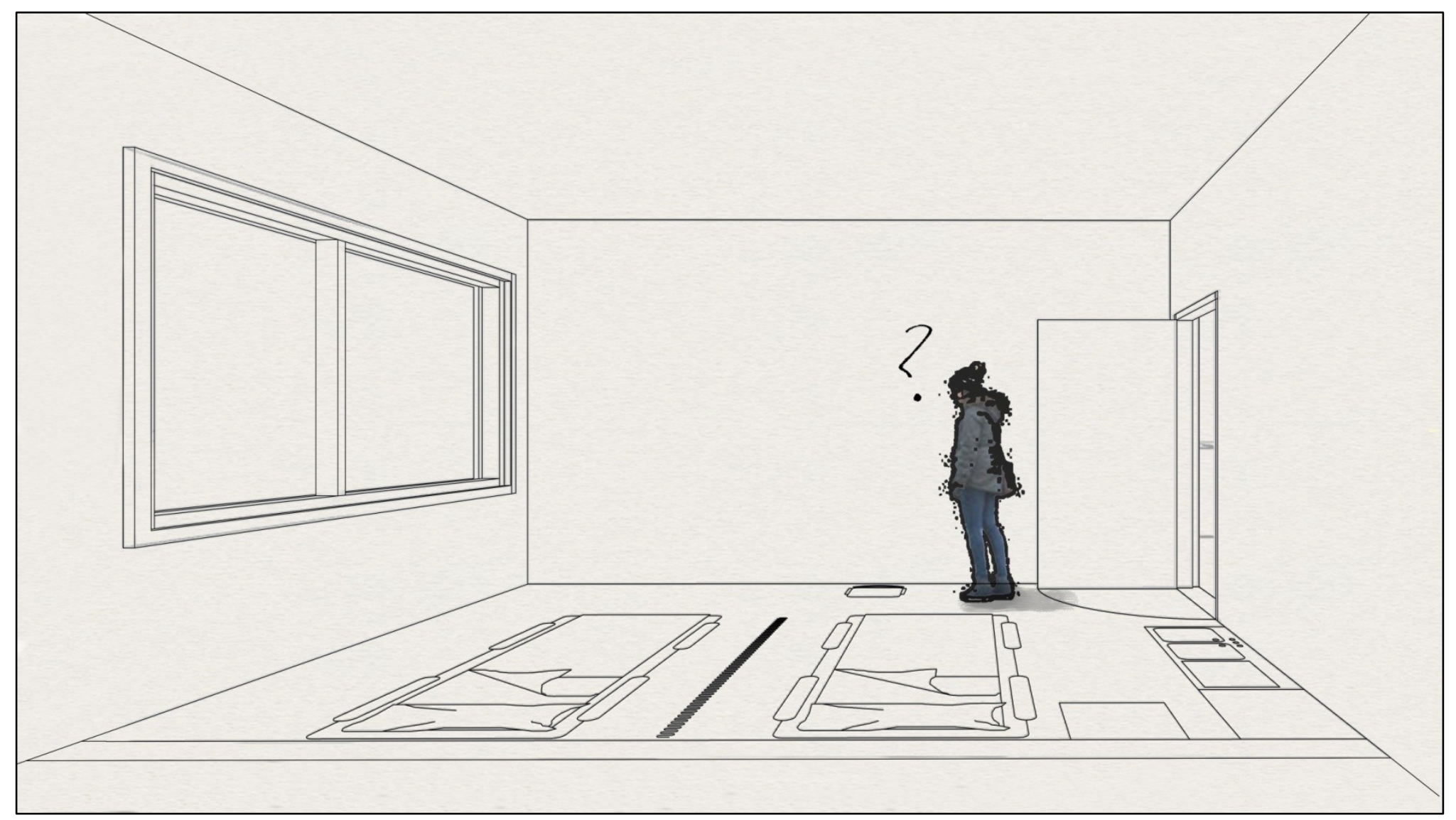

FIGURE 32

Patient's Room: The Existing 
4 the role that this proposal is playing

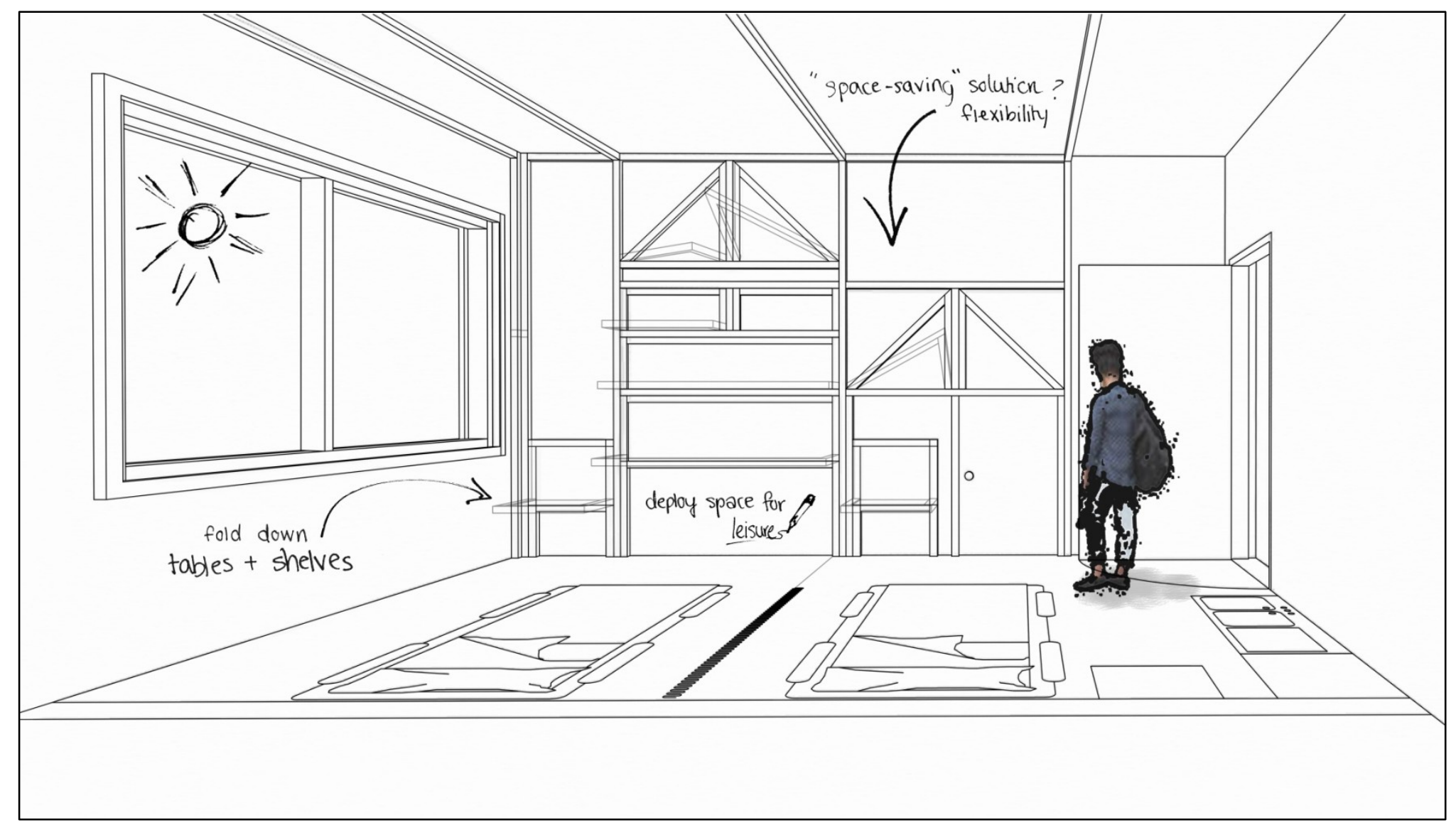

FIGURE 33

Patient's Room: The Re-invented 
4 the role that this proposal is playing

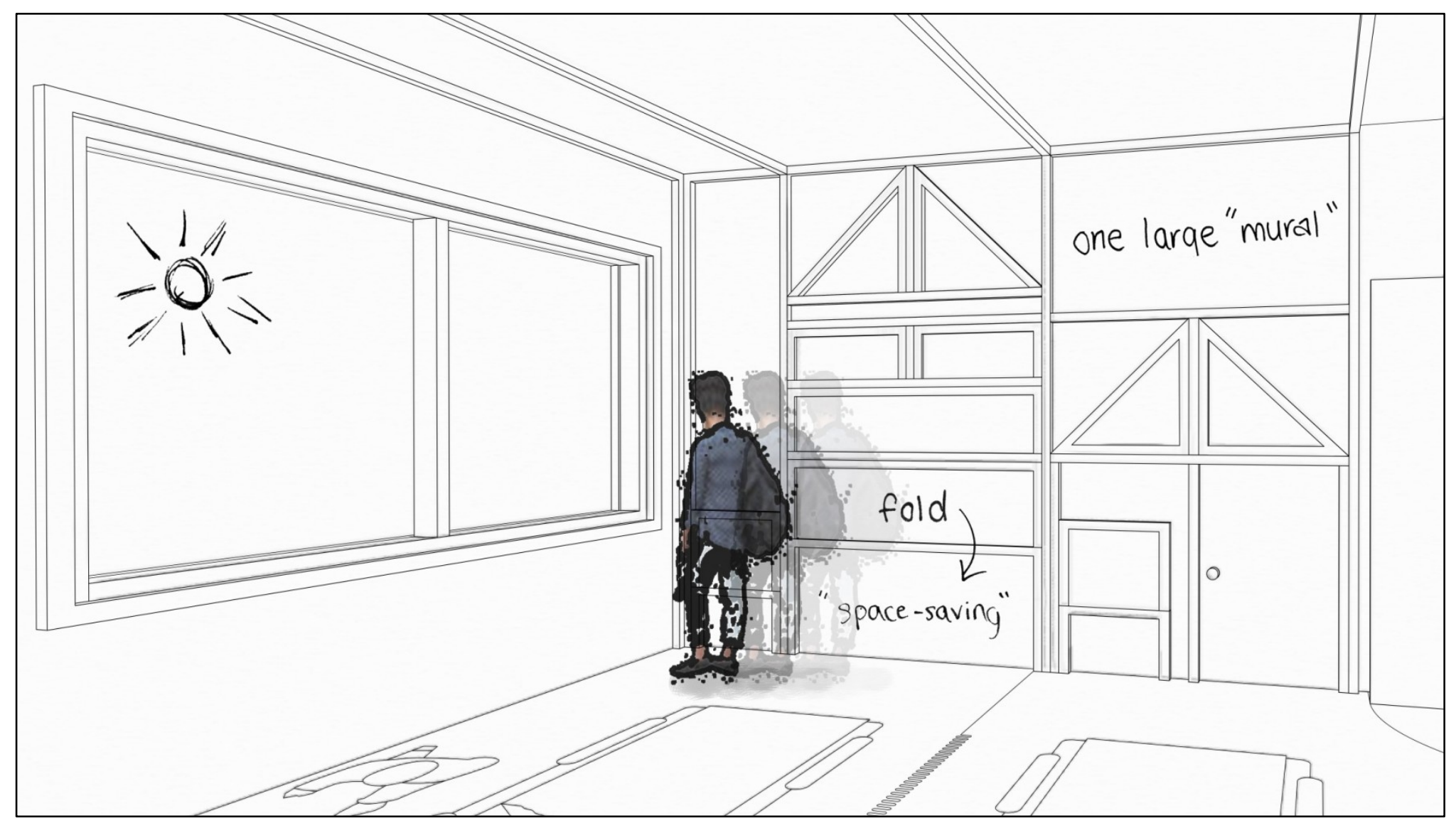

FIGURE 34

Patient's Room: The Re-invented (2) 
4 the role that this proposal is playing

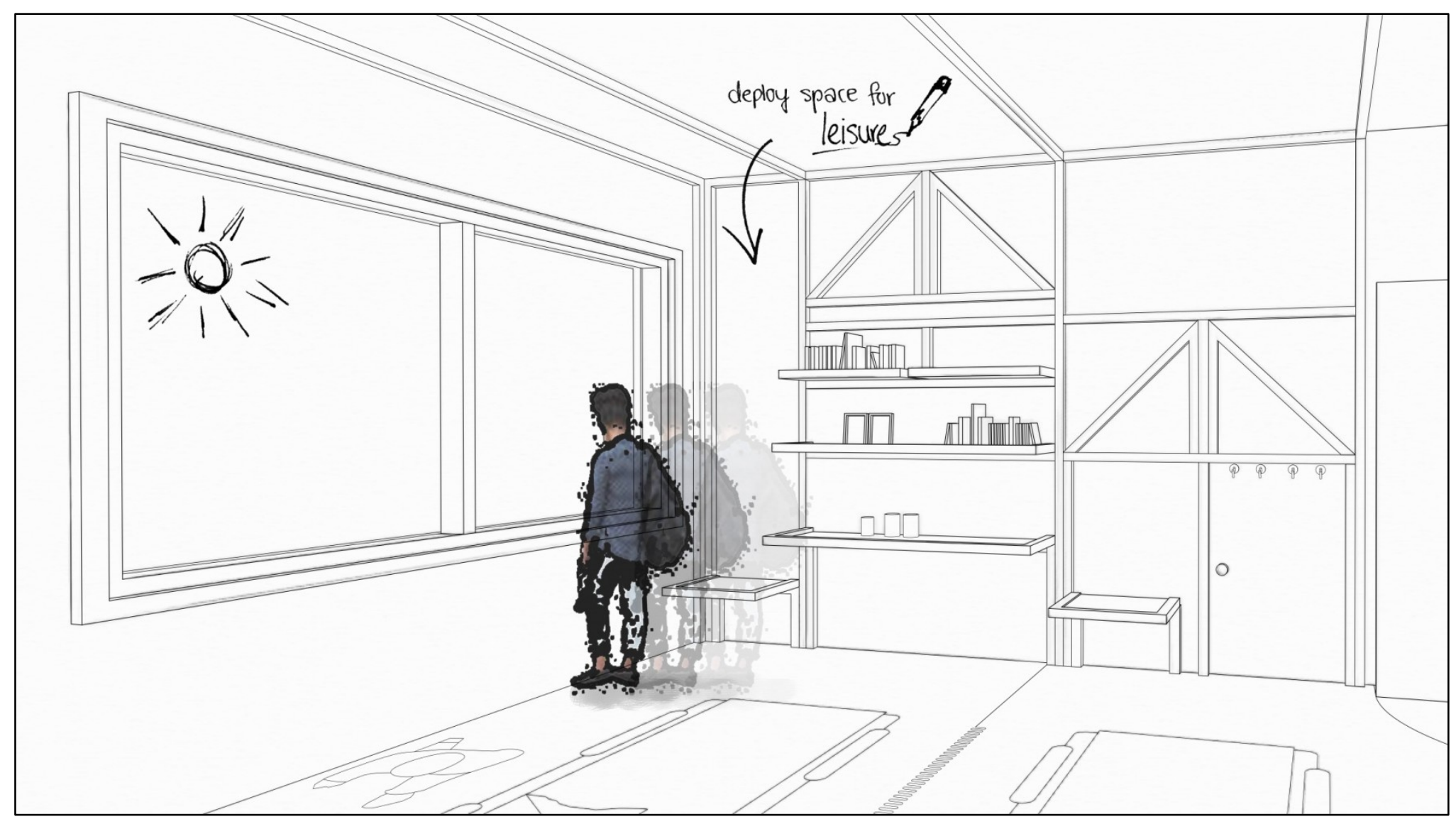

FIGURE 35

Patient's Room: The Re-invented (3) 
4 the role that this proposal is playing

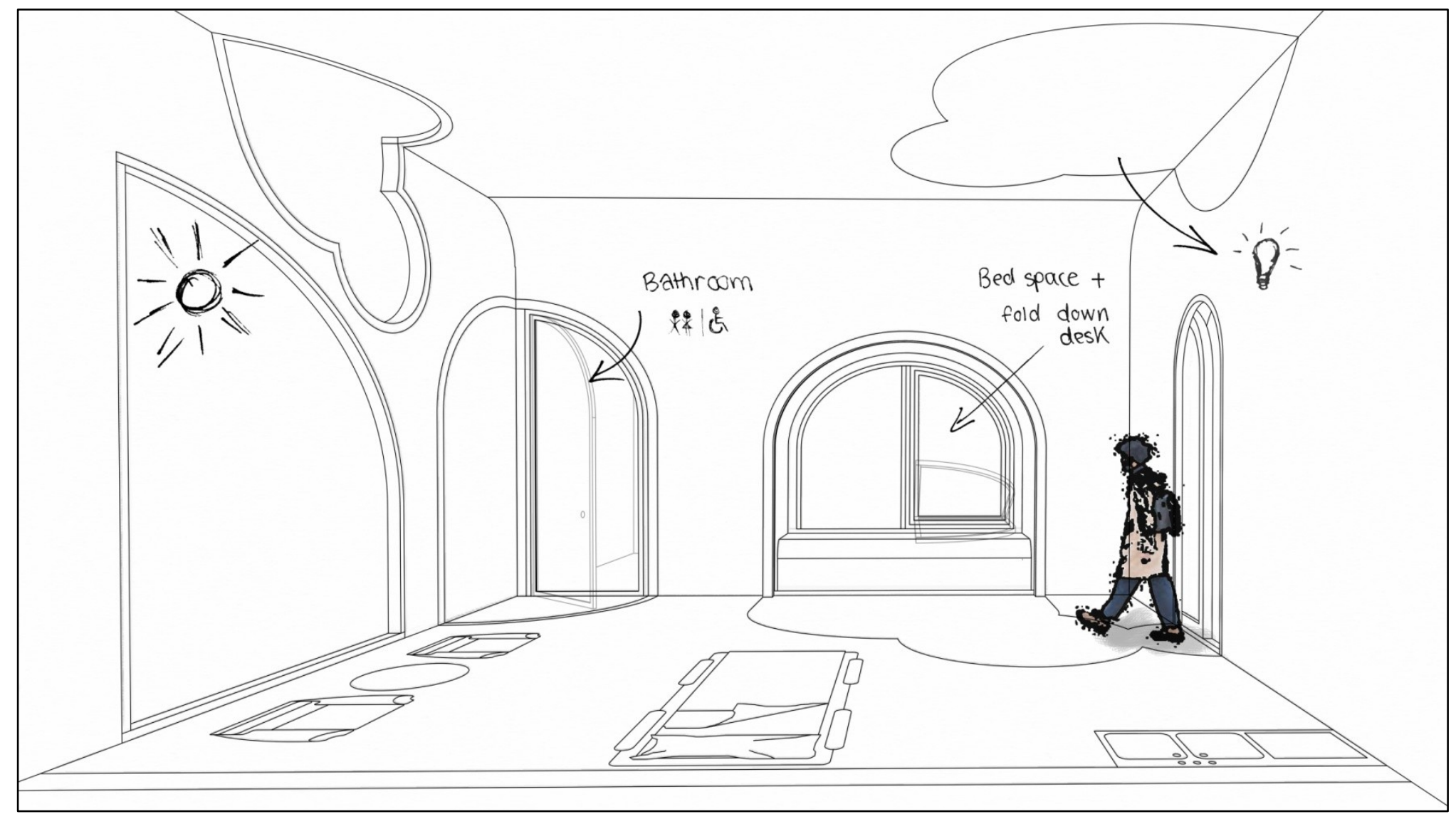

FIGURE 36

Patient's Room: The Re-imagined 
4 the role that this proposal is playing

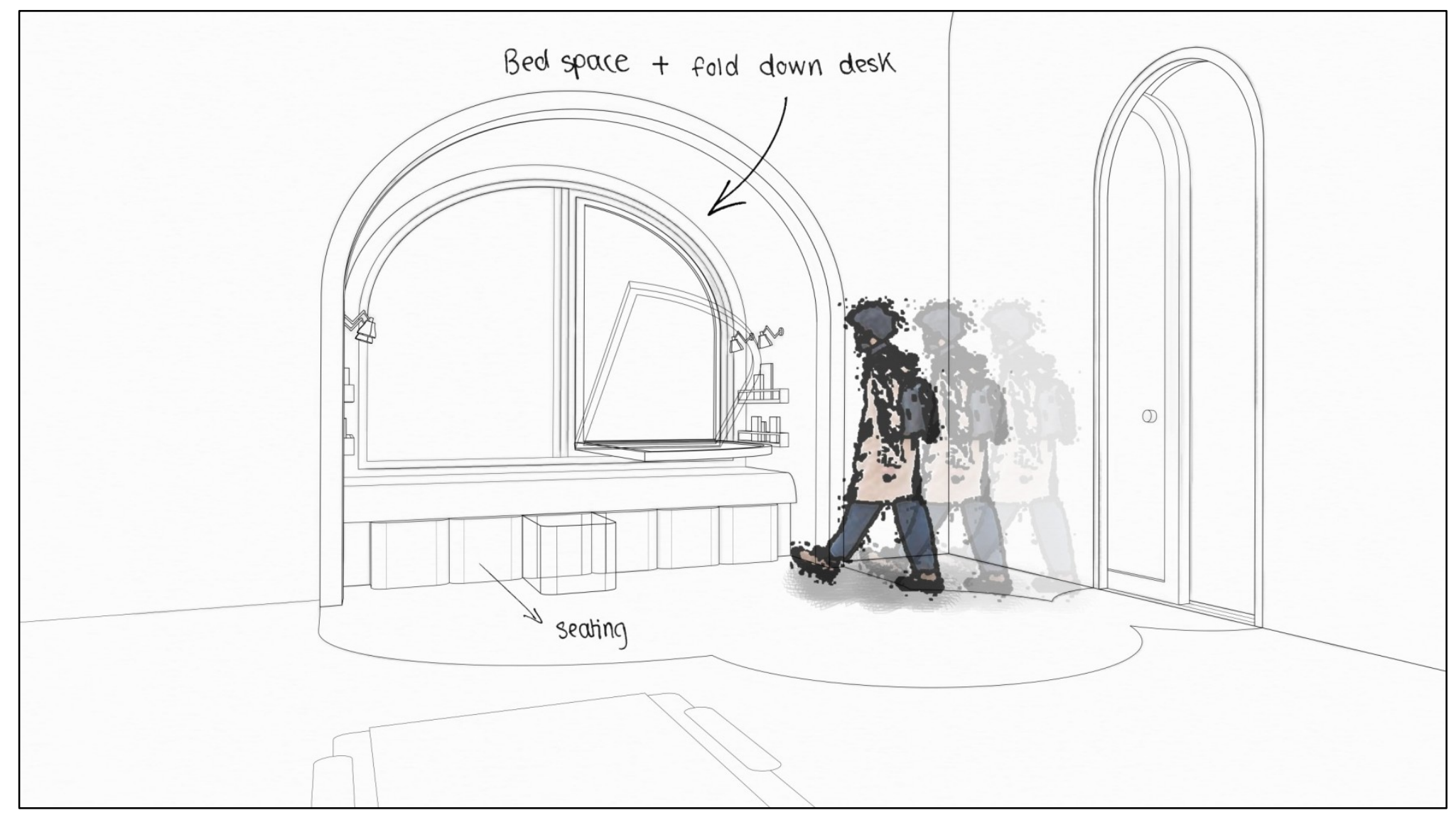

FIGURE 37

Patient's Room: The Re-imagined (2) 
4 the role that this proposal is playing

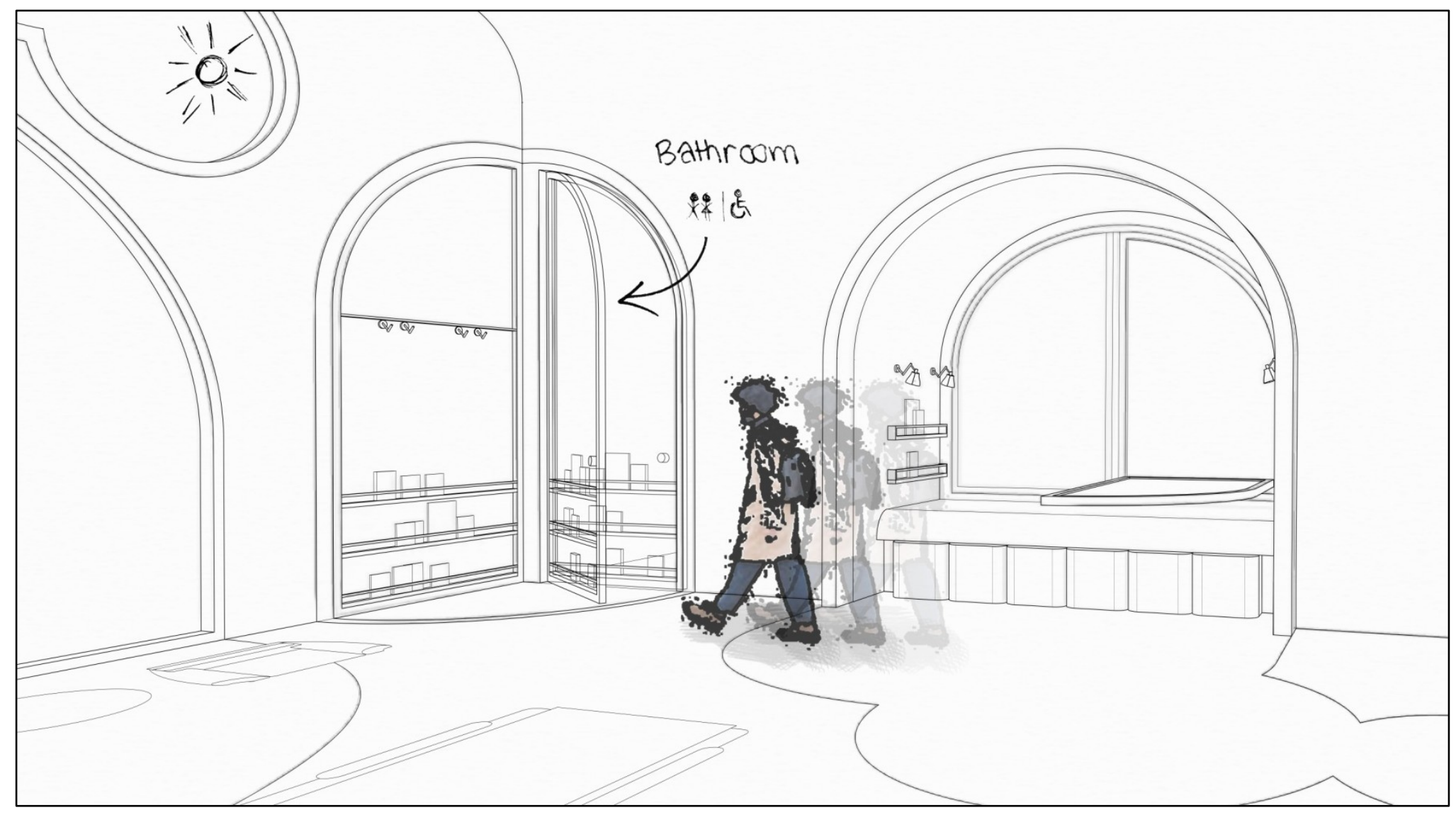

FIGURE 38

Patient's Room: The Re-imagined (3) 


\section{Cafeteria}

\section{The Existing}

The third space typology - the cafeteria - relates to the location of nourishment found within the medical facility. The current hospital condition, of the petite cafeteria at CHEO, depends heavily on its food vendors providing its customers with just enough accommodation to make the space functional. Despite its efficiency, there's a lack of gravitation towards taking a seat to enjoy ones meal, but rather to seize it on-the-go. The options are shot order and quick consumption. There is a capability that comes with a space such as the cafeteria because it's the one place that symbolizes respite. Conjointly, it is an area where the staff is not in professional contact with the patients. Hence, it becomes a multi-purpose space that can provide its guests with more than just food services - it's an opportunity to bring patients and their parents together in, once again, 'moments of pause'. It can encourage family time, confidential, or interactive, but rarely seen in that light - social engagement. Currently, the inanimate surfaces of the room create the lack of persuasion to spend time in the space. How can visual perception be applied?

\section{The Re-invented}

This strategy suggests thinking of the space as though it was a canvas - literally. By doing so, one is already inviting the artist. Since one cannot temper with the present conditions, what if the walls were covered with what 'appears' to be large blotches of paint? It is within these blotches that the programmatic narrative of the space unfolds and morph across the space. For example, the blotch on the floor becomes the furniture of the space - the booth-like seating, which may advocate privacy for families. The pretentious ambience 
awakens the performer and invites the explorer on a discovery. Another blotch on the floor may morph into the bookshelves for the reader, while a new blotch may move again from the walls into the ceiling lights of the space. If small gestures can have a large impact, these minor alterations hope to demonstrate the drastic changes that can be made to the existing. Whether its minor alterations to a smaller coffee shop, or slight modifications to a larger cafeteria, by developing a multi-purpose space for patients, visitors, and staff persuades social interaction and welcomes the enthusiast.

\section{The Re-imagined}

Beyond the minor alterations, high ceilings become very significant in this design strategy and not just because they are extremely important for breathing room. By giving the cafeteria higher ceilings the merging of different spaces of the facility together becomes a possibility. Spaces begin to overlook one another with an opportunity to expand spacial narratives. For example, the re-imagined 'moments of pause' of the hallways become cantilevered nooks, hanging on the edge of the cafeteria walls. Mimicking the idea of the dining experience in a hospital - an opportunity for social exchange and interaction - one can physically apply this concept by connecting the different typologies of the facility to heighten playful relations. Since to most people when they are concerned or stressed eating is purely perfunctory, lingering over meals is not encouraging. To add to this, cafeteria hospitals are usually operated institutionally and the place becomes a magnet to noise. ${ }^{19}$ Hence, having design considerations emphasize leisurely dining options (with play spaces for children in between, buffet style catering, etc.) may captivate lingering moments. 
4 the role that this proposal is playing

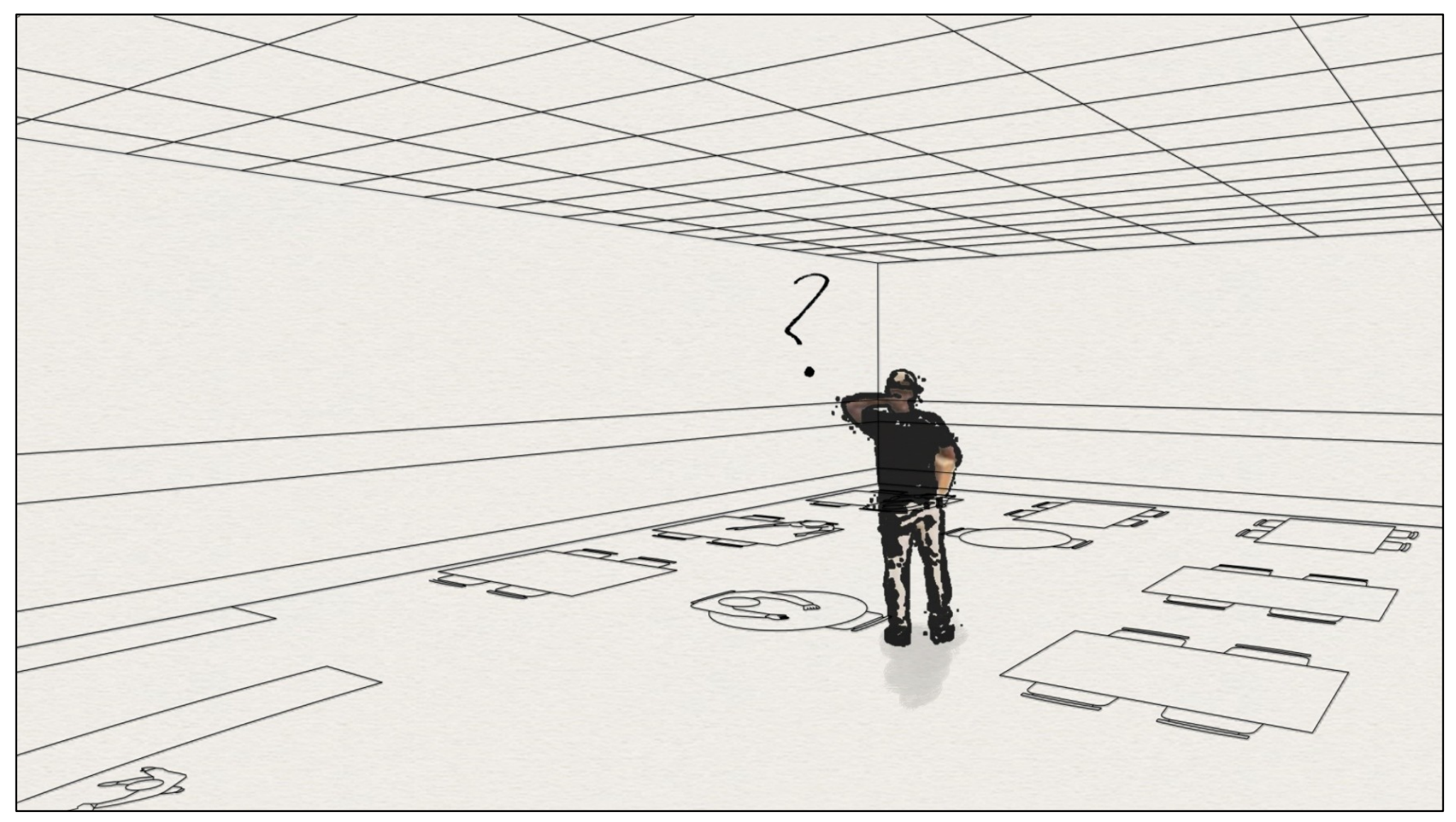

FIGURE 39

Cafeteria: The Existing 
4 the role that this proposal is playing

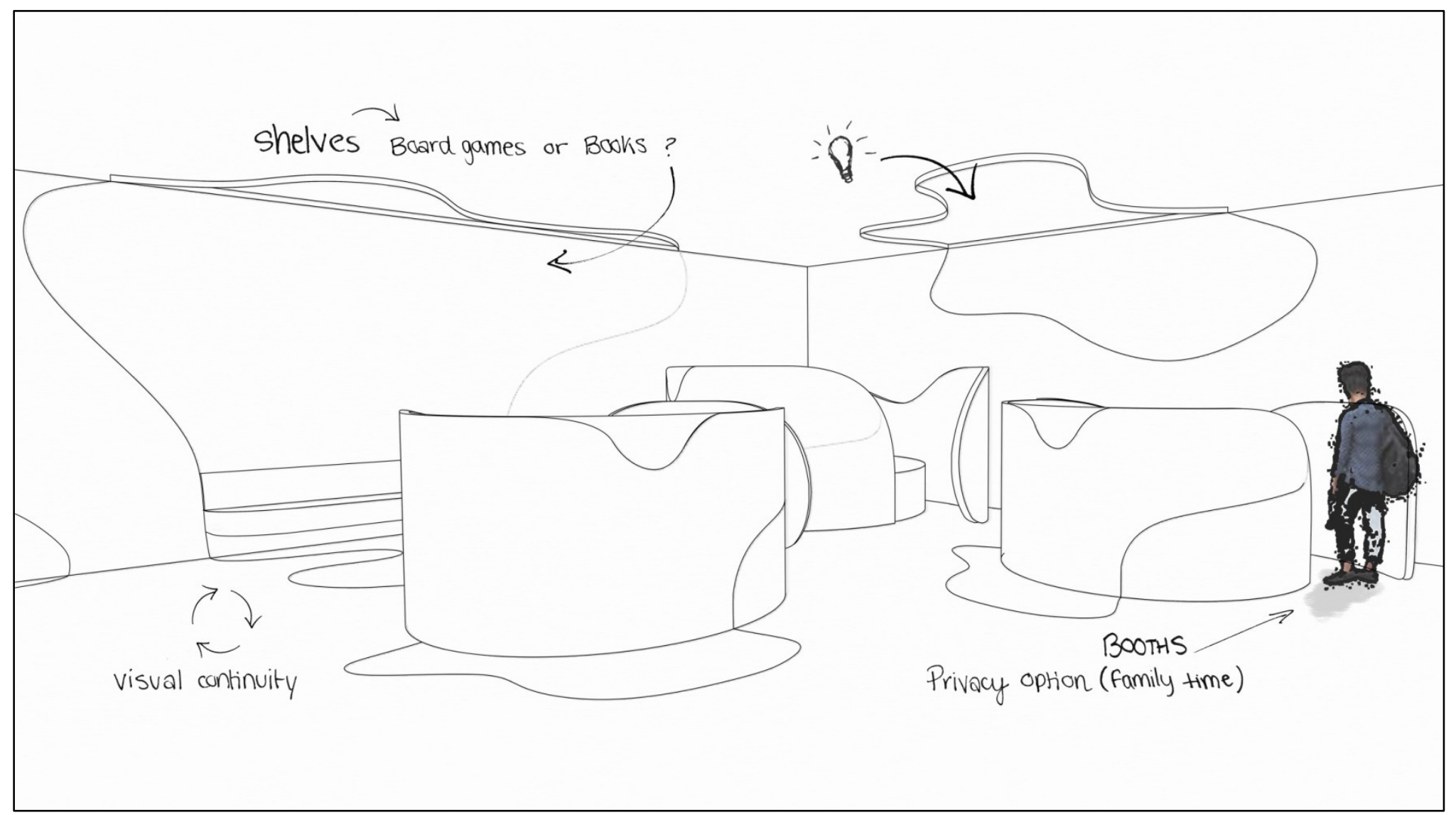

FIGURE 40

Cafeteria: The Re-invented 
4 the role that this proposal is playing

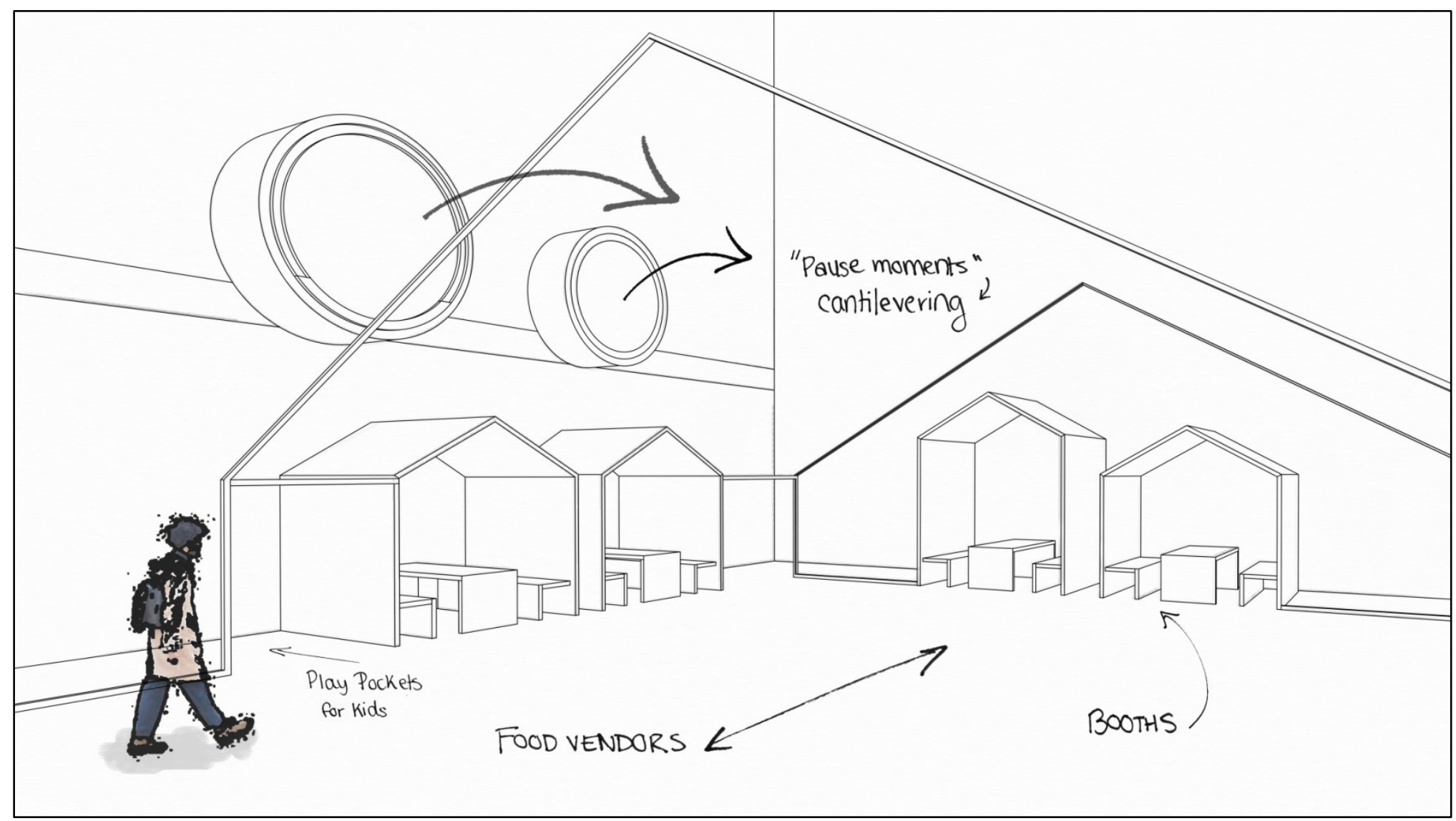

FIGURE 41

Cafeteria: The Re-imagined 
4 the role that this proposal is playing

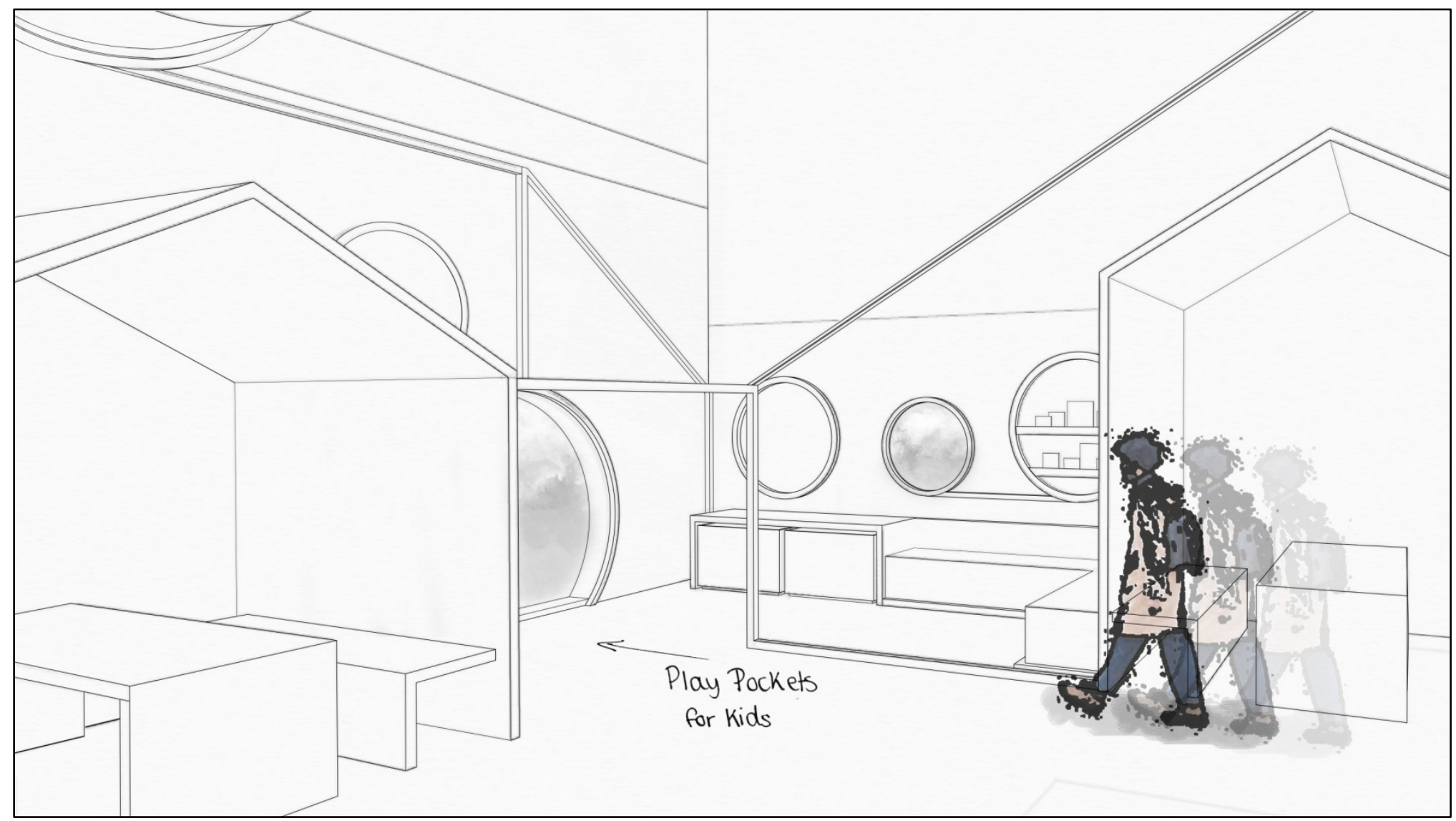

FIGURE 42

Cafeteria: The Re-imagined (2) 
4 the role that this proposal is playing

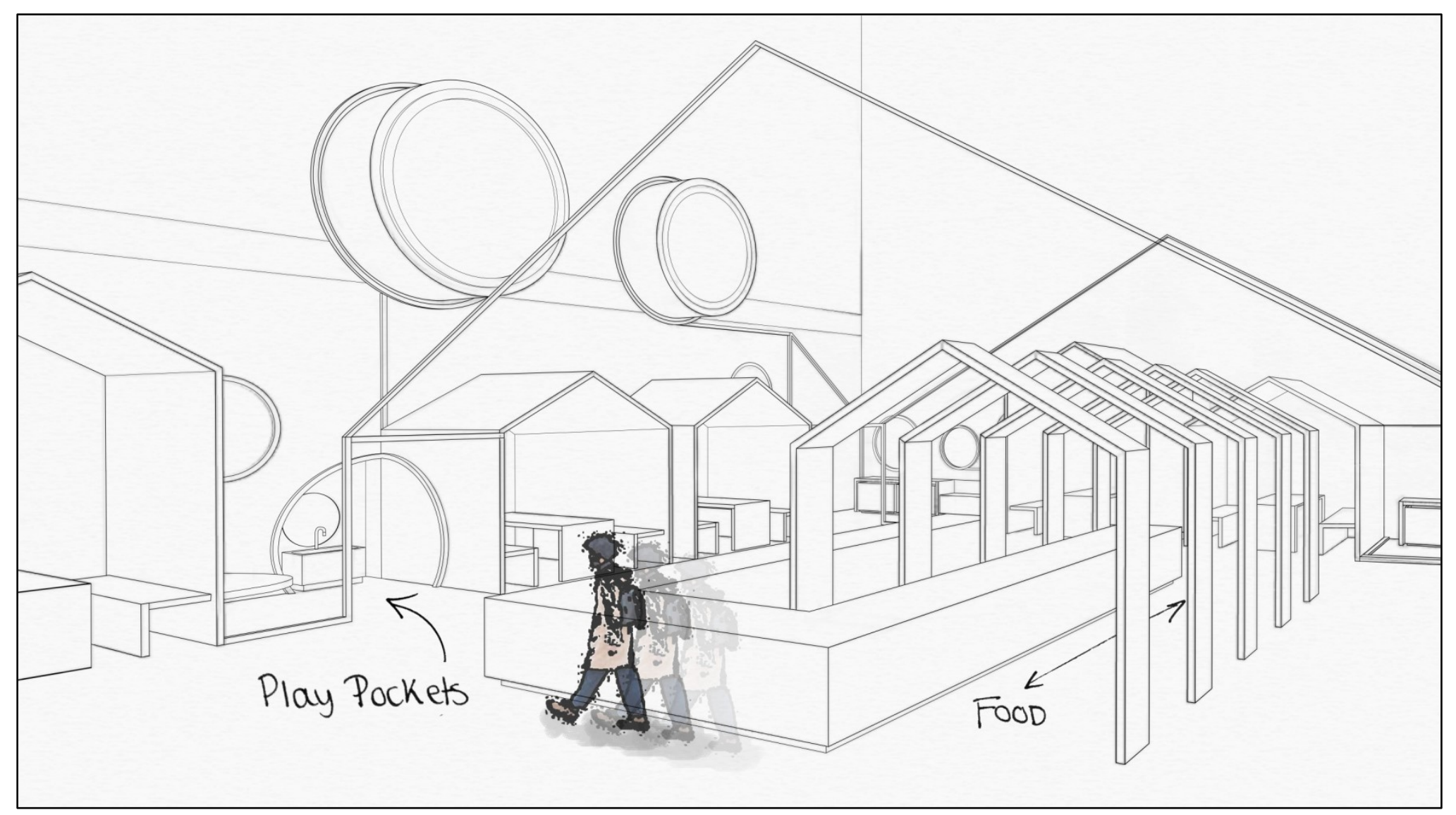

FIGURE 43

Cafeteria: The Re-imagined (3)

66 
4 the role that this proposal is playing

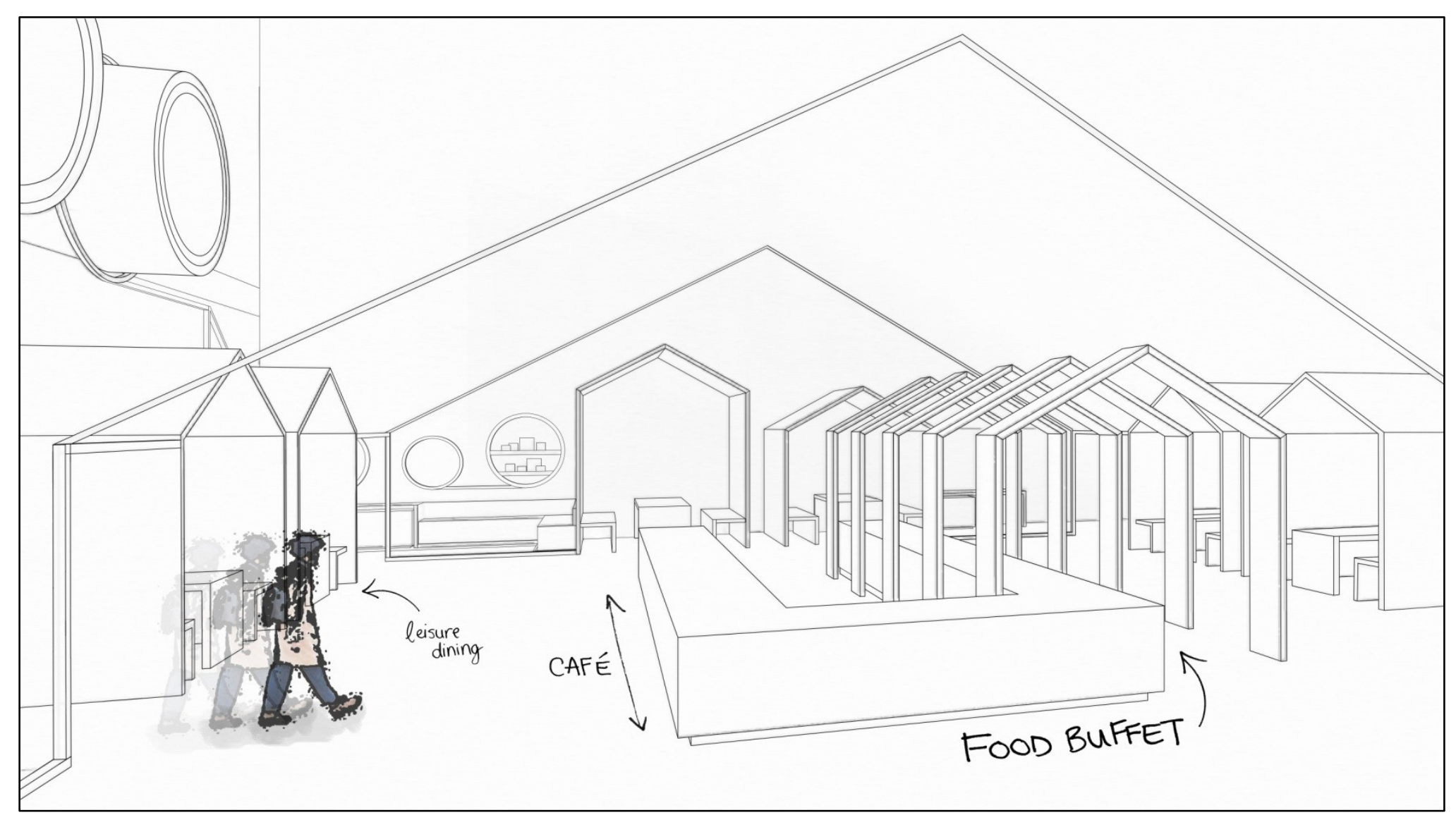

FIGURE 44

Cafeteria: The Re-imagined (4)

67 


\section{Waiting Room}

\section{The Existing}

The fourth space typology - the waiting room - relates to the inevitable anticipation that occurs at any medical facility. The existing hospital condition at CHEO varies from ward to ward. However, referenced in this scenario are clinical waiting rooms dealing with the outpatients. Issues with the present conditions are similar to the space typology of a cafeteria. For a space that could gather a large number of people, it is easy to feel congested. At the same time, it is a place with an opportunity to motivate social engagement. Currently, the waiting room seats approximately 100 outpatients, with room (the $2.5 \mathrm{~m}$ width of a corridor) to walk around the central waiting space. Despite being functional, as one waits, the excessive street traffic, the sound of equipment, alarms, nurses coming and going, sound of equipment, etc. can all be sources of circumstantial stress - especially upon arrival at a hospital. How can a narrative through play eliminate the suspense of waiting?

\section{The Re-invented}

For starters, to ask a child to sit, quietly, and wait for a long period of time is nearly impossible. The waiting process can be tortuous and especially in a stern environment. The current condition of the clinical waiting room at CHEO utilizes bright color pallets to add vibrancy to the flooring and attempts to hide the large columns that run along the borders of the central waiting space. Once again, the blank walls and grid ceilings reinforce that feeling of a casket. Instead, working with the current spacial restrictions, minor alterations such as changing the seating to appear as though they are building blocks can invite the explorer. To correlate with the furniture, clever 
application of form and different materials can formulate illusions. For example, a bright colored line on the floor of the corridor can become the border and eventually the threshold of the waiting room. It is as if the artist is drawing the space themselves and the continuous line could then become the bookshelves to suit the reader. Following this line once again, it is creating the rest of the space, highlighting the columns in a technique of hiding it. The line continues formulating meandering passages of different heights to stimulate areas of social interaction for the enthusiast. The playful divisions allow the space to feel less institutional and may activate the mind of the performer to configure the perplexing place into a fictive space of their imagination. The gestures utilizing visual perception are not only meant for the younger outpatients, but guests and visitors of all ages. To activate the imagination and distract the mind from the dreaded 'wait' can add value to their time spent in this space.

\section{The Re-imagined}

In this design strategy, the issue of filtering noise out is a significant point to consider. Similar to the re-imagined cafeteria, the initial application of high ceilings is of importance. Once again, it is a method of creating more breathing room - especially in a space that needs to accommodate a large population - but it will also aid with dispersing noise. The double height space allows for other typologies to over look one another. In this way, the sight of a younger outpatient at play in the waiting room can uplift a patient, who may be undergoing a strenuous treatment, passing through the hallway above. This is also applicable in the case of an overwhelmed parent. It may take the patient, the visitor, or even the staff's mind off their personal situation, or the challenges ahead. ${ }^{20}$ The design strategy reimagines this continuous line into a more organic one. Threshold, passages, seating and programs for all types of play formulate one 
another as though the entire space was a drawing. The entire room caters towards the enthusiast because the value to be conveyed is to encourage interaction as one waits. As for the performer, the room is a recital of the narratives of play, with areas that morph into a stage to stimulate dramatic play. The visual continuity is applied throughout other programmatic activities, such as places for the reader to lounge, the artist to draw, and the explorer to wander throughout the spacial variations of the place. Especially at a children's hospital, outpatients should engage in activities to stimulate the types of play, simply as means of getting away, or simply to let off energy. Instead of a waiting room, the space manifests itself into a miniature playhouse. 
4 the role that this proposal is playing

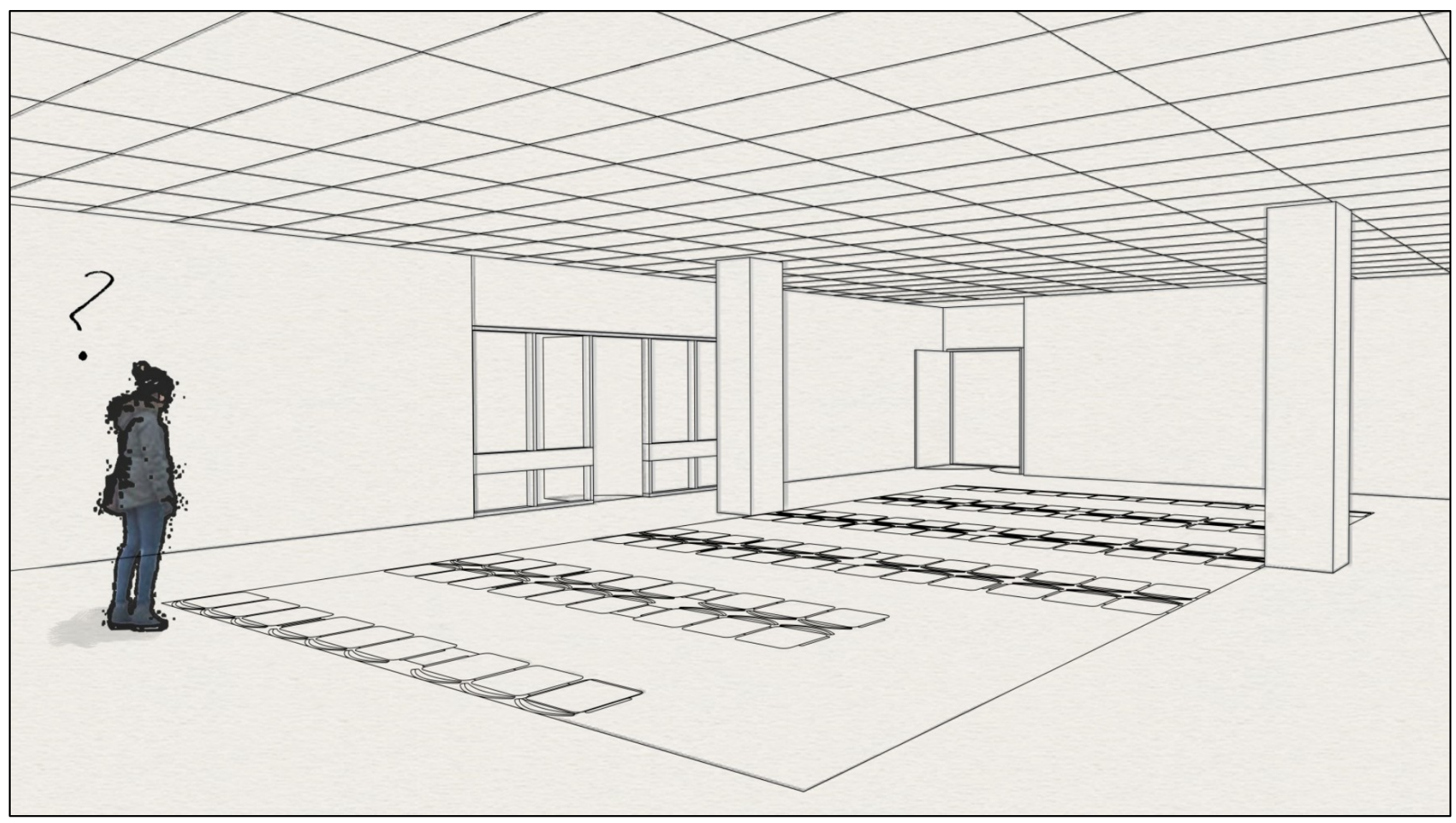

FIGURE 45

Waiting Room: The Existing 
4 the role that this proposal is playing

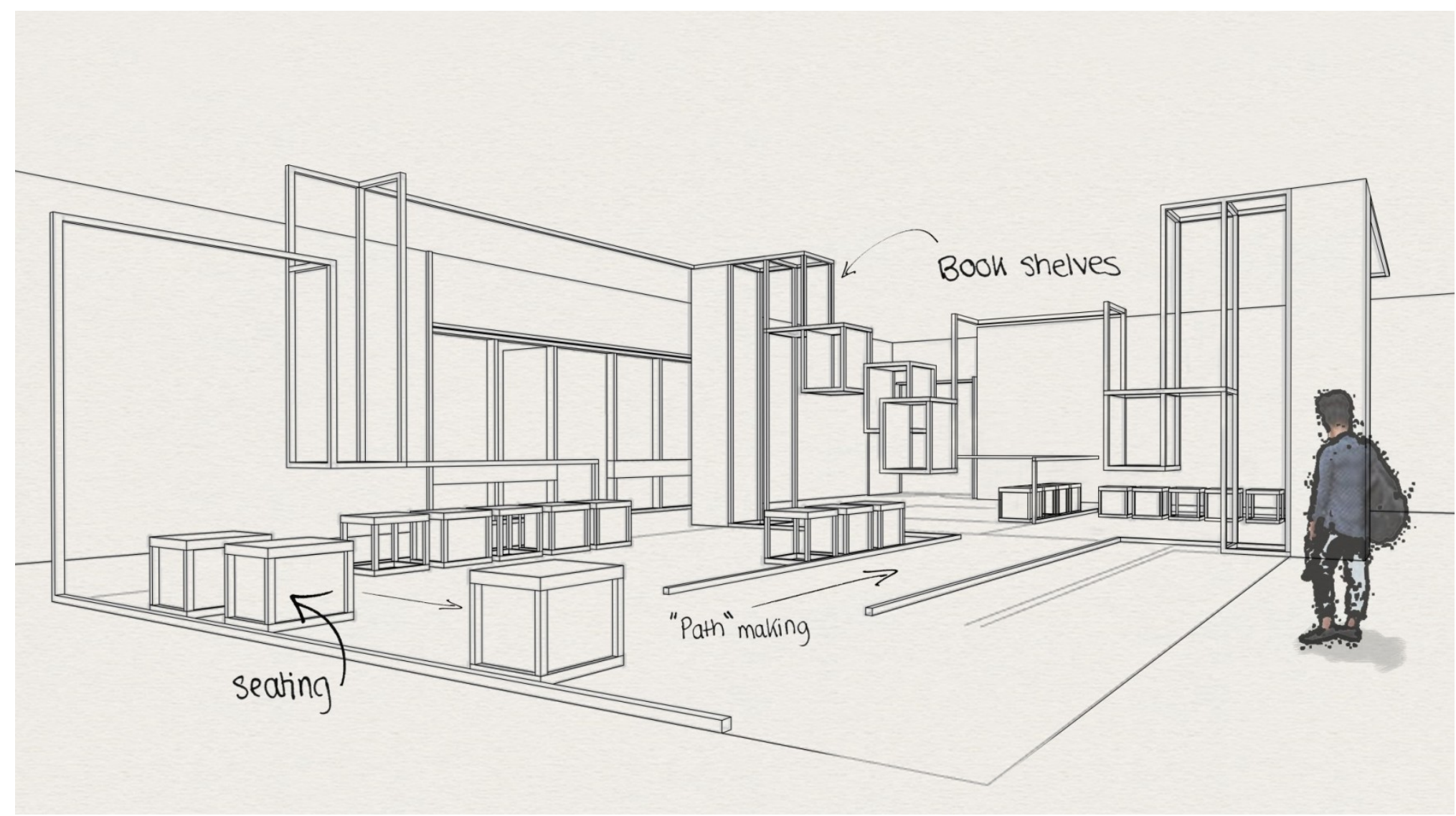

FIGURE 46

Waiting Room: The Re-invented 
4 the role that this proposal is playing

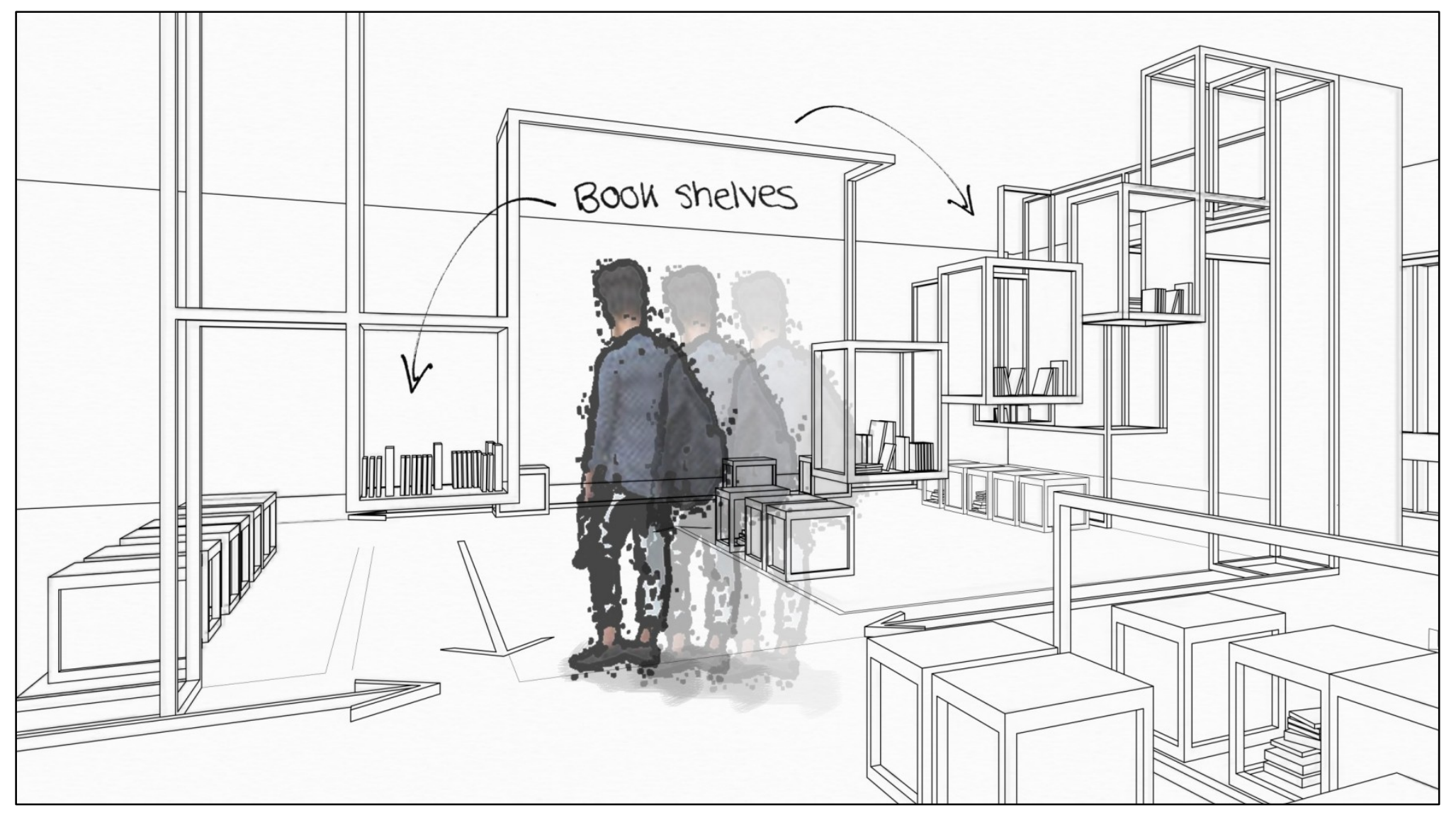

FIGURE 47

Waiting Room: The Re-invented (2) 
4 the role that this proposal is playing

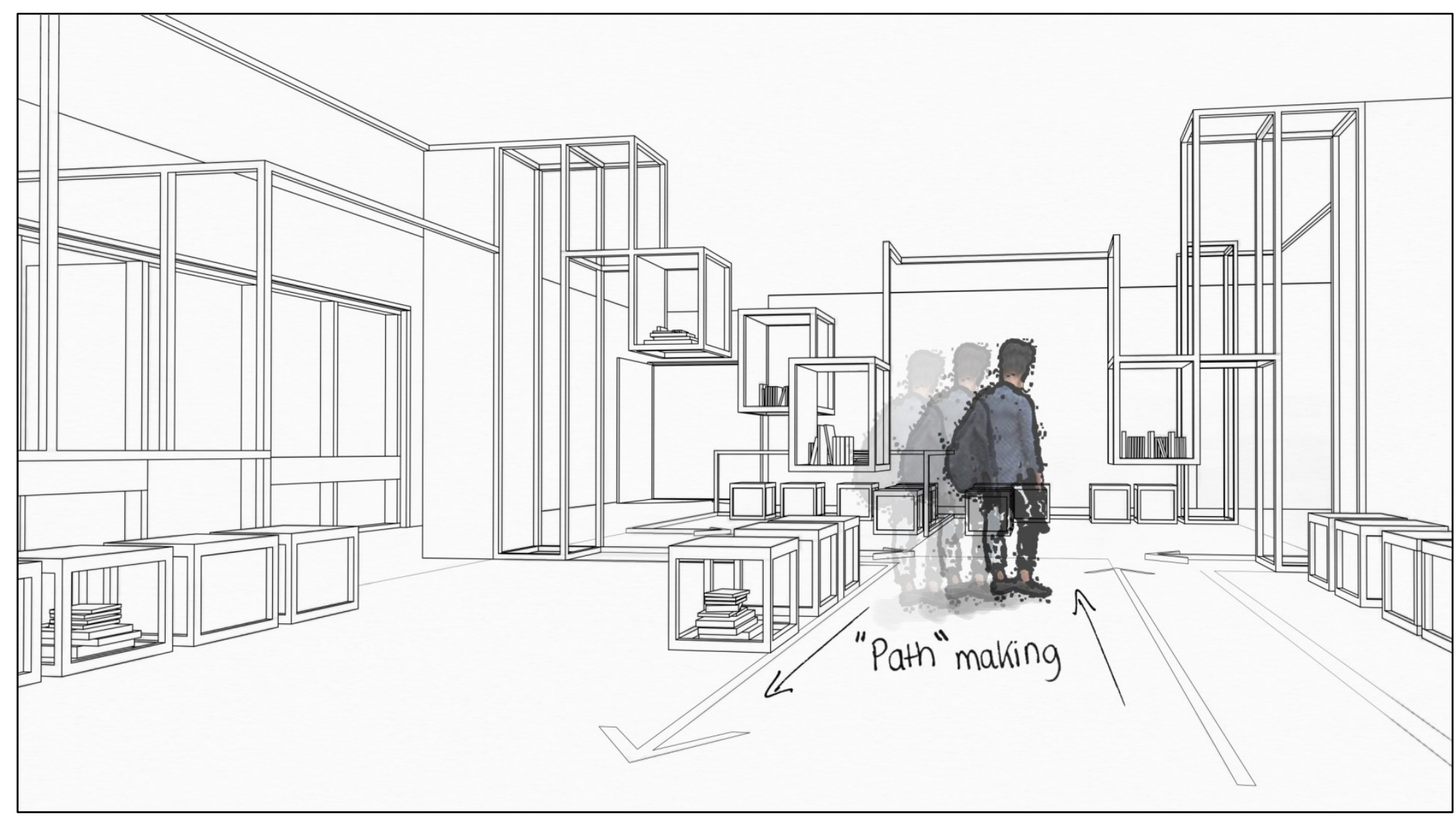

FIGURE 48

Waiting Room: The Re-invented (3) 
4 the role that this proposal is playing

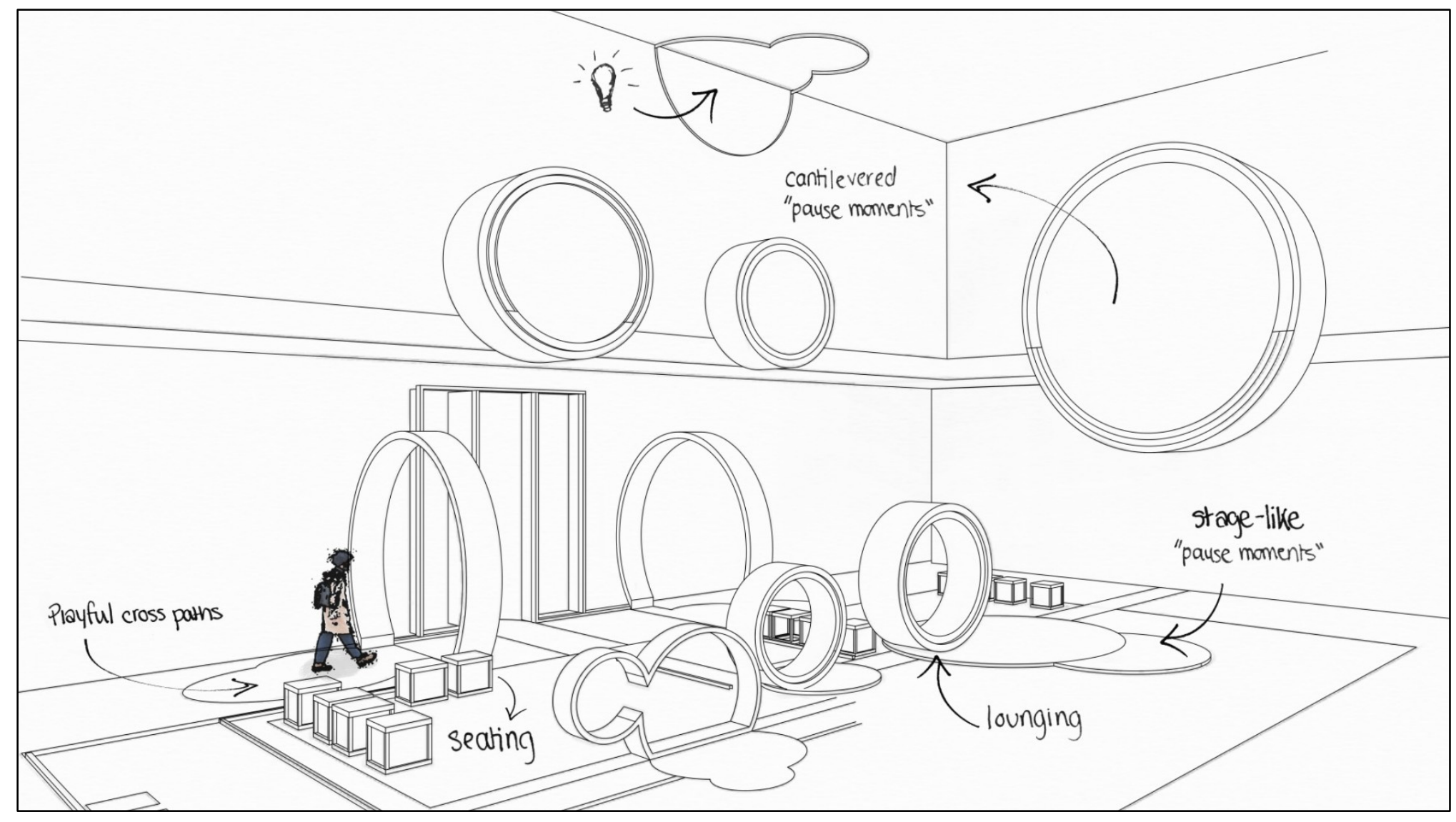

FIGURE 49

Waiting Room: The Re-imagined 
4 the role that this proposal is playing

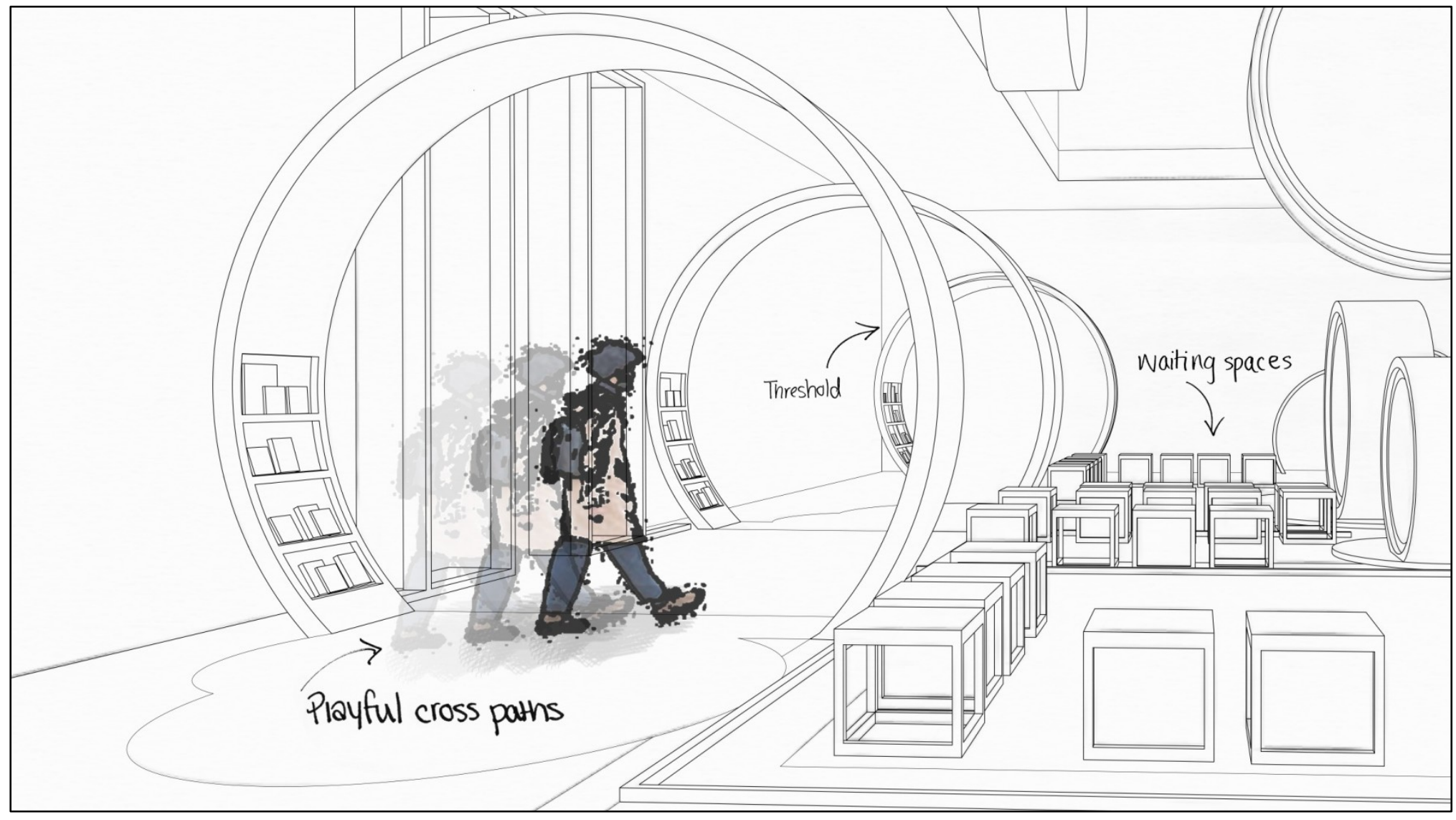

FIGURE 50

Waiting Room: The Re-imagined (2) 
4 the role that this proposal is playing

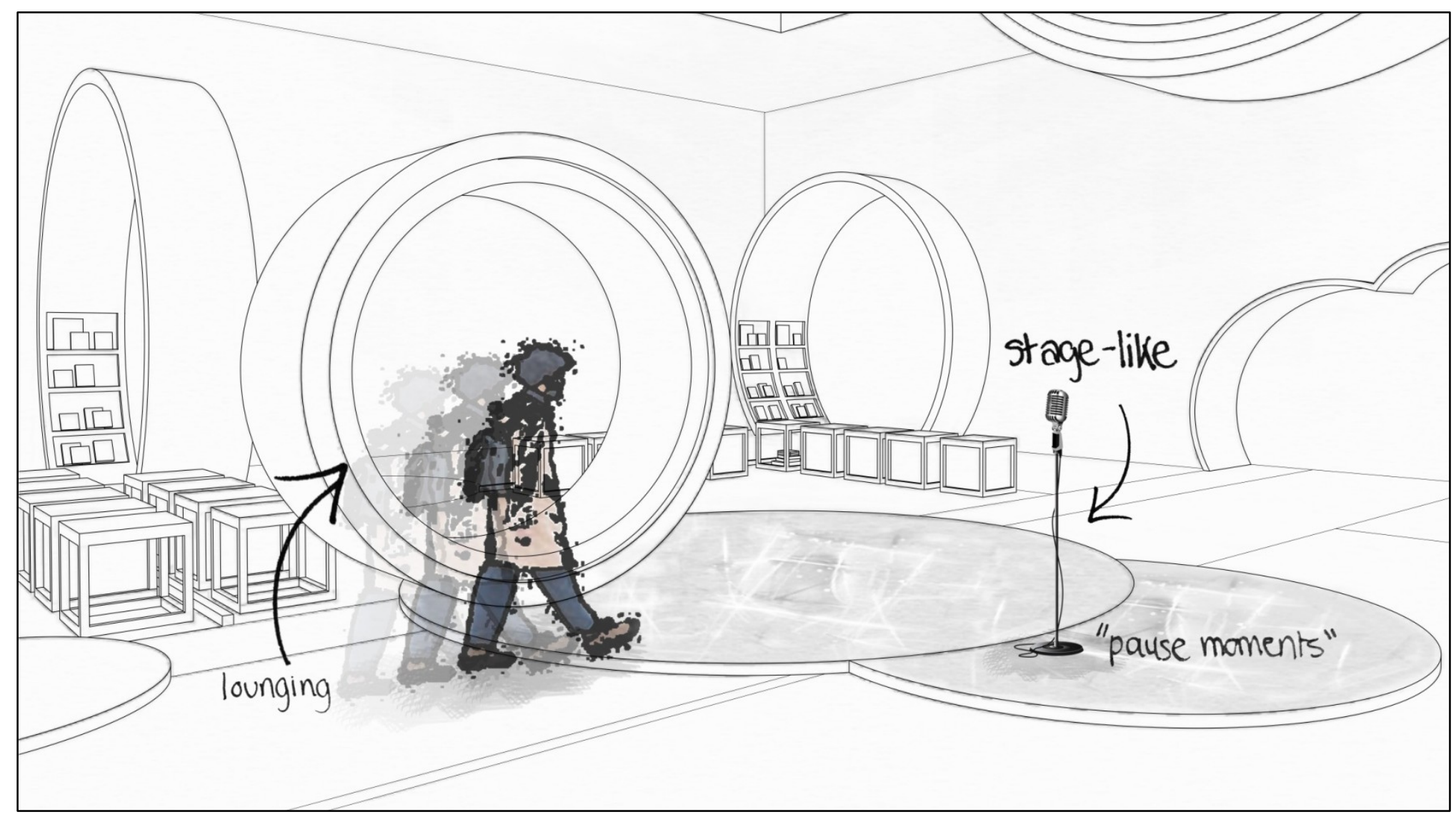

FIGURE 51

Waiting Room: The Re-imagined (3) 
4 the role that this proposal is playing

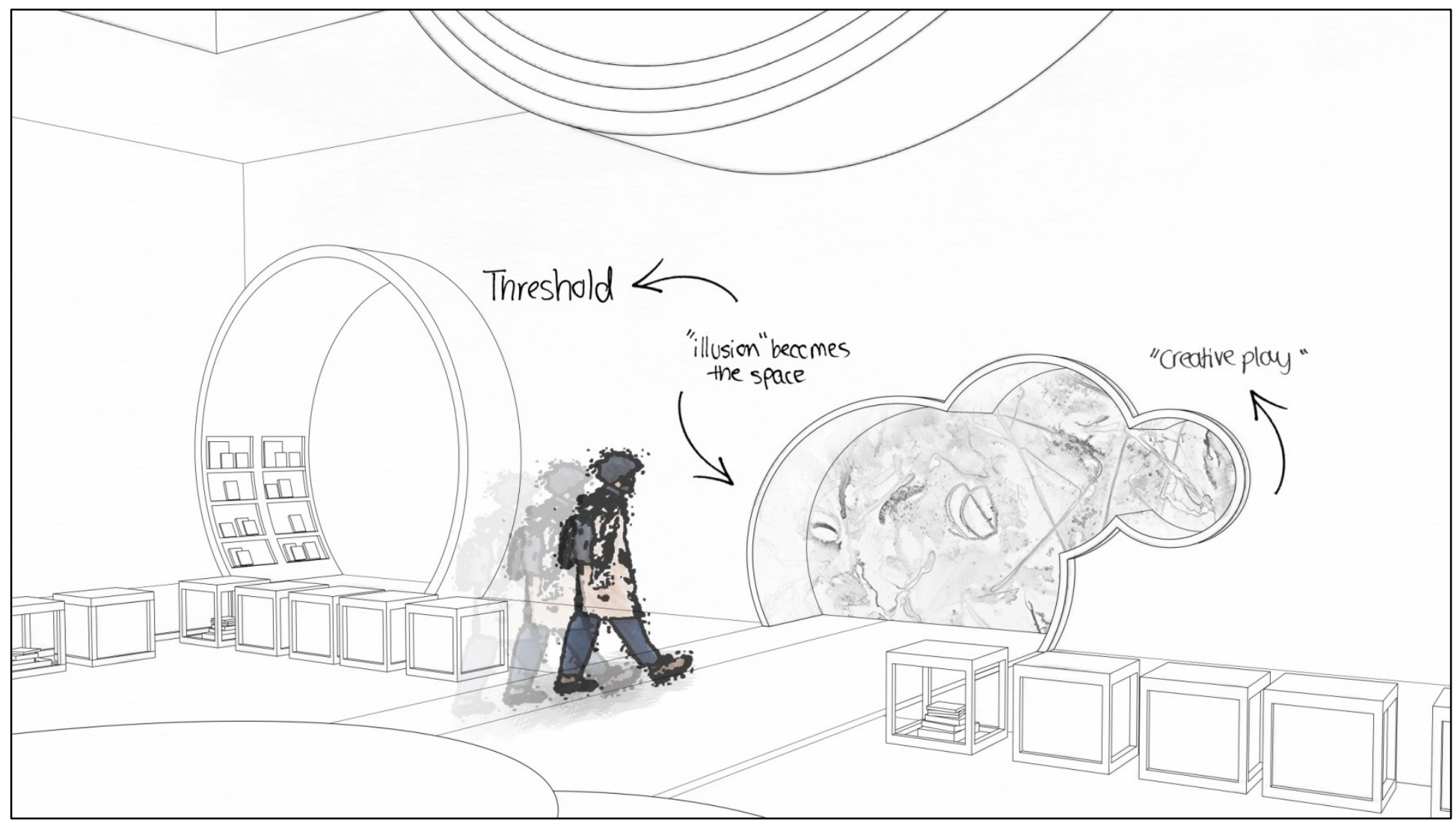

FIGURE 52

Waiting Room: The Re-imagined (4) 


\section{Examination Room}

\section{The Existing}

The fifth and final space typology - the examination room - relates to the 'strangers' of the hospital. Before being admitted, this is the room one visits and they are in their most unfamiliar state. It becomes a space that wants to be of comfort for patients, especially at first impression. Considering the room is incredibly small, and does not require many utilities such - cubbies with drawers, a sink, a bed, etc. -the space becomes challenging to work with. One would usually want to subtract to make a space less daunting, not add to it. Hence, how can one make the patient's first encounter with the doctor/nurse the least overwhelming as possible?

\section{The Re-invented}

Applying the first design strategy - creating minor alterations to the existing, one can accommodate to the characters of the types of play by merging together all five into one main attribute - imagination. Keeping in mind the existing constraints, the modifications would not obstruct with the space restrictions but attempt to reconstruct one's typical impression of a standard examination room. Once again, a bright color pallet is an initial step in making a valuable change and it would demonstrate the same techniques applied throughout the typologies above. Color may be the beginning of formulating illusions, but the size of the examination room can work towards one's advantage. The position and size of the placement of the application can be enhanced in a smaller space. One may feel as though they have entered another dimension. If one were to situate a large blotch of 'paint' across the room, what would this do to the space? The forms would merge different surfaces, as well as furniture, together. The corner condition of the wall to ceiling returns into 
play and is utilized in a way where the walls become the seating space and eventually develop into the lighting. Alluding to the characters, the performer may feel as though they have entered into another world, while the artist may feel like they have entered into their drawing. The element of surprise of the space may spark a conversation with the enthusiast and the doctor, eliminating a fraction of their anxiety. The reader may feel confident to pick up a book to read, while waiting for the doctor to arrive into the examination room. In the case of exploratory play, the continuous color and organic form of the blotch may heighten the child's sensory, especially towards their sense of touch and discovery.

\section{The Re-imagined}

Moving beyond minor alterations, this design strategy zooms into the organics of a space. When one thinks of a hospital, apart from the stern ambience, one may not envision curvature. The organic shape of the blotch inspires the organic design characteristics. Instead of an organic form on a surface, what if the walls began to curl? This will aid in the tempering of the visual illusion of the space. Although the rest of the hospital may not utilize the same language per se, encouraging the 'element of surprise' is crucial for children of all ages, or visiting guests, to be diverted from their present situation. This is achievable given that there are no existing restrictions in this scenario, which opens up the possibilities of reimagining how one typically sees this typology. On the whole, the space would articulate relations with other people by instructing scales and framing performances, interrelations, perceptions and thoughts. ${ }^{21}$ 
4 the role that this proposal is playing

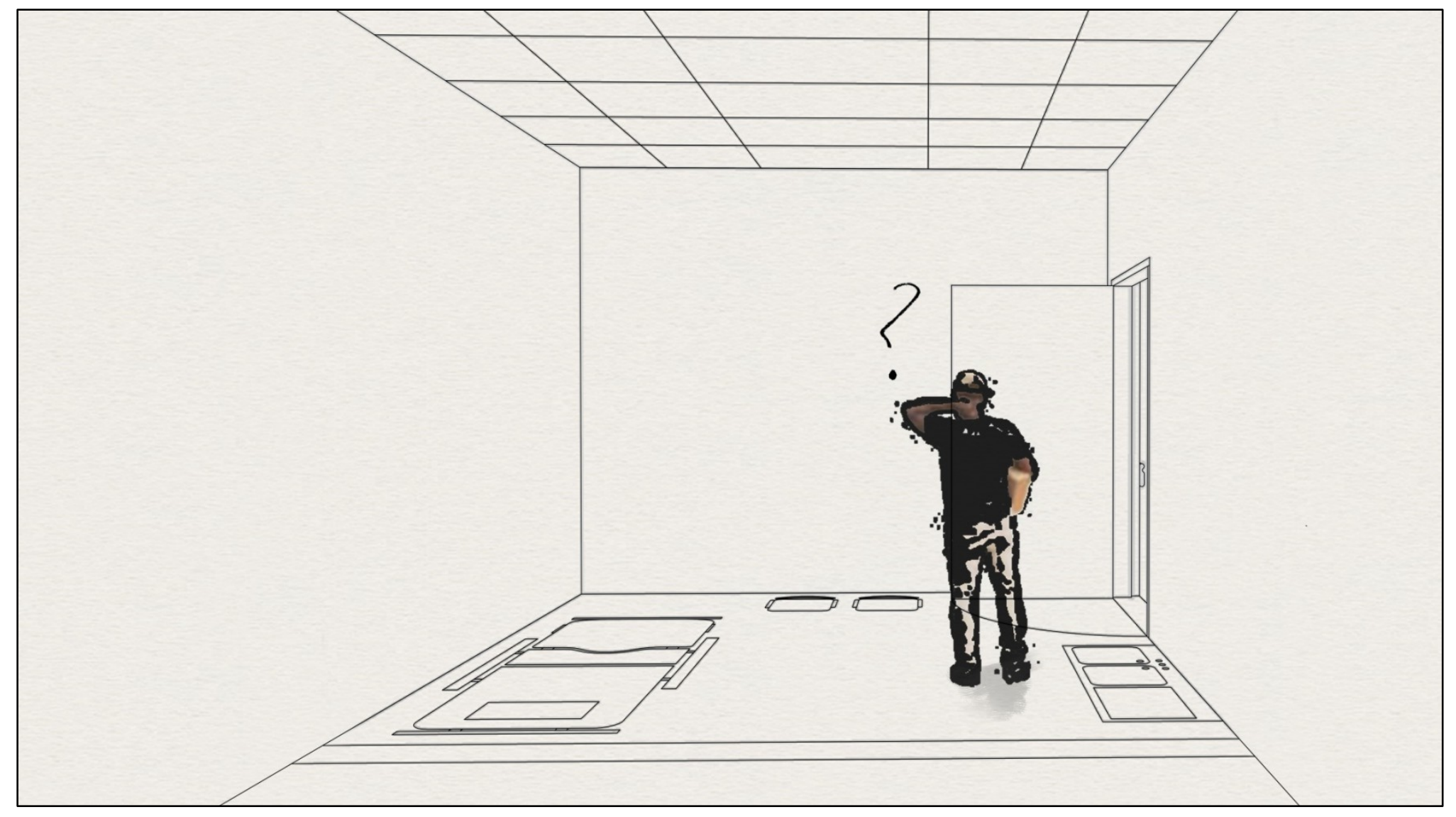

FIGURE 53

Examination Room: The Existing 
4 the role that this proposal is playing

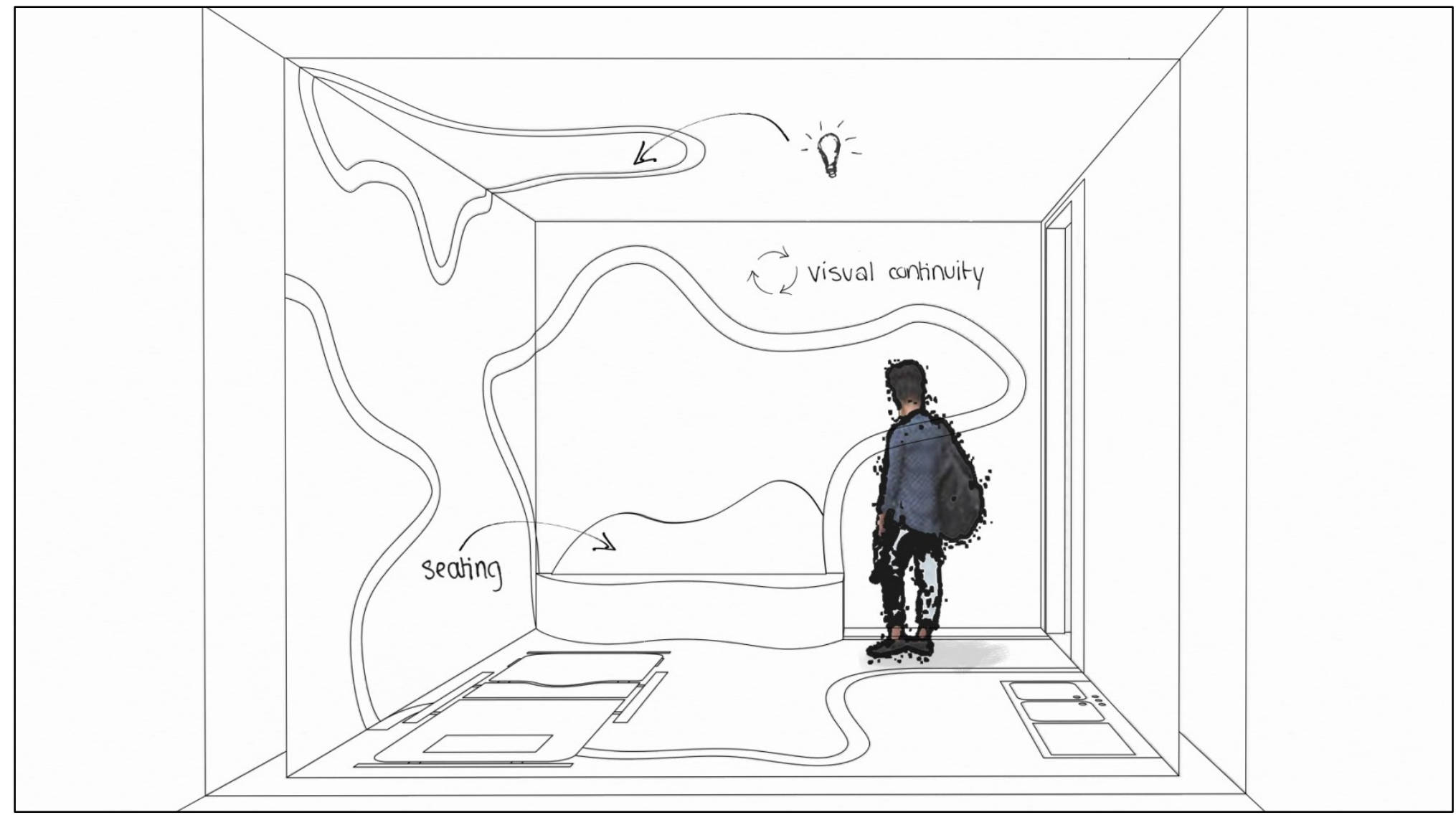

FIGURE 54

Examination Room: The Re-invented 
4 the role that this proposal is playing

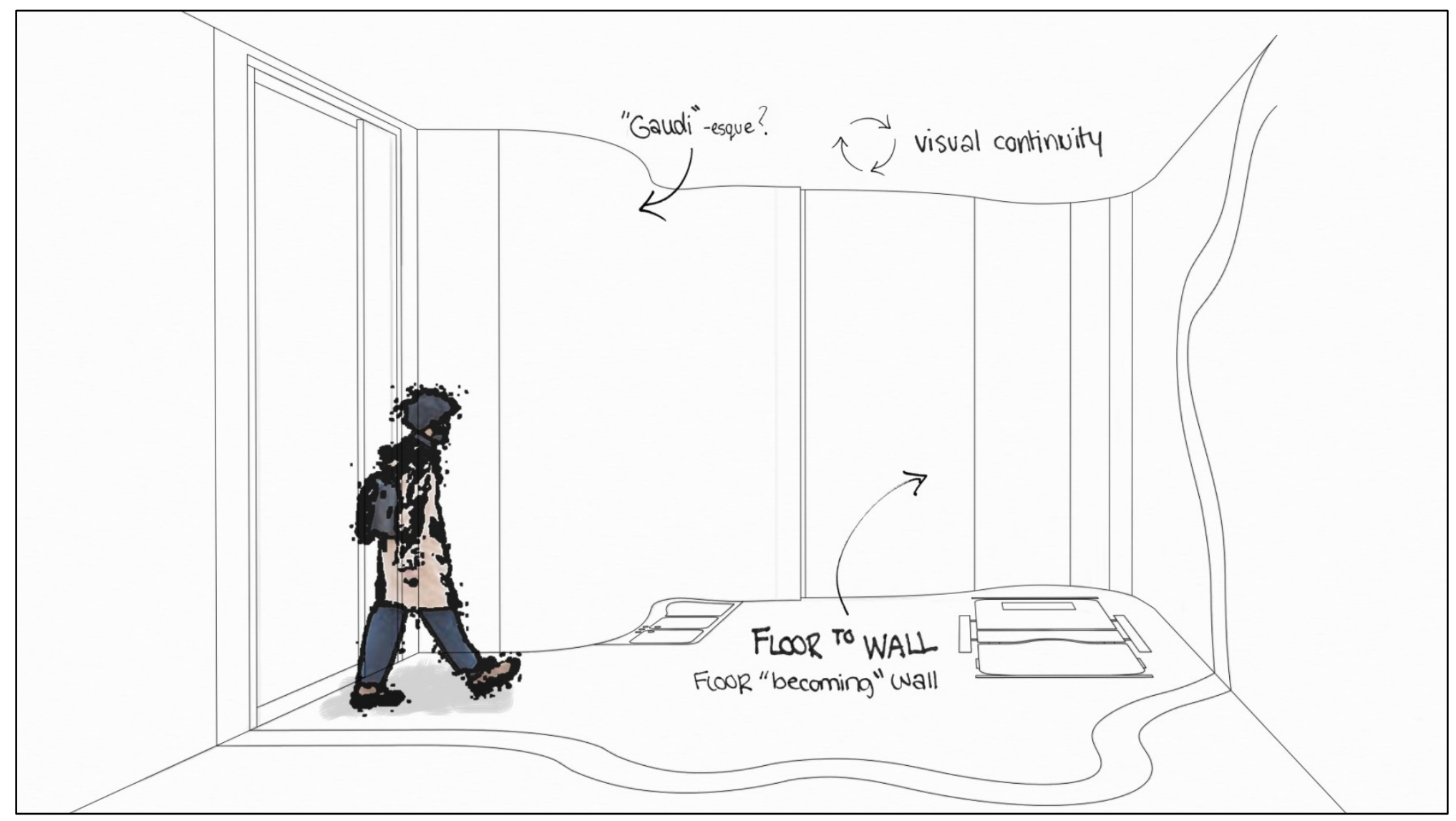

FIGURE 55

Examination Room: The Re-imagined 


\section{5 conclusion}

Play is a fundamental element in a child's development. It has the capability of stimulating interaction and freedom of self expression. This thesis explores the line between architecture and wellbeing utilizing the concept of narrative through play. To classify a patient by their illness is a loss of empathy when, first and foremost, architecture is meant to sympathize with the habitual dweller. Sometimes, this loss appears to be ordinary in the everyday built environment which cuts to the heart of the problem. Architectural experience impacts one's physical and mental being, and is gifted with the ability to uplift the human spirit. Empathetic architecture utilizes passion and compassion to bring into play a building's programmatic narrative, which is just as significant as the physical end results. Designing for the types of play targets the patient's distinctive personality and introduces a playful tale of characters.

The craft of play in children's hospitals suggests that the play that is being played is interrelated with the play that this proposal is playing. What ties the two together is perception - one can stimulate and enhance the other. The end results are a constant work in progress because the play that is being played is everlasting. The characters are simultaneously bringing the space to life - using figments of their imagination - by their engagement in recreation within the space. The five typologies are a short introduction to showcase that utilizing play as an instrument stimulates a sense of wonder, with an emphasis on being scale conscious. The typologies demonstrate a language that is rare in the built environment, especially in an institutional setting of a medical facility. This kind of project, which addresses mental and physical health issues, motivates minor alterations. It aims to showcase that sometimes, the 
smallest of changes within a facility can have the largest impact - beyond the mere obligation of accommodating medical equipment serving a purpose that is beyond function.

Compassion is fundamental to human existence. Although this thesis motivates design to engage the imagination of the patient to stimulate feedback and support, as a way of coping with illness, this project challenges a co-design oriented exercise in which it enables a range of people to make a creative contribution in the formation and solution to a problem - experts of their own experience become central to the design process. The benefits that derive from employing this approach consist of the instant confirmation of ideas and listening to the voice of the habitual dweller. Considering that social support is the most important component of healing, and is that we ultimately need one another to heal, once again in order to design meaningful solutions to boost the staff and occupant's wellbeing, we must make room for their input.

This research was inspired by my perceived experiences in space and atmospheres with surreal characteristics. The tracing of a space through movement looms towards the cognitive process of the sensory. Moments we experience are valuable and architecture plays a main role in our everyday occurrences, which in due time, impacts our psyche. This project hopes to inspire and empower people to reinvent or re-imagine spaces in ways they never thought they would. To play is essential in leading a balanced life, despite being seen as an intrinsic relief from seriousness. This experiment proposes that architecture utilize qualities of wit and challenge spaces of medical practice to incorporate the component that children, and the rest of us subconsciously, already employ - play. 


\section{BIBLIOGRPAHY}

Adams, Annmarie. Medicine by Design: The Architect and the Modern Hospital, 1893-1943. Minneapolis: University of Minnesota Press, 2008.

Gadamer, Hans-Georg. The Relevance of the Beautiful and Other Essays. Cambridge: Cambridge University Press, 1986.

Gesler, Wilbert M. Healing Places. Lanham, Maryland: Rowman \& Littlefield, 2003.

Huizinga, Johan. Homo Ludens: A Study of the Play-Element in Culture. London: Routledge \& Kegan Paul Ltd, 1949.

Pallasmaa, Juhani. The Embodied Image: Imagination and Imagery in Architecture. Chichester: John Wiley \& Sons Ltd, 2011.

Sternberg, Esther M. Healing Spaces: The Science of Place and Well-Being. Cambridge, Massachusetts: Belknap Press of Harvard University Press, 2010.

Verderber, Stephen. Innovations in Hospital Architecture. New York: Routledge, 2010.

\section{IMAGES}

Dezeen: https://www.dezeen.com/2008/07/07/the-public-by-will-alsop/

Google: https://i.pinimg.com/736x/2d/a1/9f/2da19f4e534c3bf2ac984de15052a4c7--curve-jeans-superdome.jpg 